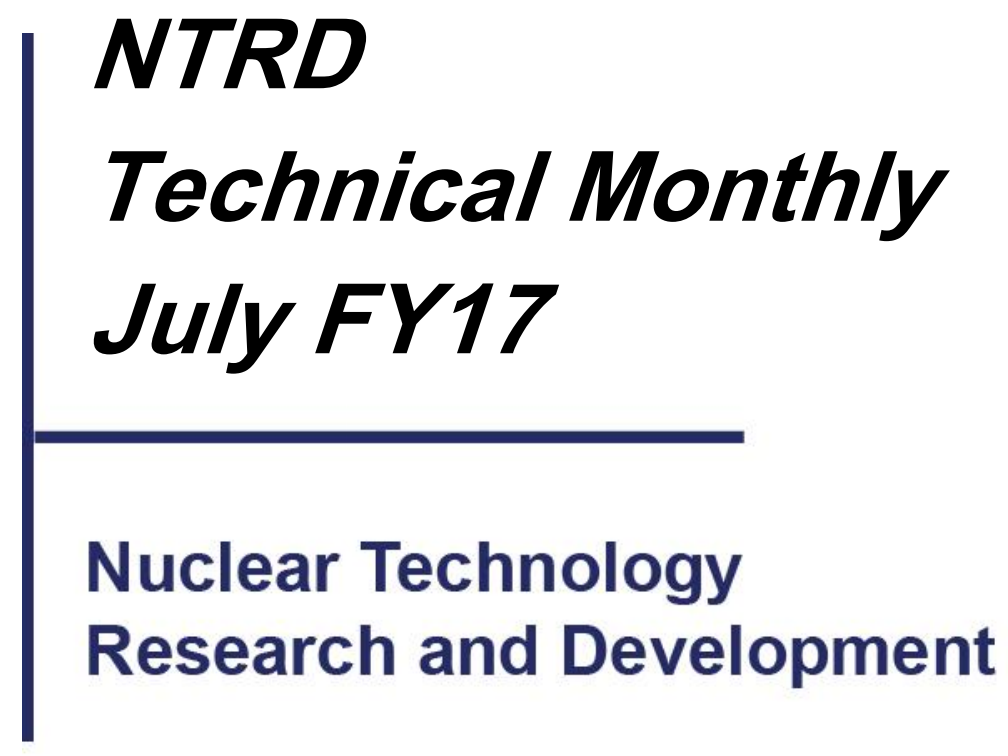

Prepared for U.S. Department of Energy

September 22, 2017

NTRD-PAC-2017-000438 INL/EXT-17-43367 


\section{DISCLAIMER}

This information was prepared as an account of work sponsored by an agency of the U.S. Government. Neither the U.S. Government nor any agency thereof, nor any of their employees, makes any warranty, expressed or implied, or assumes any legal liability or responsibility for the accuracy, completeness, or usefulness, of any information, apparatus, product, or process disclosed, or represents that its use would not infringe privately owned rights. References herein to any specific commercial product, process, or service by trade name, trade mark, manufacturer, or otherwise, does not necessarily constitute or imply its endorsement, recommendation, or favoring by the U.S. Government or any agency thereof. The views and opinions of authors expressed herein do not necessarily state or reflect those of the U.S. Government or any agency thereof. 


\section{CONTENTS}

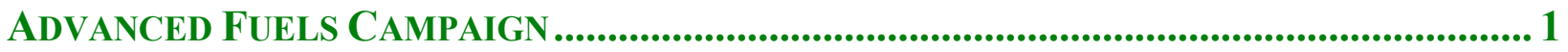

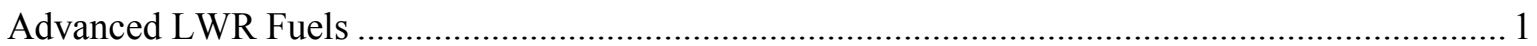

LWR Computational Analysis ……………………………………………………... 1

LWR Fuels ........................................................................................................ 1

LWR Core Materials ......................................................................................................... 3

LWR Irradiation Testing \& PIE Techniques ...................................................................... 11

LWR Transient Testing.............................................................................................. 13

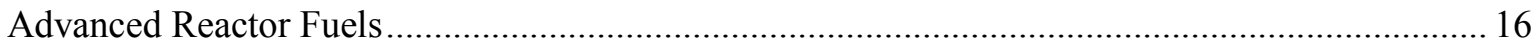

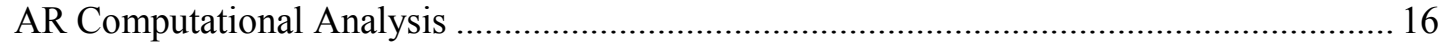

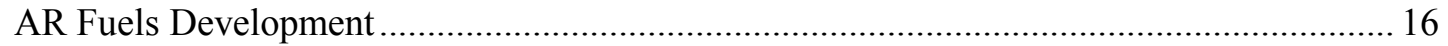

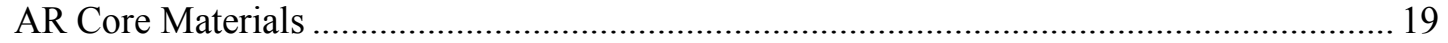

AR Irradiation Testing \& PIE Techniques................................................................... 21

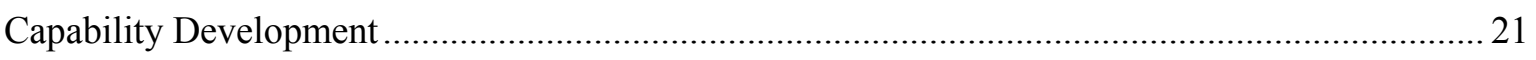

Fuels 21

Irradiation, Testing, and PIE ……………………………………………………… 22

MATERIAl ReCOVERY AND WASTE FORMS DEVEloPMENT .......................................... 23

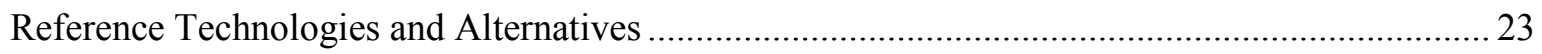

Sigma Team for Advanced Actinide Recycle ………………………………………………...2 24

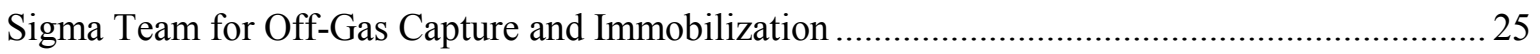

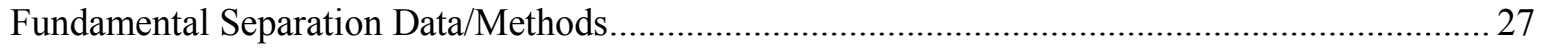

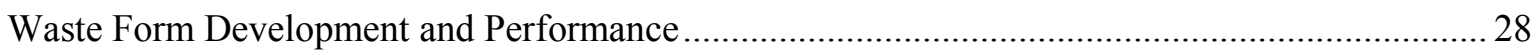

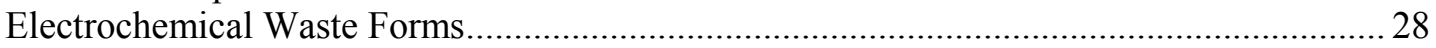

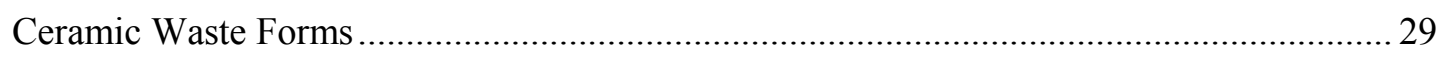

Glass Ceramics Waste Forms........................................................................................... 30

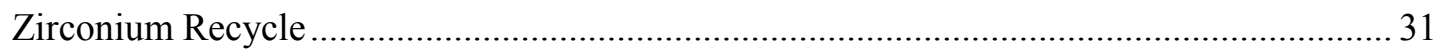

Advanced Waste Form Characterization ……………………………………………... 32

Domestic Electrochemical Processing................................................................................... 33

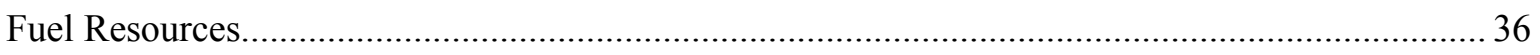

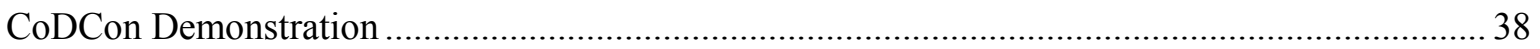

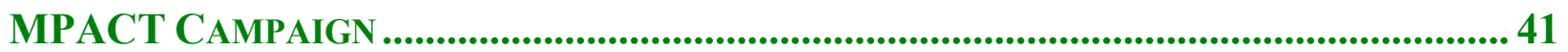

Management and Integration ................................................................................................ 41

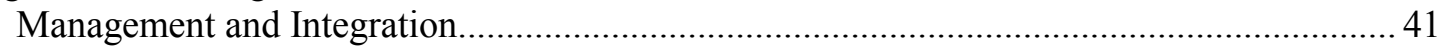

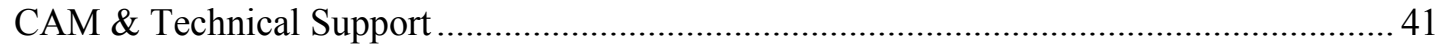

Safeguards and Security by Design - Echem................................................................................ 41

Microfluidic Sampler ................................................................................................. 41

Modeling and Simulation for Analysis of Safeguards Performance....................................... 41

Electrochemical Sensor ............................................................................................. 41

Sensor for Measuring Density and Depth of Molten Salt ...................................................... 41

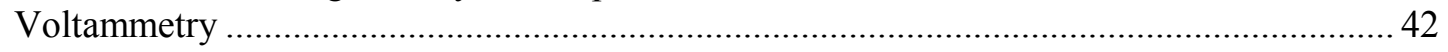

Electrochemical Signatures Development …………………………………………… 42

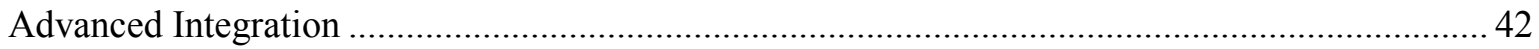

Advanced Integration (Methods) ……………………………………………………... 42 


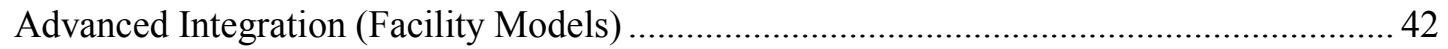

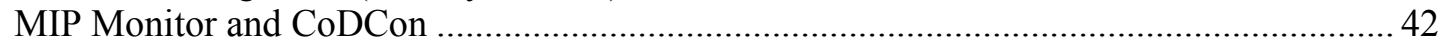

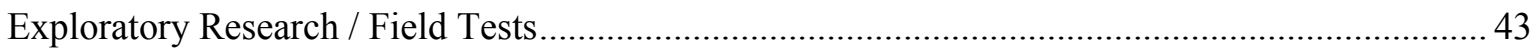

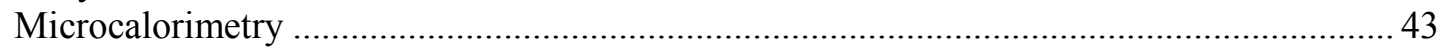

In situ Measurement of Pu Content in U/TRU Ingot ....................................................... 43

FUEL CYCLE OPTIONS CAMPAIGN ................................................................................ 45

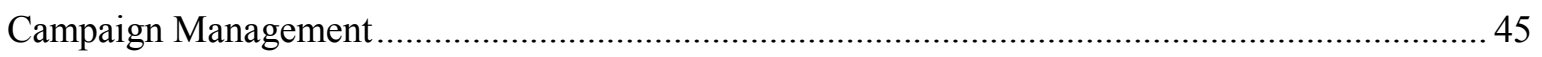

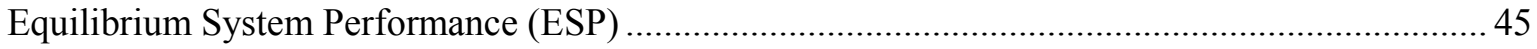

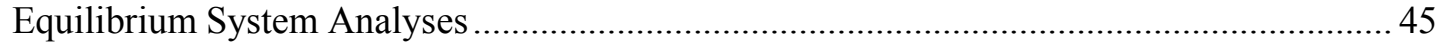

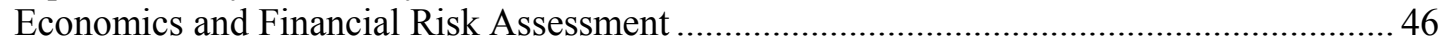

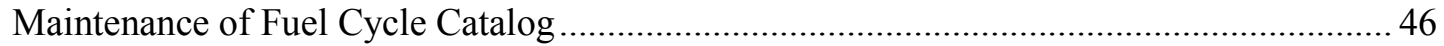

Development, Deployment And Implementation Issues (DDII) ........................................... 46

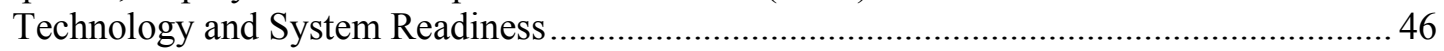

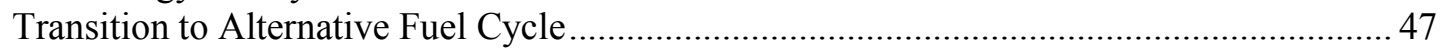

Transition Economics ........................................................................................... 47

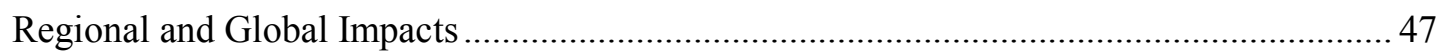

JOINT FUEL CYCLE STUdY ACTIVITIES.................................................................. 49

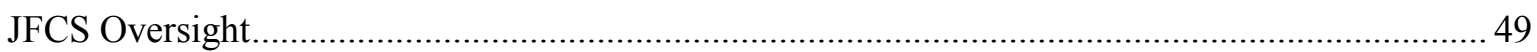

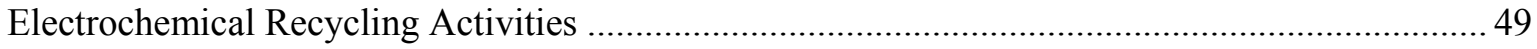

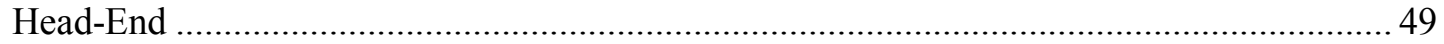

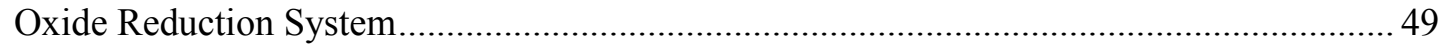

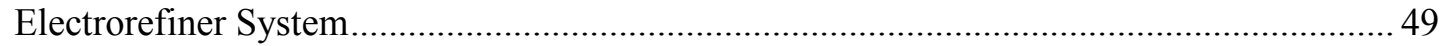

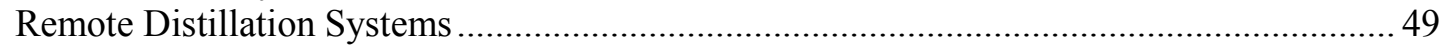

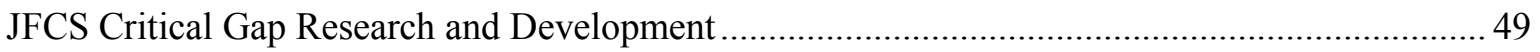

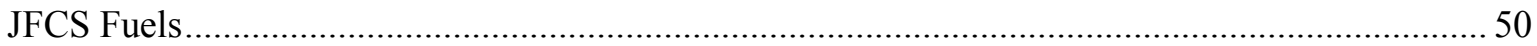

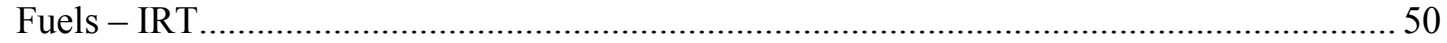

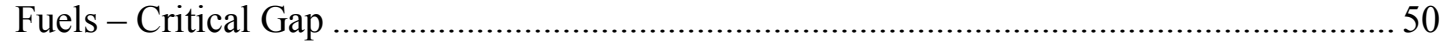

PROGRAM ASSESSMENT \& COORDINATION .............................................................. 51

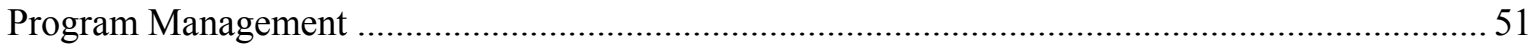

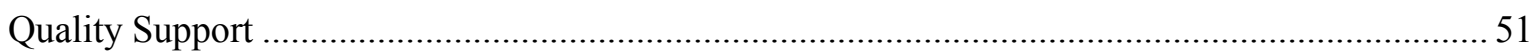

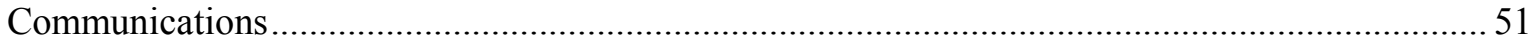

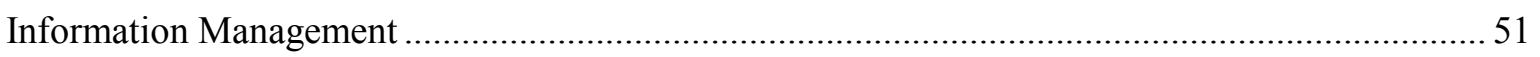

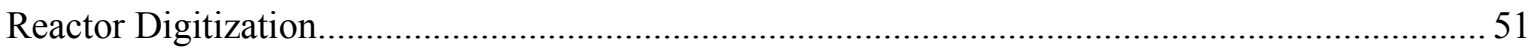

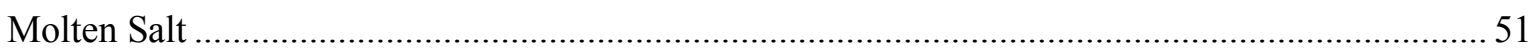

AFCI-HQ PROGRAM SUPPORT .................................................................................. 53

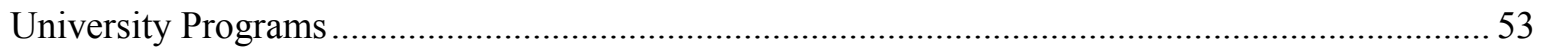

Universities engaged in Nuclear Technology research via URA programs since

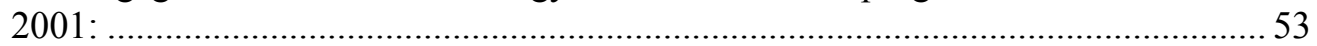

Innovations in Nuclear Technology R\&D Awards (formerly Innovations in Fuel Cycle

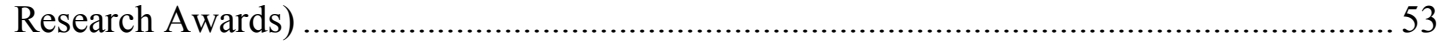

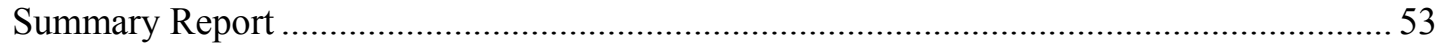




\section{FIGURES}

\section{AdvanCed Fuels CAMPaign}

Figure 1. Thermal diffusivity as a function of temperature for UO2-UB2 (squares) and UO2-UB4 (circles) composites along with reference thermal diffusivity data on UO2 [3] and UB2 [2].

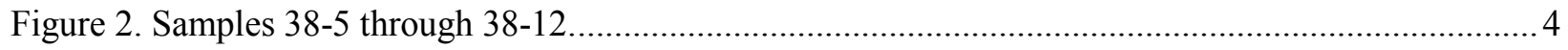

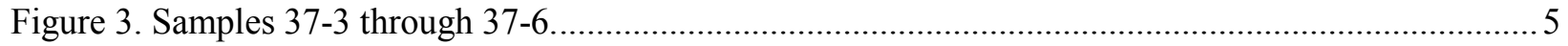

Figure 4. Samples 37-3 - 37-6 and 38-5 - 38-12 ........................................................................ 7

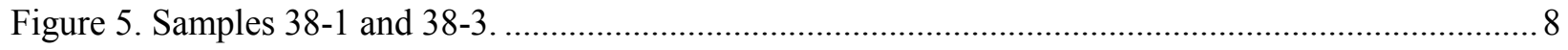

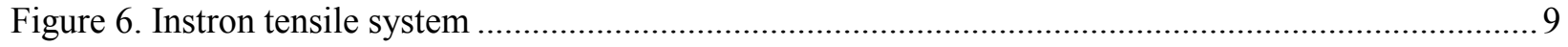

Figure 7. Comparison of Database Version 1 and 2 to experimental phase diagram. ............................ 13

Figure $8.360^{\circ}$ view of the outer surface of the $\mathrm{SiC} / \mathrm{SiC}$ composite sample before fracture (a), at the fiber rupture (b) and at the ultimate fracture (c). ............................................................ 14

Figure 9. Severe accident test station insertion into the 3525 Hot Cell facility at ORNL (left). LOCA furnace orange glow through hot cell window during initial furnace testing (right).

Figure 10. $\mathrm{SiC} / \mathrm{SiC}$ composite channel box calculated temperatures. ..................................................... 16

Figure 11. MCNP model of assembly using solid metal fuel ................................................................. 17

Figure 12. MCNP model of assembly using annular metal fuel........................................................... 17

Figure 13. Pressed samples at $800 \mathrm{lb}$ (left) and $1600 \mathrm{lb}$ (right) ......................................................... 18

Figure 14. Interaction zone between U-10Zr-4.3Sn and lanthanides.................................................. 19

Figure 15. Two 14YWT thick-wall tubes extruded and staged for pilgering. ........................................2

Figure 16. Visual exam of AFC 3C R5 that contained U-1Pd-13Zr sodium bonded fuel.......................21

\section{MATERIAL RECOVERY AND WASTE FORMS DEVELOPMENT}

Figure 1. Concentrations of ${ }^{241} \mathrm{Am},{ }^{244} \mathrm{Cm}$ and ${ }^{147} \mathrm{Pm}$ in the organic phase of the ALSEP minor actinide strip section.

Figure 2. Schematic of test system for cold testing of iodine and tritium traps......................................27

Figure 3. Results of 7-d PCT and RWS with various ACWF materials..............................................29

Figure 4. Results of potentiostatic test with Type 4320 carbon steel in $\mathrm{pH} 4$ brine solution at -0.4 $\mathrm{V}_{\mathrm{SCE}}$..

Figure 5. Image of pour stream at ${ }^{~} 1550^{\circ} \mathrm{C}$ of SYNROC material being drained from a cylindrical induction melter at SRNL.

Figure 6. X-sectional TEM observations of irradiated I2-2013 samples after 28 days test.

Figure 7. Co-deposition cathode test in which the cathode assembly was raised above the salt level while passing current. White crust layer is clear confirmation of local $\mathrm{UCL}_{3}$ depletion near the cathode as predicted. 
Figure 8. Same co-deposition cathode as previous photograph after removal of the crust of white salt. Co-deposited metal on cathode is clearly visible.

Figure 9. Cyclic voltammetry (CV) plot obtained using tungsten for working and counter electrodes and nickel for the reference electrode.

Figure 10. Chronopotentiometry (CP) plot.

Figure 11. CV plots obtained from three salt systems: $\mathrm{ScCl}_{3}, \mathrm{YcL}_{3}$, and a mixture of $\mathrm{ScCl}_{3}$ and $\mathrm{YCl}_{3}$

Figure 12. a) Ligands considered in our study; b) experimental crystal structures; c) the most stable complexes in aqueous solution obtained at the M06/SSC/6-311++ $\mathrm{G}^{* *}$ level of theory.

Figure 13. UO3 produced by MDD.

Figure 14. Mixed uranium/plutonium oxides produced by MDD. 


\section{NUCLEAR TECHNOLOGY RESEARCH AND DEVELOPMENT TECHNICAL MONTHLY JULY FY17}

\section{ADVANCED FUELS CAMPAIGN}

\section{ADVANCED LWR FUELS}

\section{LWR Computational Analysis}

\section{Metrics Development for ATF}

- [INL] The OECD/NEA EGATFL deliverable on systems assessment (Task Force 1 in the expert group, chaired by S. Bragg-Sitton) was submitted to the full expert group for review and final edits in early June. Additional comments and modified sections of country-specific information were submitted in mid-July. They are being incorporated prior to submission for final editing by NEA. A complete draft of the state-of-the-art report on accident tolerant fuel and cladding was distributed by the leads of Task Forces 2 and 3 at the end of July (updated from the draft distributed in June). This report is now under review by the full expert group, with a target completion of all edits by the end of September. (S. Bragg-Sitton)

\section{LWR Fuels}

- $\quad$ [LANL] An initial characterization study was completed for a range of compositions surrounding U3Si5 in the U-Si binary. U3Si5 has been of interest within AFC as an alternative to U3Si2 given early data suggesting that it may have improved oxidation resistance. While that preliminary data has not been substantiated, the fundamental structure of the U-Si binary is important to modeling of U3Si2 fuels during burnup, as well as development of thermochemical models for U-Si and fission products. Experiments executed to date have revealed that the accepted phase diagram for U-Si contains a number of features that do not agree with experimental observations. A series of U-Si compositions were synthesized with nominal compositions ranging from USi3 to USi to assess phase stability. To date, these samples have been subjected to a range of heat treatments and room temperature analysis using conventional techniques and augmented by differential scanning calorimetry. The results suggest that two compounds presently absent from the U-Si binary, one more U-rich than U3Si5 and a second of a composition approximately USi1.84 dominate structures at room temperature. Furthermore the USi1.84 phase appears to undergo a transformation at roughly 180C that may correspond to the USi2 phase reported occasionally in the literature. These measurements will be augmented by neutron diffraction data scheduled to be collected in August and September ( $\mathrm{J}$ White).

- [LANL] Milestone M3FT-17LA0202010210, titled "Neutron Characterization of Encapsulated Metallic Fuel," was completed. The report covered bulk characterization of four slugs of metallic fuels with a nominal composition of U-20Pu-10Zr (wt. \%), produced at INL and loaded in two rodlet/capsule assemblies. Material in one capsule also contained $\operatorname{Am}(\sim 2$ wt. \%) and $\mathrm{Np}(\sim 3 \mathrm{wt} . \%)$. Tomographic imaging and diffraction measurements were performed to characterize these samples at the Flight-Path 5 and HIPPO beam lines at LANSCE/LANL. Due to the presence of Pu, the penetration of the material by thermal neutrons is limited to $\sim 1.3 \mathrm{~mm}$ (e-1 penetration depth) and 
since diffracted neutrons are also attenuated, the volume probed by thermal neutrons is only a layer of $\sim 650 \mu \mathrm{m}$. However, access to transmission data in the epi-thermal neutron range, provided by the pulsed neutron spallation source at LANSCE and captured with a 512x512 pixel time-of-flight imaging detector, allows characterization of sample dimensions, cracks, chemical and isotopic inhomogeneities for these samples. (K. McClellan)

- [LANL] Using detailed analysis of the neutron absorption resonances in the transmission data, using the SAMMY code and known neutron absorption cross sections for interpretation of neutron transmission data, isotope specific density maps through arbitrary slices of the reconstructed volume can be displayed. The same analysis provides partial densities for isotopes averaged over the entire sample, which are except for $238 \mathrm{U}$ in excellent agreement with results from other methods and provided non-destructively. The density maps of the major isotopic constituents of the slugs, computed for slices containing spherical features identified in the tomography, allowed to identify voids as the most likely nature of the features (S. Vogel, A. Losko, M. Bourke/LANL, R.

Fielding/INL)

- [LANL] An initial assessment of the thermophysical properties of the UO2-UB2 and UO2-UB4 composite pellets that were sintered to high densities ( $>90 \%$ TD) via SPS in RPI (October 2016) was carried out. The thermal diffusivity of the composite samples was measured to $873 \mathrm{~K}$ and is shown in Figure 1. It was found that the thermal diffusivity values for all composite samples was increased, when compared to the diffusivity of UO2. The thermal diffusivity of the UO2-30\%wt UB2 sample showed the largest increase with respect to UO2. (K. McClellan)

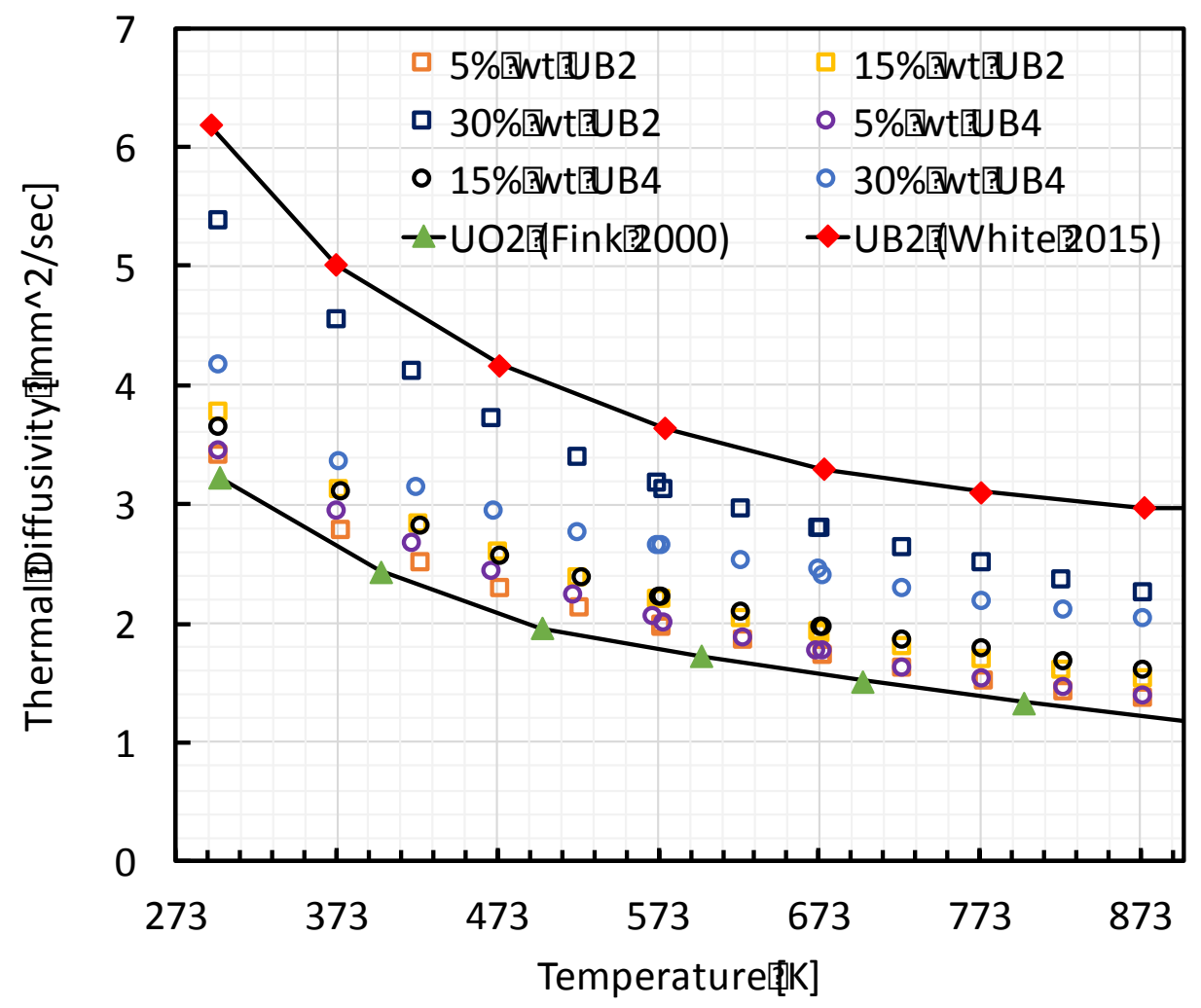

Figure 1. Thermal diffusivity as a function of temperature for UO2-UB2 (squares) and UO2-UB4 (circles) composites along with reference thermal diffusivity data on UO2 [3] and UB2 [2]. 
- [INL] All 1605 weight-percent enriched U3Si2 pellets required for the ATF-2 test have been sintered and ground. 13 of the 160 ground pellets did not meet dimensional requirements. Replacement pellets were not immediately available, so the fuel fabrication team began producing material to fabricate a batch of 5 weight-percent enriched pellets. Pellet inspections are scheduled to begin in August. (G. Core)

\section{LWR Core Materials}

\section{Thin Walled Tube Development}

- [INL] For pressure resistance weld (PRW) joining, samples 38-5 through 38-12 were joined using established parameters (Error! Reference source not found.). Samples 38-5 - 38-8 and 38-11 \& 3812 used the "r10" endplug design, where 38-5, 38-6, 38-11 \& 38-12 are for tensile testing and 38-7 \& 38-8 are for hydraulic rupture testing. Samples 38-9 \& 38-10 used the "r11" endplug design and are for tensile testing. (J. Gan)

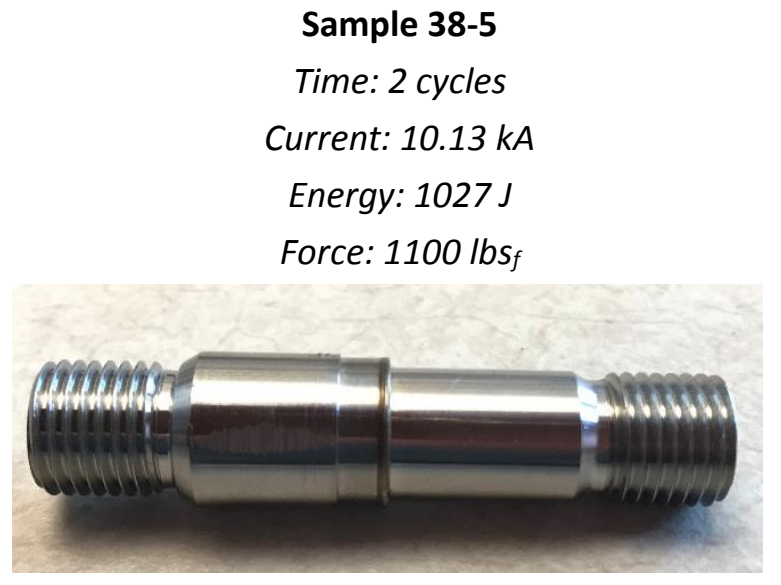

Sample 38-7

Time: 2 cycles

Current: $12.51 \mathrm{kA}$

Energy: $1114 \mathrm{~J}$

Force: $1100 \mathrm{lbsf}$

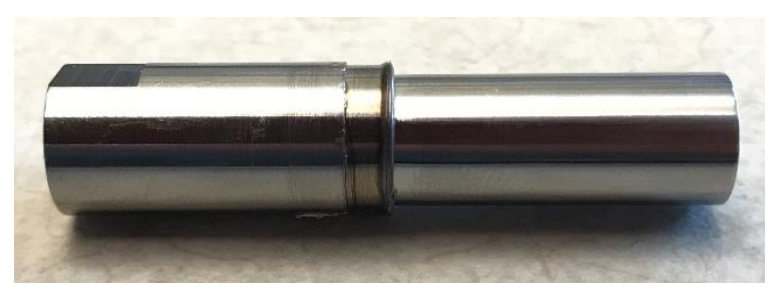

\section{Sample 38-6}

Time: 2 cycles

Current: $11.91 \mathrm{kA}$

Energy: $1097 \mathrm{~J}$

Force: $1100 \mathrm{lbs}_{f}$

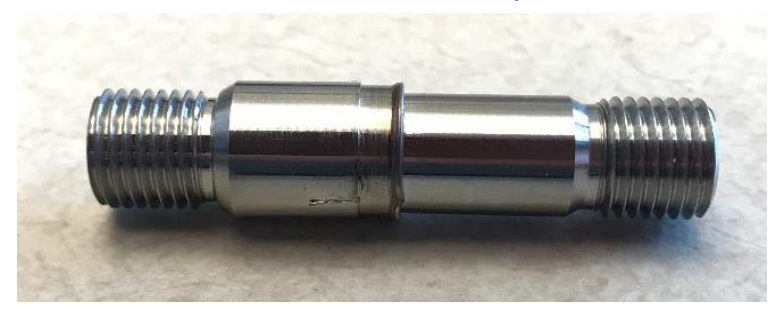

Sample 38-8

Time: 2 cycles

Current: 11.92 kA

Energy: $1110 \mathrm{~J}$

Force: $1100 \mathrm{lbsf}$ 


\section{Sample 38-9}

Time: 2 cycles

Current: $12.49 \mathrm{kA}$

Energy: $1111 \mathrm{~J}$

Force: $1100 \mathrm{lbs}_{f}$

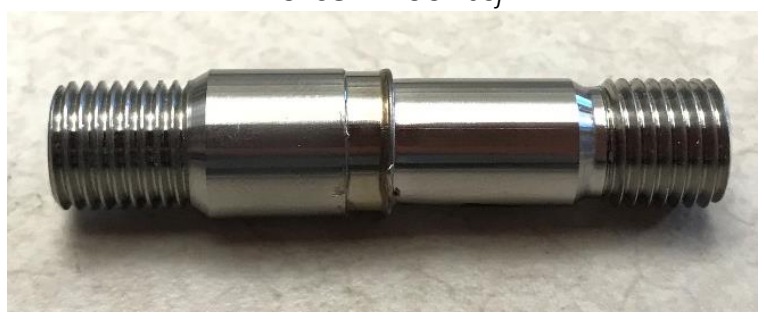

Sample 38-11

Time: 2 cycles

Current: 12.46 kA

Energy: $1133 \mathrm{~J}$

Force: 1100 lbsf

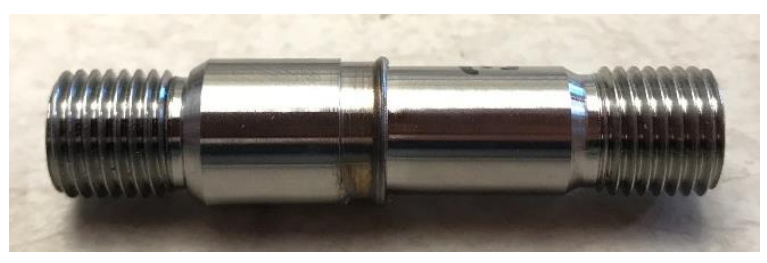

Sample 38-10

Time: 2 cycles

Current: $12.65 \mathrm{kA}$

Energy: $1120 \mathrm{~J}$

Force: $1100 \mathrm{lbs} f$

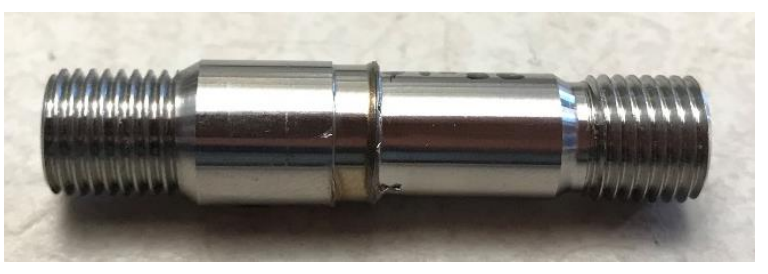

Sample 38-12

Time: 2 cycles

Current: $12.07 \mathrm{kA}$

Energy: $1106 \mathrm{~J}$

Force: 1100 lbsf

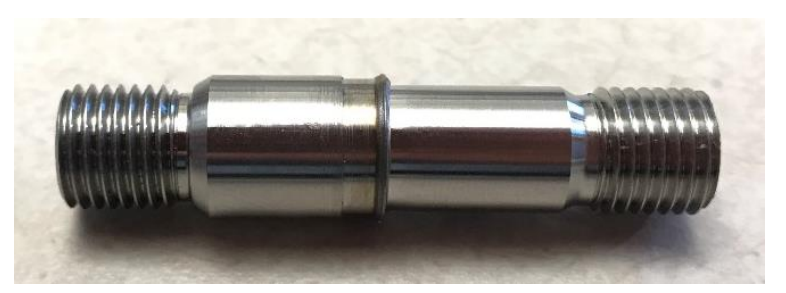

Figure 2. Samples 38-5 through 38-12.

- $\quad[$ INL] For laser beam weld (LBW) joining, samples 37-3 through 37-6 were joined to be used for tensile testing at elevated temperatures (Figure 3$)$. For these samples, a small $(0.50$ " dia.) weep hole was drilled into the side of the endplugs to alleviate internal pressurization at elevated temperatures. EBSD analysis of sample 37-1 showed the penetration depth was equal to that of the thickness of the cladding wall and penetration into the endplug was limited. Using the laser power meter, measurements showed a small drop in lasing power has occurred on the laser welder under the established welding parameters. Using the laser power meter, the welder voltage was adjusted until the lasing peak powers were increased to be between $2.1 \mathrm{~kW}-2.2 \mathrm{~kW}$ - the new voltage was found to be $255 \mathrm{~V}$. It has been previously seen that lasing peak powers above $2 \mathrm{~kW}$ is needed in order to get adequate penetration. (J. Gan) 


\section{New Joining Parameters:}

Welder voltage: $255 \mathrm{~V}$ | Pulse width: $11 \mathrm{~ms}$ | Repetition Rate: $2 \mathrm{~Hz}$ | Beam Diameter: $0.75 \mathrm{~mm}$ |Welding Speed: $0.573 \mathrm{rpm}$

Sample 37-3

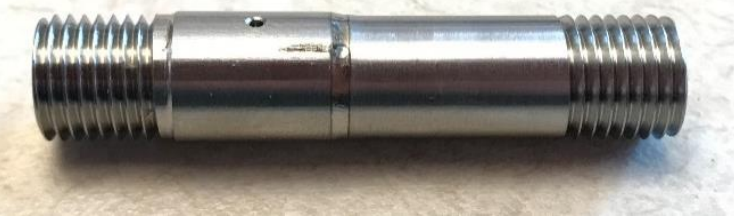

Sample 37-5

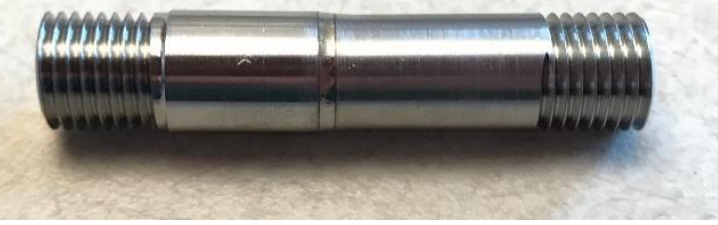

\section{Sample 37-4}

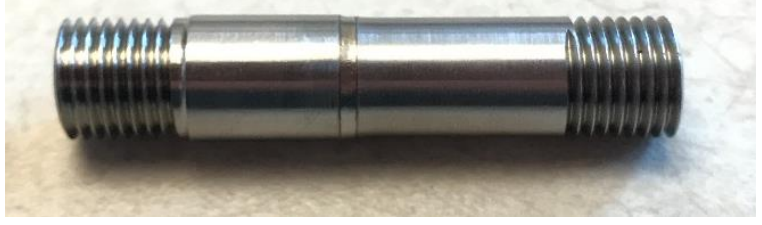

Sample 37-6

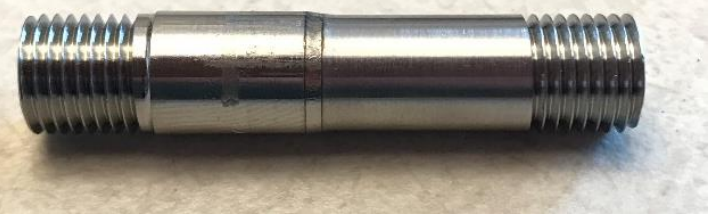

Figure 3. Samples 37-3 through 37-6.

- [INL] Samples 37-3 - 37-6 and samples 38-5 - 38-12 were analyzed via X-ray CT to visualize the bond formation and the presence of any major defects (Figure 4).

\section{Laser Welding: Sample Set 37}

Sample 37-3

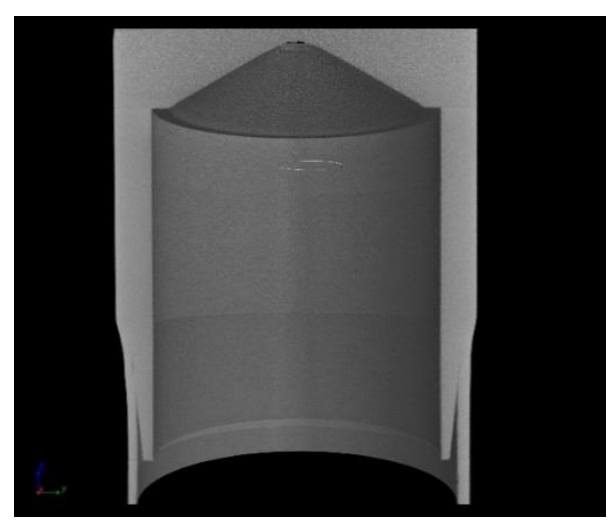

Sample 37-4

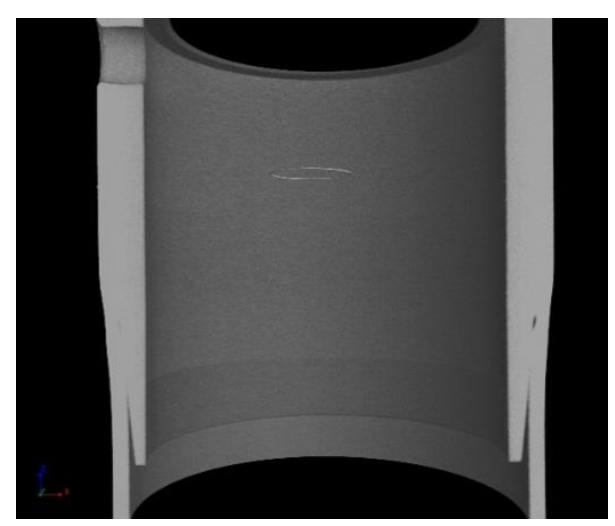


Sample 37-5

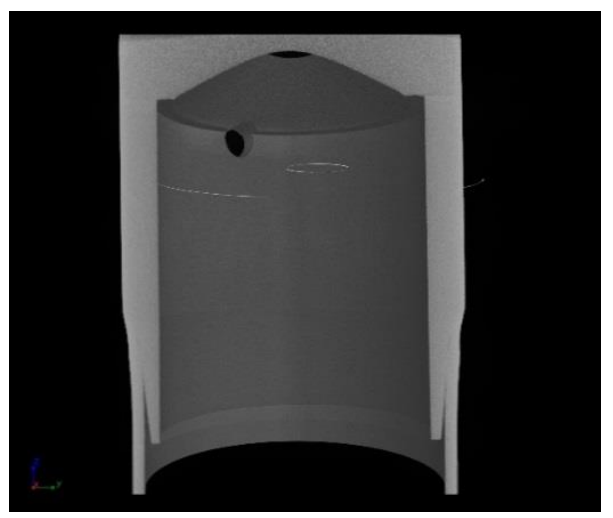

Sample 37-6

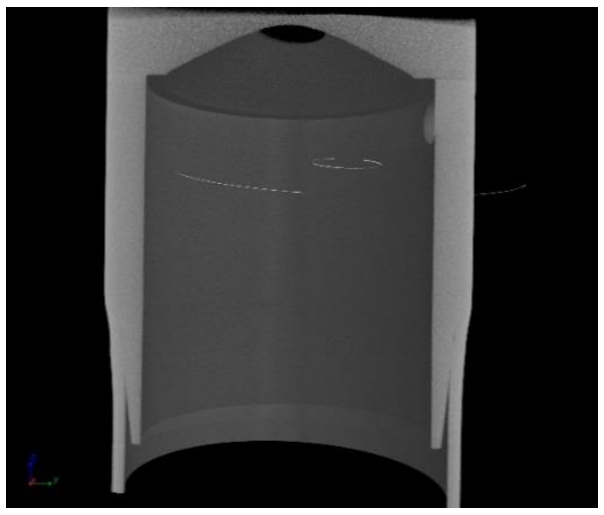

Pressure Resistance Welding: Sample Set 38

Sample 38-5

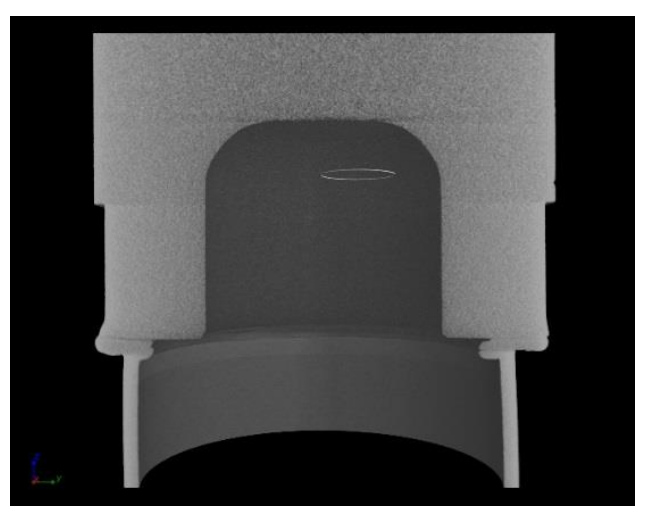

Sample 38-7

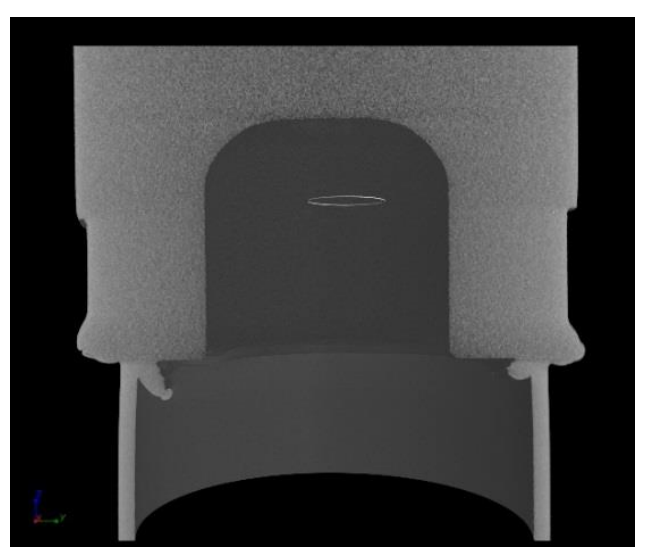

Sample 38-6

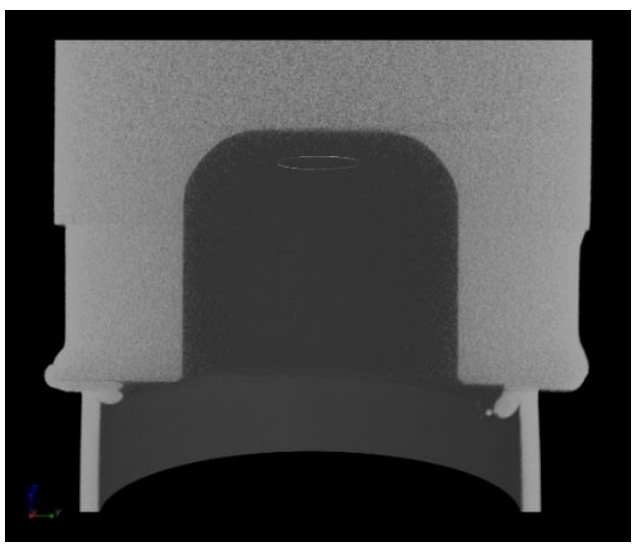

Sample 38-8

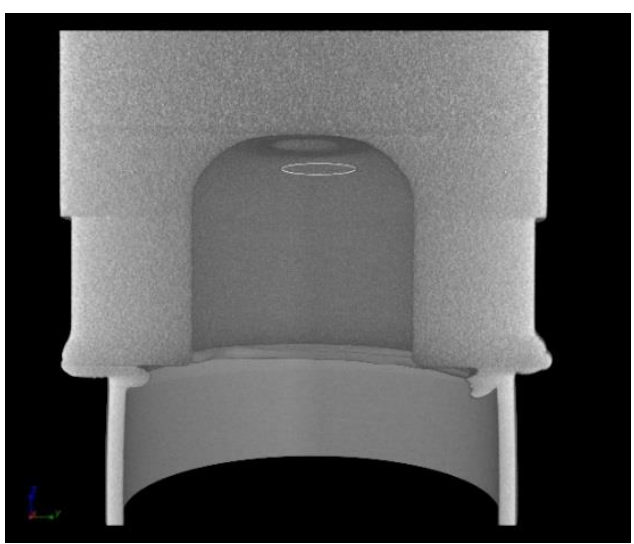




\section{Sample 38-9}

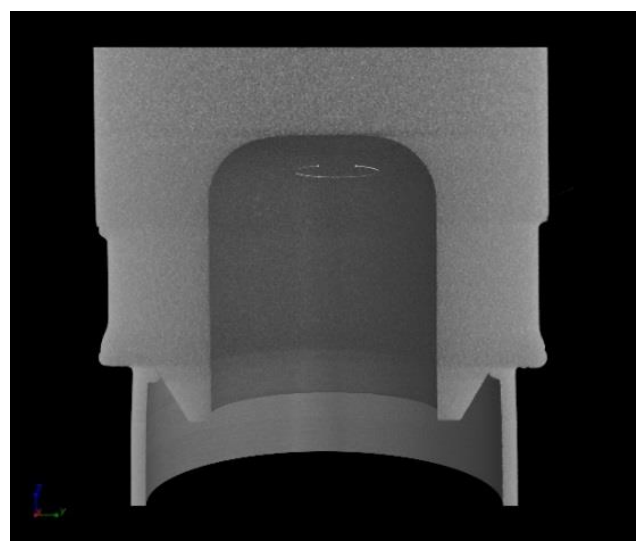

Sample 38-11

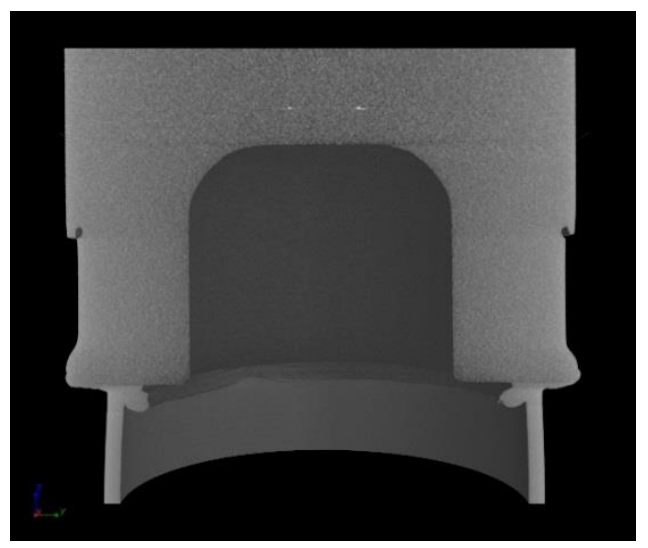

Sample 38-10

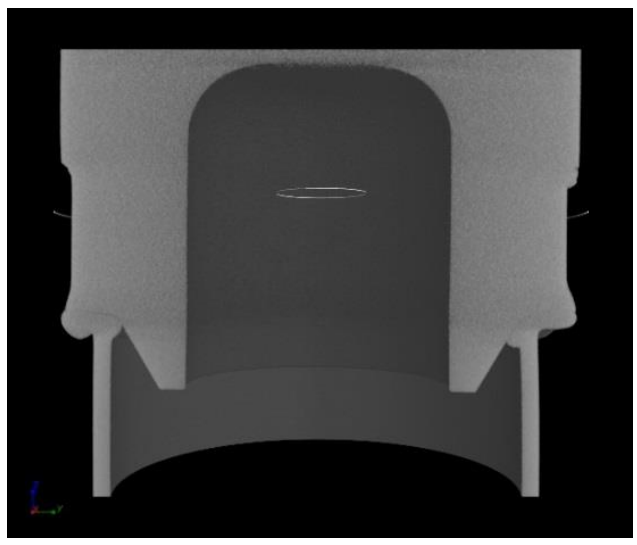

Sample 38-12

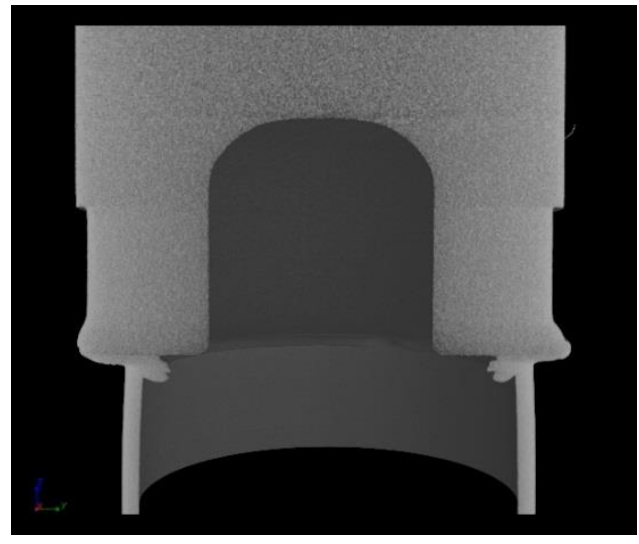

Figure 4. Samples 37-3 - 37-6 and 38-5 - 38-12

Samples 37-3 - 37-6, which were joined using laser welding, all show consistent weld regions, with some surface ablation noticed. Such surface ablation was not visible in samples 37-1 or 37-2, and is a result of the increased voltage, but is an acceptable weld feature.

Samples 38-5 \& 38-6, joined using the PRW process, show similar bonds have formed but both show slight misalignment occurred through the joining process. Sample 38-5 shows some lack of bonding and the bond line is visible in a section of the bond, also visually, the amount of deformation seen at the endplug is lower compared to the other samples of set 38 . During joining, the measured current for 38-5 was low which lead to a decreased joining energy, this likely lead to the insufficient bond.

Samples 38-7 \& 38-8, joined using the PRW process for rupture testing, also show consistent bond formation and deformation between the cladding and endplug. However, some misalignment can also be seen in these two samples.

Samples 38-9 \& 38-10 were joined using the PRW process using the full new endplug design, the r11 design. The endplug features a reduced outer diameter, an internal hole and an angled protrusion to aid in alignment. Both samples show good bond formation, deformation and excellent alignment.

Samples 38-11 \& 38-12 were also joined using the PRW but used the r10 endplug design - the same endplug used in samples 38-1 - 38-8. Samples 38-11 \& 38-12 show better alignment than samples 
38-5 - 38-8 and also show good bond formation. They appear to be fully bonded and no defects or lack of bonding can be seen. (J. Gan)

- [INL] Samples 38-1 \& 38-3 were bonded using the PRW process with the r10 design endplugs (Figure 5). After bonding the samples were then subjected to tensile testing with each failing in the tube. The tested bond was then cross-sectioned and prepared for SEM/EBSD evaluation to visualize the welding region. NOTE: sample 38-1 utilized a cladding tube weldment having a knife edge projection, where sample 38-3 utilized a cladding tube weldment having NO projection.

Sample 38-1

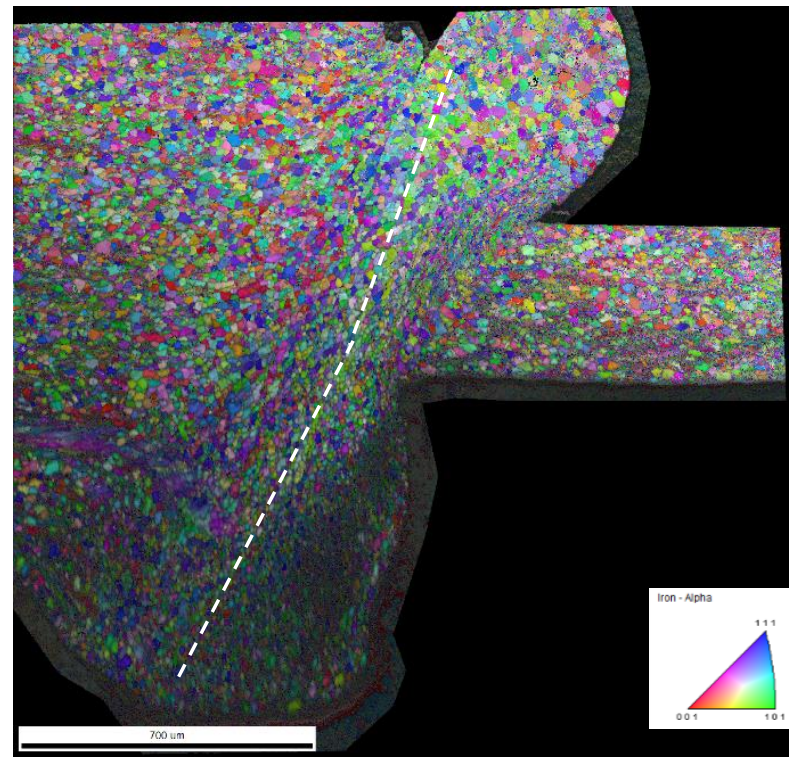

Sample 38-3

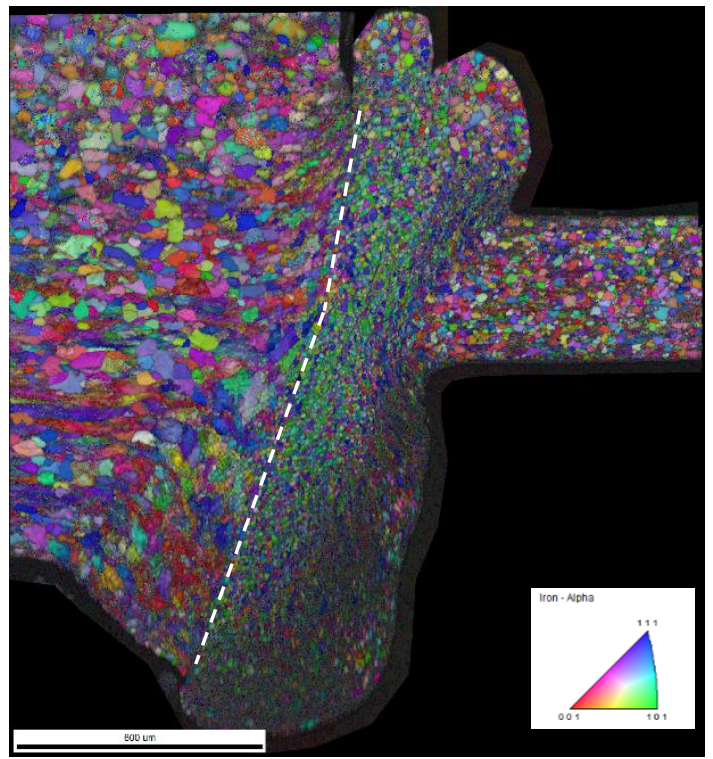

Figure 5. Samples 38-1 and 38-3.

In general, the bond formation for the r10 endplug design shows the bonding area exhibits an increased level of deformation within the endplug, seen in both samples. This in turn has caused the bonding line to become more angled and thus a larger bonded area \& strength.

In comparing the size of the bonding region, that of sample 38-3 (having no projection on the tube) appears to have a welding region that is larger on the tube side compared to sample 38-1 (having a projection on the tube) - this could be a result of the difference in tube weldments. However, both samples showed a bond strength that was larger than that of the tubing and thus it is difficult to determine if the variation in the size of the weld region would reflect a variation in bond strength.

Overall, the bond region shows a refined microstructure on the tube side of the bond in both samples. Interestingly, the endplug microstructure appears to vary between the two samples, which needs to be looked into more to determine if the variation is an effect of the joining process or just reflective of a variation in stock material. (J. Gan)

- [INL] Samples 37-1 \& 37-2 were welded using the same joining parameters which yielded a lowerthan-expected peak power value. However, although sample 37-1 exhibited a lack in weld penetration, as seen in the SEM/EBSD evaluation, sample 37-2 was tensile tested after a PWHT process to determine its bond strength. Although given the likely lack in penetration depth into the 
endplug, sample 37-2 experienced elongation and failure within the tube section of the sample exhibiting bond strength greater than that of the tube material. (J. Gan)

- $\quad$ [INL] The tensile fixtures for elevated temperature testing were completed and an initial fit-up within the Instron tensile system and attached furnace was performed (Figure 6). Initial heat-up of the furnace with the fixtures was performed with no issues seen. The PID settings of the temperature controllers were tuned at the proposed testing temperature of $300^{\circ} \mathrm{C}$ using the new tensile fixtures to represent the correct thermal mass of the system. (J. Gan)
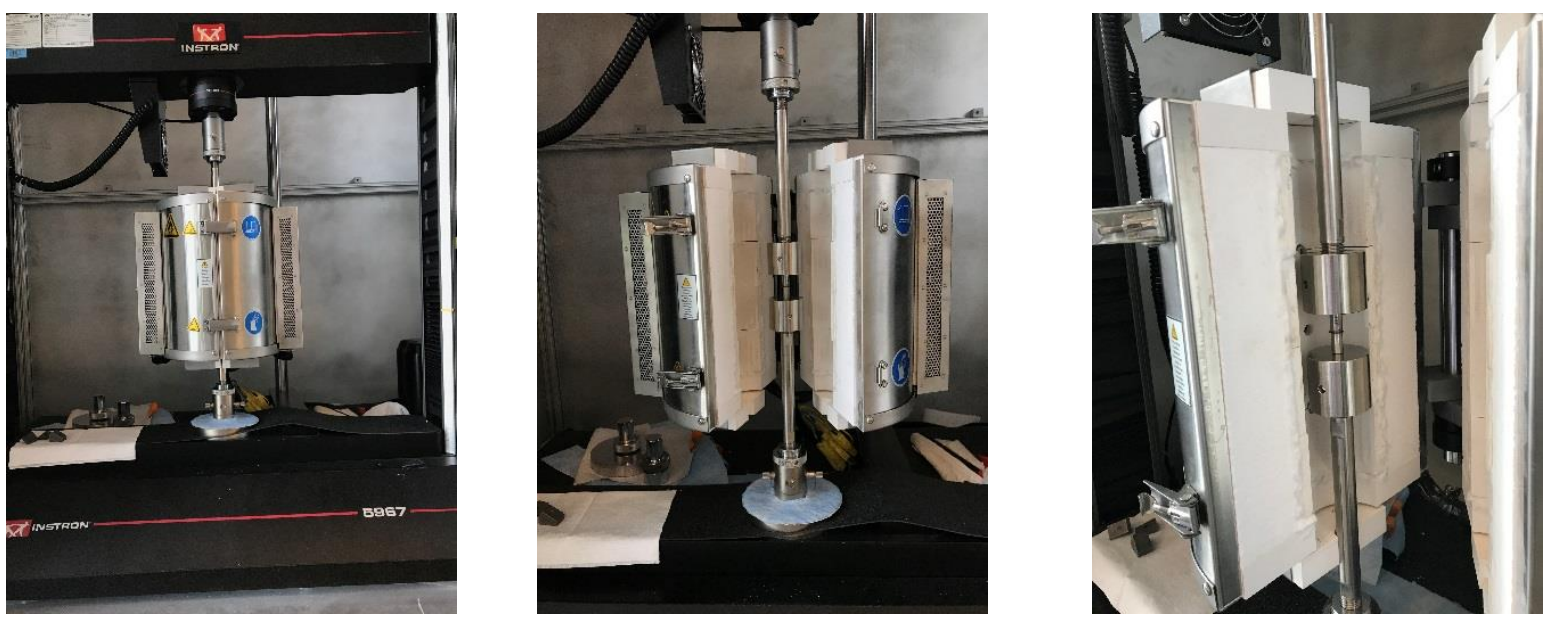

Figure 6. Instron tensile system

- $\quad$ [LANL] An order was submitted to Century tubing to procure tubing from Generation $2 \mathrm{FeCrAl}$ alloys. (S. Maloy)

\section{Advanced LWR Materials Development and Testing}

- $\quad$ [LANL] Details are being worked with Kevin Field to have tensile specimens of FeCrAl alloys that were irradiated in HFIR shipped to LANL for mechanical testing at room and elevated temperatures. (T. Saleh)

- [ORNL] The Level 3 milestone (M3FT-17OR020202122) titled, "Examination of Powder Metallurgy vs. Induction Melting for FeCrAl Alloy Production," was successfully completed. A technical report, ORNL/TM-2017/381 titled, "Examination of Powder Metallurgy vs. Induction Melting for FeCrAl Alloy Production" summarizes the latest efforts on the impact toughness evaluation of $\mathrm{FeCrAl}$ alloys made though powder-metallurgy (PM) and ingot-metallurgy (IM), and discusses the ductile-brittle transition temperature (DBTT) and the absorbed impact energy as a function of alloy composition, microstructure (e.g. grain and texture), and process conditions. Commercial powder-metallurgy APMT alloys and newly developed wrought ingot-metallurgy FeCrAl alloys [Fe-(10-13) Cr-6Al-2Mo base, wt. \%], the candidate alloys for ATF cladding materials, were selected as test materials. Two important findings are reported: (1) fine and uniform recrystallized grain structure would be preferable for lowering DBTT as well as increasing the absorbed impact energy, and (2) residual stresses played a role in reducing the impact toughness significantly. Detailed microstructure characterization coupling with the Charpy impact test results were used to identify the controlling factors for the impact toughness of FeCrAl alloys, which provides guidelines for optimizing the $\mathrm{FeCrAl}$ alloy tube production process and further alloy/process development for improved properties. (Z. Sun, Y. Yamamoto, X. Chen) 
- [ORNL] Procurement of seamless Gen II. C26M alloy tubes (Fe-12Cr-6Al-2Mo-Si-Y, wt. \%) with $9.5 \mathrm{~mm}$ outer diameter was initiated. The second heat of Fe-12Cr-6Al-2Mo base alloy (C26M2, heat \#17025001) was prepared by a vacuum induction melting, and the ingot was hot-isostatically pressed and extruded to prepare 1.25 " diameter bars. These were straightened, followed by centerlessgrinding into $1.000 "+/-0.001$ " diameter to prepare total 23 master bars. The master bars will be delivered to ORNL in August, 2017, and they are to be gun-drilled and tube-drawn at Century Tubes, Inc. The expected total tube length is $\sim 300 \mathrm{ft}$, and they will be delivered to ORNL and LANL. The expected delivery date is November 2017 or earlier. (Y. Yamamoto)

- [ORNL] Microstructure characterization of as-received C26M2 wire production, prepared for the fuel end cap materials, was completed. The rotary-forged wires were produced by Sophisticated Alloys, Inc., and delivered to ORNL in as-forged condition. Microstructure consists of dynamicallyrecrystallized grains $(\sim 200-300 \mu \mathrm{m})$ near the center of the wires combined with deformed, elongated grains near the surface. The average hardness of the wire was $\sim 240 \mathrm{HV}$, indicating that the material is not in fully annealed (recrystallized) condition but the residual strains remain, similar to the as-drawn C26M tube products. (Y. Yamamoto)

- [ORNL] The Charpy test results of commercial powder metallurgy APMT alloys and newlydeveloped wrought $\mathrm{FeCrAl}$ alloys have been analyzed by correlating with their compositions, processing conditions, and microstructure to identify main influencing factors for the impact toughness of $\mathrm{FeCrAl}$ alloys. It is found that materials with a fine, uniform recrystallized grain structure showed better impact toughness than alloys with a coarse, non-uniform grain structure at a given test condition. The residual stress significantly decreased the impact absorbed energy and increased the ductile-brittle transition temperature (DBTT) of FeCrAl alloys. The compositions (e.g., minor alloying elements and secondary particles) may also contribute to the impact toughness of $\mathrm{FeCrAl}$ alloys, which needs further investigation to clarify their effects. At the same time, the powder metallurgy process did not show clear advantages for the impact toughness of FeCrAl alloys compared with the traditional ingot metallurgy based on the current results. Proper process and annealing conditions are needed to achieve desirable microstructures for improved impact toughness of FeCrAl alloys. Tensile tests on selected alloys will be performed as complement to the Charpy tests. (Z. Sun, Y. Yamamoto)

- [LANL] Samples of two FeCrAl alloys (B136Y3 and C35M4) are being prepared for ion irradiation testing to obtain initial irradiation data on these alloys. (S. Maloy)

- $\quad$ [LANL] Tensile testing was completed on Generation $2 \mathrm{FeCrAl}$ alloys in tube form at low temperatures to investigate their properties during transport. This data will be pulled together in a L3 milestone due next month (S. Maloy)

- [ORNL] The Level 3 Milestone M3FT-17OR020202091, titled “ATF-1/2 Irradiation Coordination and PIE," was successfully completed. A technical report titled "Status of Wrought FeCrAl-UO2 Capsules Irradiated in the Advanced Test Reactor," summarizes the collaborative efforts between INL and ORNL to use the ATF-1 and ATF-2 test trains in the ATR to test and validate the use of wrought $\mathrm{FeCrAl}$ alloys for accident tolerant fuel applications. Currently, two experimental configurations are deployed in ATR using ORNL-derived FeCrAl alloys, one to simulate a miniaturized PWR fuel rod, the other to determine the interactions, if any, between FeCrAl and UO2 in a neutron environment. To date, PIE on the lowest burn-up rodlet has been on-going. The initial results indicate a possible failure of the cladding but further investigations are on the way. Please note, the alloy used within this rodlet is C35MN. C35MN is a FeCrAl alloy no longer being pursued as a candidate alloy for known issues with fabricability which could also be a reason for the observed failure. The report highlights the ongoing collaborative nature of the FeCrAl development program. (K. Field, J. Harp, G. Core, K. Linton) 
- [ORNL] A journal paper titled, "Mechanical properties of $\mathrm{SiC}$ composites neutron irradiated under light water reactor relevant temperature and dose conditions," has been published by the Journal of Nuclear Materials. This paper proved that nuclear grade SiC composites retained the mechanical properties following neutron irradiation at LWR relevant temperature up to 12dpa. (T. Koyanagi, Y. Katoh)

- [ORNL] The task, "Handbook of $\mathrm{SiC}$ tube properties" aims to summarize properties of SiC composite tubes for better multi-physics modeling of ATF SiC cladding. During this period, the draft report for the M3FT-17OR020202104 milestone was submitted for ORNL internal review. The report will be submitted to DOE at the beginning of August. (T. Koyanagi, Y. Katoh)

- [ORNL] The Level 2 milestone (M2FT-17OR020202102) titled, "Determination of He and D permeability of neutron-irradiated $\mathrm{SiC}$ tubes to examine the potential for release due to microcracking," was submitted to DOE. The experimental capability was developed to evaluate gas leak tightness of neutron irradiated $\mathrm{SiC}$ tubes, and demonstrated that CVD $\mathrm{SiC}$ tube was hermetic following neutron irradiation with a high radial heat flux at average temperature of $\sim 300^{\circ} \mathrm{C}$ to $\sim 2 \mathrm{dpa}$. (X.Hu, T. Koyanagi, Y. Katoh)

- [ORNL] The following paper was published in the Journal of Nuclear Materials: Takaaki Koyanagi, and Yutai Katoh, "Mechanical properties of SiC composites neutron irradiated under light water reactor relevant temperature and dose conditions, "Journal of the Nuclear Materials Volume 494, 2017, Pages 46-54 (T. Koyanagi, Y. Katoh)

- [ORNL] A manuscript for journal publication on the interlaboratory round robin axial tensile testing of $\mathrm{SiC} / \mathrm{SiC}$ tube was prepared and reviewed internally at ORNL. The manuscript presents the statistics on the mechanical properties of nuclear grade $\mathrm{SiC} / \mathrm{SiC}$ composite and the precision statement for the ASTM standard C1773 which is employed for testing ceramic fiber reinforced ceramic matrix composite tubes. The mirror holder equipment was manufactured, and the test station preparation for performing hoop tensile testing of $\mathrm{SiC} / \mathrm{SiC}$ tubes with Digital Image Correlation (DIC) was completed. These tests will help in verifying the accuracy of the strains measured through extensometer, and will also serve as a part of the lead test for the planned interlaboratory round robin study on hoop tensile testing of $\mathrm{SiC} / \mathrm{SiC}$ tubes. (G. Singh, Y. Katoh)

- [ORNL] Simulations were run for understanding the effect of fuel creep on the stress distribution and its variation with time in $\mathrm{SiC} / \mathrm{SiC}$ cladding. The study will help understand the range of stresses and temperature that may be expected in the cladding, considering that there is significant uncertainty about the creep behavior of UO2 fuel. (G. Singh, Y. Katoh)

- [ORNL] In order to provide integral data for accident models, materials interaction tests are being conducted in the high temperature furnace examining interactions between FeCrAl and Ni-base alloy 718 or type 316 stainless steel at $1300^{\circ}$ and $1400^{\circ} \mathrm{C}$ in steam. Unlike $\mathrm{Zr}$-base alloys, little interaction was observed. A manuscript titled, "Steam Oxidation Behavior of FeCrAl Cladding," was accepted for publication in the proceedings of the 18th International Conference on Environmental Degradation of Materials in Nuclear Power Systems (August 2017 in Portland, OR). (B. Pint)

\section{LWR Irradiation Testing \& PIE Techniques}

- [INL] Samples from the ATF-1A (Areva concept) rodlets were dissolved at the MFC Analytical Laboratory for chemical analysis to determine burnup. Visual examinations were performed on rodlets from the Westinghouse concept (U3Si2 Zirlo) and from the ORNL concept (UO2 FeCrAl). Neutron radiography was performed on rodlets from the Westinghouse concept (U3Si2 Zirlo) and from the ORNL concept (UO2 FeCrAl). Gamma spectrometry was performed on rodlets from the Westinghouse concept (U3Si2 Zirlo) including gamma tomography on uranium silicide which has not previously been performed. Samples from the ATF-1A (Areva concept) rodlets were sectioned and 
prepared for optical microscopy. These samples will be examined in the next reporting period. (J. Harp)

- [INL] Two GE-sponsored capsules were removed from irradiation in the ATR during a successful basket reconfiguration in support of the upcoming ATR Cycle 162A-1. Multiple Engineering Calculations and Analysis Reports were effectively revised to reflect the corrigendum issued to update the thermal diffusivity of $\mathrm{U} 3 \mathrm{Si} 2$. Analysis documentation continues to be altered to streamline cycle-specific analyses and data provided to experiment sponsors. (G. Core)

- [INL] All Accident Tolerant Fuels 2 (ATF-2) Sensor Qualification Test (SQT) components have been fabricated and assembly of the test train is in progress. Installation of SQT support equipment (electrical and gas panel systems) is in progress. Fabrication of "low risk" ATF-2 (Fuel Test) components is in progress with expected completion date by end of fiscal year (FY) 2017. ATF-2 fuel rod components are being machined and weld development is in progress. (G. Hoggard)

- [INL] The final draft of the (Transmutation) Metallic Fuels Handbook is being circulated for technical/peer review and has been approved through STIMS. The schedule is on track to issue this report on August 31 to meet the milestone. (C. Papesch)

- [INL] Measurements and analysis are completed on U3Si2. We have shown that 5 f-electrons (responsible for electronic properties) in this material are delocalized and that the thermal conductivity govern by lattice vibrations can be neglected above room temperatures with electrons being main source of heat transport at this temperature range. The results have been analyzed and a paper has been submitted to J. Nuc. Matt (currently under review). (C. Papesch)

- $\quad$ IINL] Efforts have been made to refine and finalize the thermodynamic modeling of the Mo-Ti-Zr system using the CALPHAD approach. To further improve the quality of the model parameters for Mo-Ti, Mo-Zr and Ti-Zr binary subsystems, additional quantum mechanical calculations have been performed using VASP code. As the result of these efforts, a new improved thermodynamic database for the Mo-Ti-Zr ternary system has been obtained (referred to as Version 2). Compared with the May version of the database (referred to as Version 1), the new database gives results in better agreement with available experimental phase diagrams (Figure 7). (C. Papesch) 

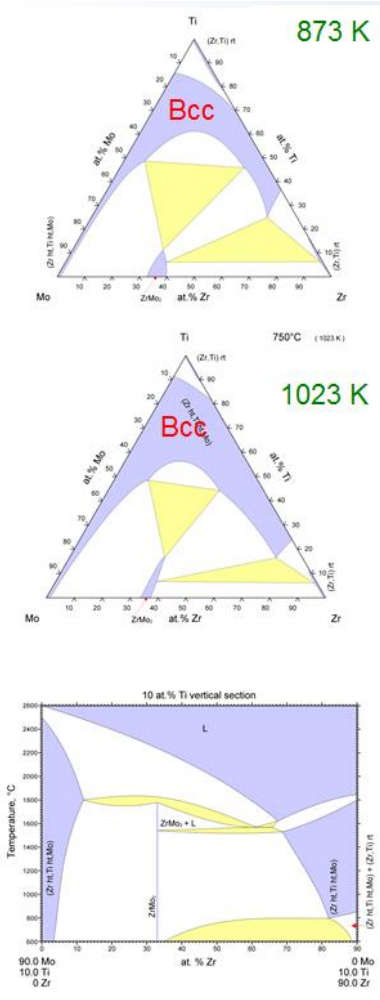

Experimental phase diagram
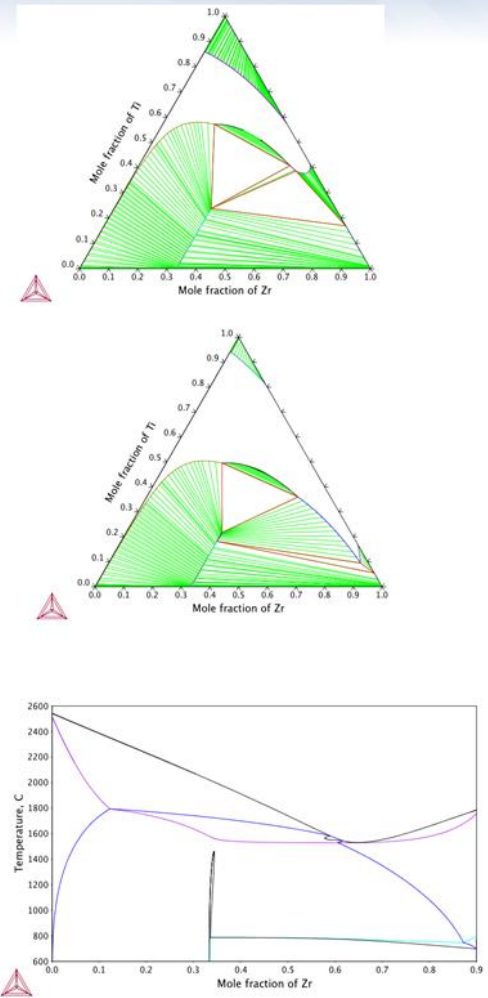

Database version 2
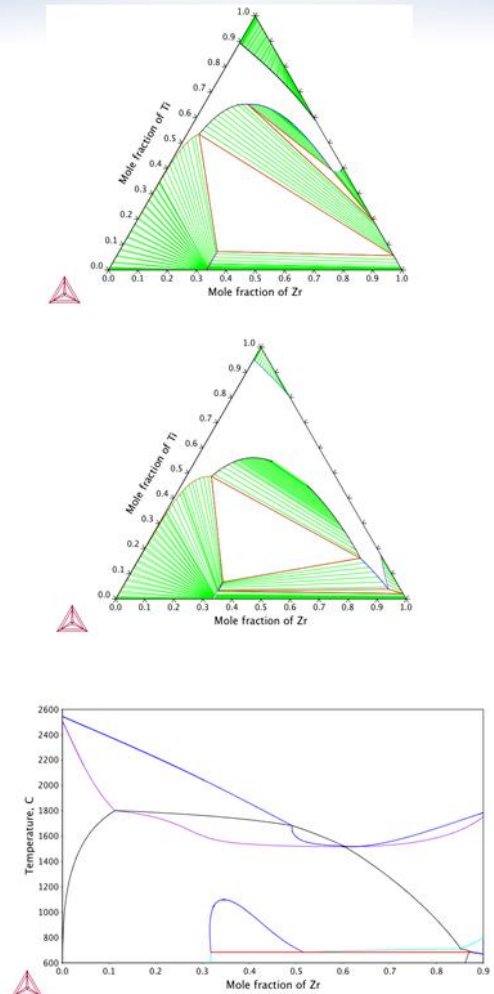

Database version 1

Figure 7. Comparison of Database Version 1 and 2 to experimental phase diagram.

\section{LWR Transient Testing}

- [INL] Design review comments were collated for the Multi-SERTTA-CAL vehicle and identified performers/plan for resolution was completed. This effort will help ensure a timely resumption of Multi-SERTTA related work in order to support fabrication, qualification, and irradiation of crucially-important specimen-core power coupling data, planned to start in late FY18, in support of final ATF-3 test design and irradiation parameters. (J. Schulthess)

- [ORNL] The Level 3 milestone (M3FT-17OR020204032) titled, "RIA simulation tests using driver tube for ATF cladding," was delivered ahead of schedule. The milestone summarizes the current research activities to evaluate PCMI-like hoop-strain-driven mechanical response of ATF cladding materials using a modified-burst test (MBT) device. Calibration testing using unirradiated Gen-I $\mathrm{FeCrAl}$ tube cladding specimens indicates a variety of transient mechanical loading conditions can be imposed on ATF cladding to investigate RIA-like behavior and inform failure models. Due to the uncertainty of the failure location on the sample, the MBT device is further enhanced by a novel Digital Image Correlation (DIC) system with a $360^{\circ}$ view of the sample surface capable of recording strain data and the exact failure location during testing. The mechanical behavior of $\mathrm{SiC} / \mathrm{SiC}$ cladding subjected to the MBT using a DIC system was presented in the milestone with preliminary results and analysis. An example test is shown in Figure 8. (M. Cinbiz, N. Brown, R. Lowden, K. Linton, K. Terrani) 

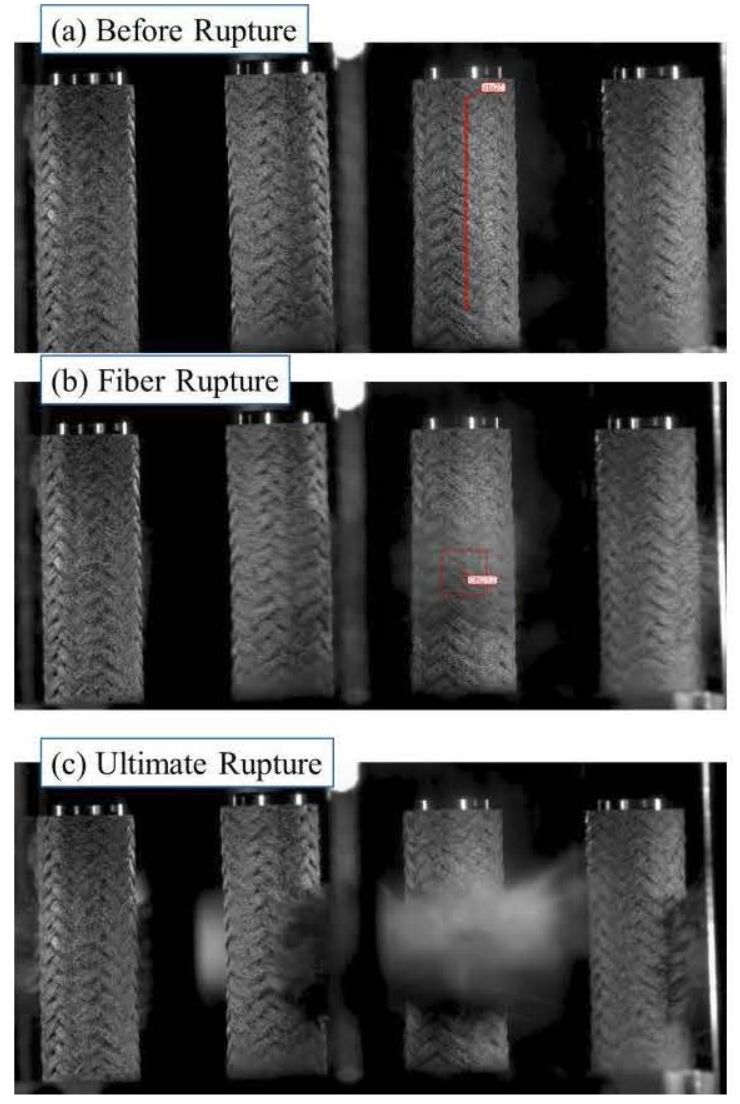

Figure $8.360^{\circ}$ view of the outer surface of the $\mathrm{SiC} / \mathrm{SiC}$ composite sample before fracture (a), at the fiber rupture (b) and at the ultimate fracture (c).

- [ORNL] An in-cell Severe Accident Test Station (SATS) capable of examining the oxidation kinetics and accident response of cladding materials for design basis accident (DBA) and beyond design basis accident (BDBA) scenarios has been inserted into the 3525 Irradiated Fuels Examination Laboratory (IFEL), a hot cell facility at Oak Ridge National Laboratory (as shown in Figure 9). Connections to the control cabinet and utilities have been completed and initial system tests performed. A demonstration integral loss-of-coolant accident (LOCA) test of unirradiated $\mathrm{Zr}$ cladding will be performed in August, as well as, a high temperature BDBA test at $1400^{\circ} \mathrm{C}$. (K. Linton, Y. Yan, Z. Burns) 


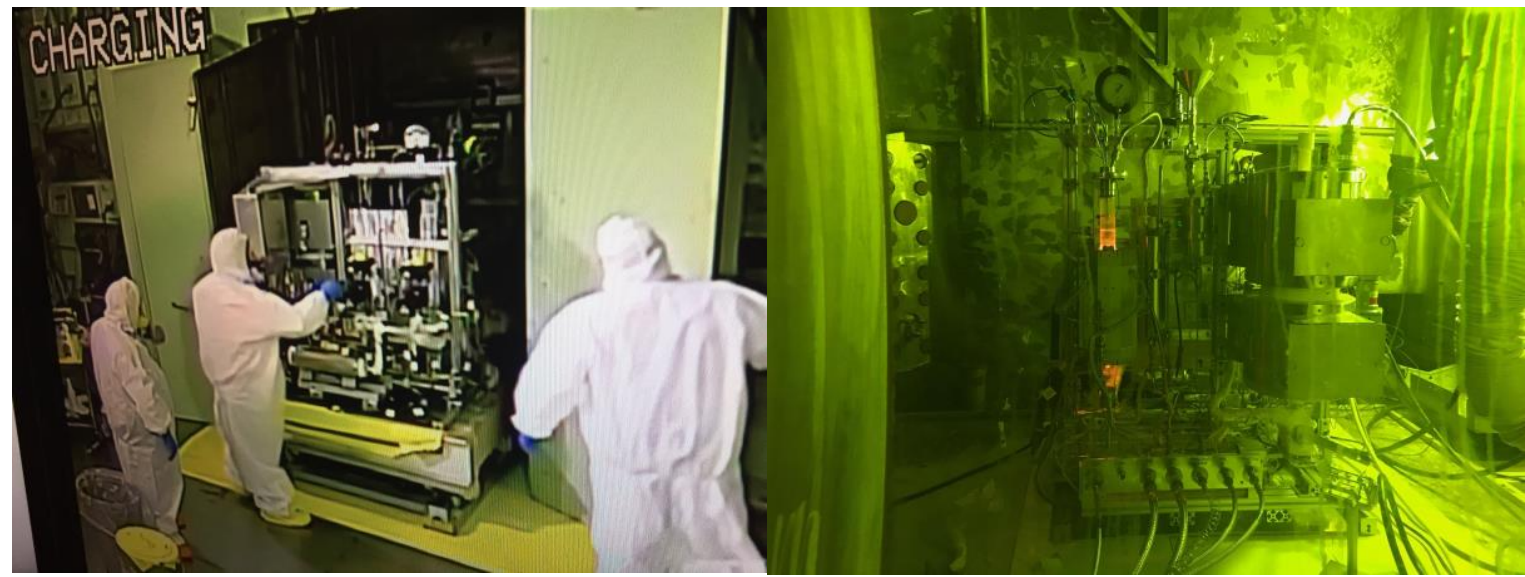

Figure 9. Severe accident test station insertion into the 3525 Hot Cell facility at ORNL (left). LOCA furnace orange glow through hot cell window during initial furnace testing (right).

- [ORNL] A journal article was published titled, "A Pulse-Controlled Modified Burst Test Instrument for Accident-Tolerant Fuel Cladding," describing the shakedown testing of the modified burst test instrument at ORNL. Pellet-cladding mechanical interaction due to thermal expansion of nuclear fuel pellets during a reactivity-initiated accident (RIA) is a potential mechanism for failure of nuclear fuel cladding. To investigate the mechanical behavior of cladding during a RIA, we developed a mechanical pulse-controlled modified-burst test instrument that simulates transient events with a pulse width from 10 to $300 \mathrm{~ms}$. The paper describes how the data generated from these tests are expected to be useful to inform future TREAT testing. The publication citation is: Cinbiz, M. N., Brown, N. R., Terrani, K. A., Lowden, R. R., Erdman, D., 2017. "A pulse-controlled modified-burst test instrument for accident-tolerant fuel cladding," Annals of Nuclear Energy 109, pp. 396-404. (M. Cinbiz, N. Brown, K. Terrani, K. Linton)

- [ORNL] A journal article was published titled, "Potential impact of accident tolerant fuel cladding critical heat flux characteristics on the high temperature phase of reactivity initiated accidents." The article details over 2000 scoping RELAP5-3D simulations to assess the potential impact of boiling heat transfer coefficients and Critical Heat Flux (CHF) on peak cladding temperature (PCT) of key Accident Tolerant Fuel (ATF) cladding types in a design basis accident. The simulation results show that both PCT and duration of film boiling are particularly sensitive to the value of CHF. The publication citation is: Liu, M., Brown, N. R., Terrani, K. A., Ali, A. F., Blandford, E. D., Wachs, D. M., 2017. "Potential impact of accident tolerant fuel cladding critical heat flux characteristics on the high temperature phase of reactivity initiated accidents," Annals of Nuclear Energy 110, pp. 48-62. (N. Brown, K. Terrani, D. Wachs)

- $\quad$ OORNL] Temperature and neutron flux boundary conditions have been generated for future 3D thermo-mechanical analysis of a SiC-f/SiC-m based channel box in a BWR. Under differential temperature and irradiation, SiC-based materials swell based on the local conditions, so the objective is to use some simplified boundary conditions to predict the dimensional change of a channel box during a typical reactor cycle. The goal of this model is to accurately calculate thermal and neutronic boundary conditions for the surface temperature and flux of a silicon carbide fuel bundle channel box in a GE14-like BWR. Reasonable inputs from a variety of sources on similar reactors were used to assembly GE14-like data. The CASL subchannel analysis code CTF and neutronics code Serpent were used to generate the boundary conditions. Example temperature conditions are shown in Figure 10. (N. Brown, G. Singh, B. Wirth, K. Terrani) 


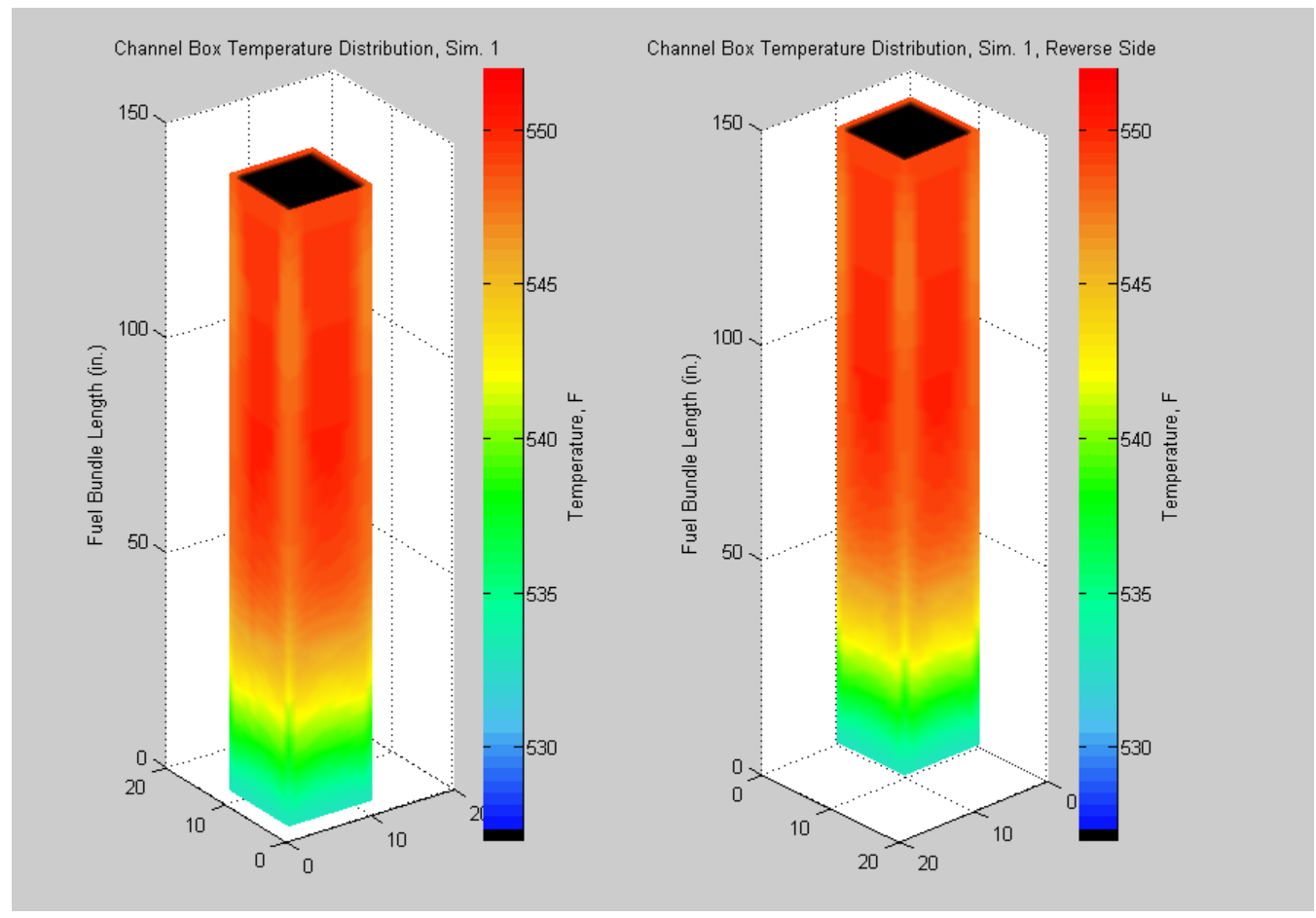

Figure 10. SiC/SiC composite channel box calculated temperatures.

\section{ADVANCED REACTOR FUELS}

\section{AR Computational Analysis}

- [INL] INL continues collaboration with JAEA on pore migration modeling in fast reactor MOX fuel. There is still a difference between Bison and CEPTAR (JAEA code) porosity migration calculations, which is due to discrepancies in the pore velocity equation. This is primarily due to calculations of vapor pressure and the derivative of vapor pressure with respect to temperature. While this discrepancy is being resolved, INL personnel are working on documenting and updating the Bison repository regarding fast MOX capability, which INL hopes will facilitate better communication between INL and JAEA and help address the calculation differences. (P. Medvedev)

\section{AR Fuels Development}

- $\quad[$ ANL] A comparative study was carried out between an annular and a solid metal fuel assembly. Due to the absence of a sodium bond, the use of annular metal fuel allows for placement of the gas plenum below the active fuel region. Because of this, the use of annular metal fuel is expected to reduce the pressure of the fission products, due to the lower temperature of a gas plenum located below the active core region. Additionally, the presence of a lower gas plenum increases the distance of the lead-bearing grid plate from the driver fuel. Thus, the annular fuel is also expected to be better suited than the solid fuel to meet the irradiation damage (i.e., DPA) limit of the level of the grid plate due to the exposure to lower flux levels. It is noted that the DPA of the grid plate is one of the factors to determine reactor lifetime. Calculations were performed this month to demonstrate the better performance of the annular fuel compared to the solid fuel with respect to the DPA constraints of the grid plate. For this, a Monte Carlo (MCNP) model was made for the ABR single assembly using both annular and solid metal fuels (see Figure 11 and Figure 12 below). From preliminary results, it is found that the DPA ratio at the grid plate between the annular and solid fuel assembly is $\sim 5 \%$. (Aliberti, Kim) 


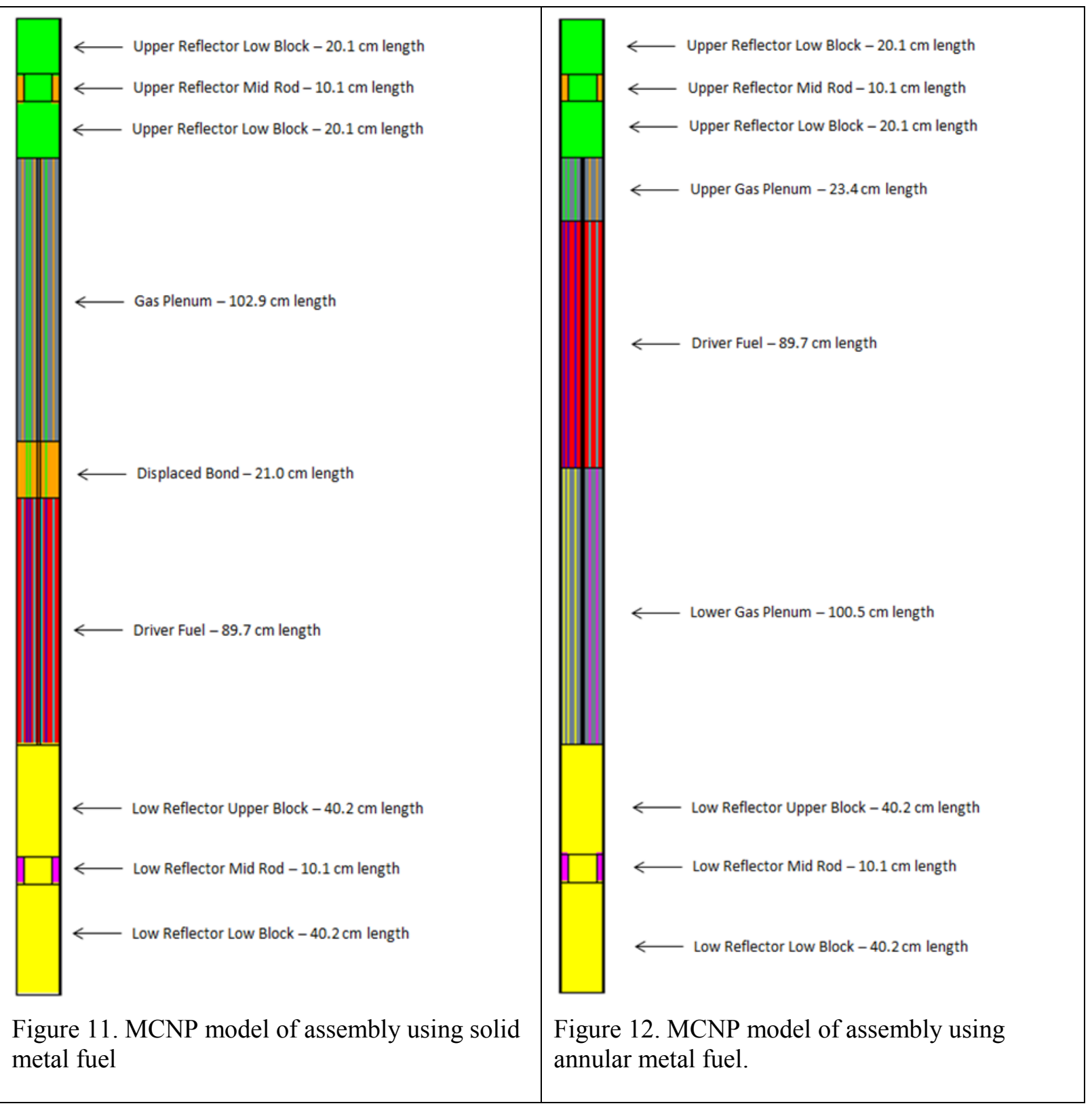

- $\quad$ [INL] The Level 2 milestone to complete the production of americium metal needed for AmBB fuel fabrication was completed. The U.S. and France are working together on an objective to transmutate americium bearing fuel by placing it in the blanket of a fast neutron reactor. As part of the U.S. commitment to this objective, approximately $10 \mathrm{~g}$ of pure americium metal was to be produced by the end of July 2017. INL successfully produced upwards of $15 \mathrm{~g}$ of this material using their distillation capabilities. This effort has exhausted the supply of Am/Np metal starting material for the distillation process and efforts are now underway to modify the method for the retrieval of americium from a new starting material containing Am and $\mathrm{Pu}$ metal. The additional $5 \mathrm{~g}$ of americium will allow for continued fuel fabrication to meet project needs in the interim as the current method is adjusted. (L. Squires) 
- [INL] As previously reported, all planned modifications for the stoichiometry control system gas panel have been finished. The piping modifications have been successfully helium leak tested. In preparation for initiation of $\mathrm{MOX}$ fabrication, several $\mathrm{DUO}_{2}$ pellets were pressed to determine the optimal pressing parameters. Pressing was completed using a $6.25 \mathrm{~mm}$ diameter die. Force was varied from 400-1600 pounds. Based on the resulting calculated green densities, it would appear that the die needs to be optimized. Despite forces as high as 1600 pounds, the resulting pellets had a low green density which lead to poor handling strength. Based on these results, options will be investigated such as powder preparation, die lubricants, die design, etc. Figure 13 below shows the pellets pressed using 800 and 1600 pounds of force.

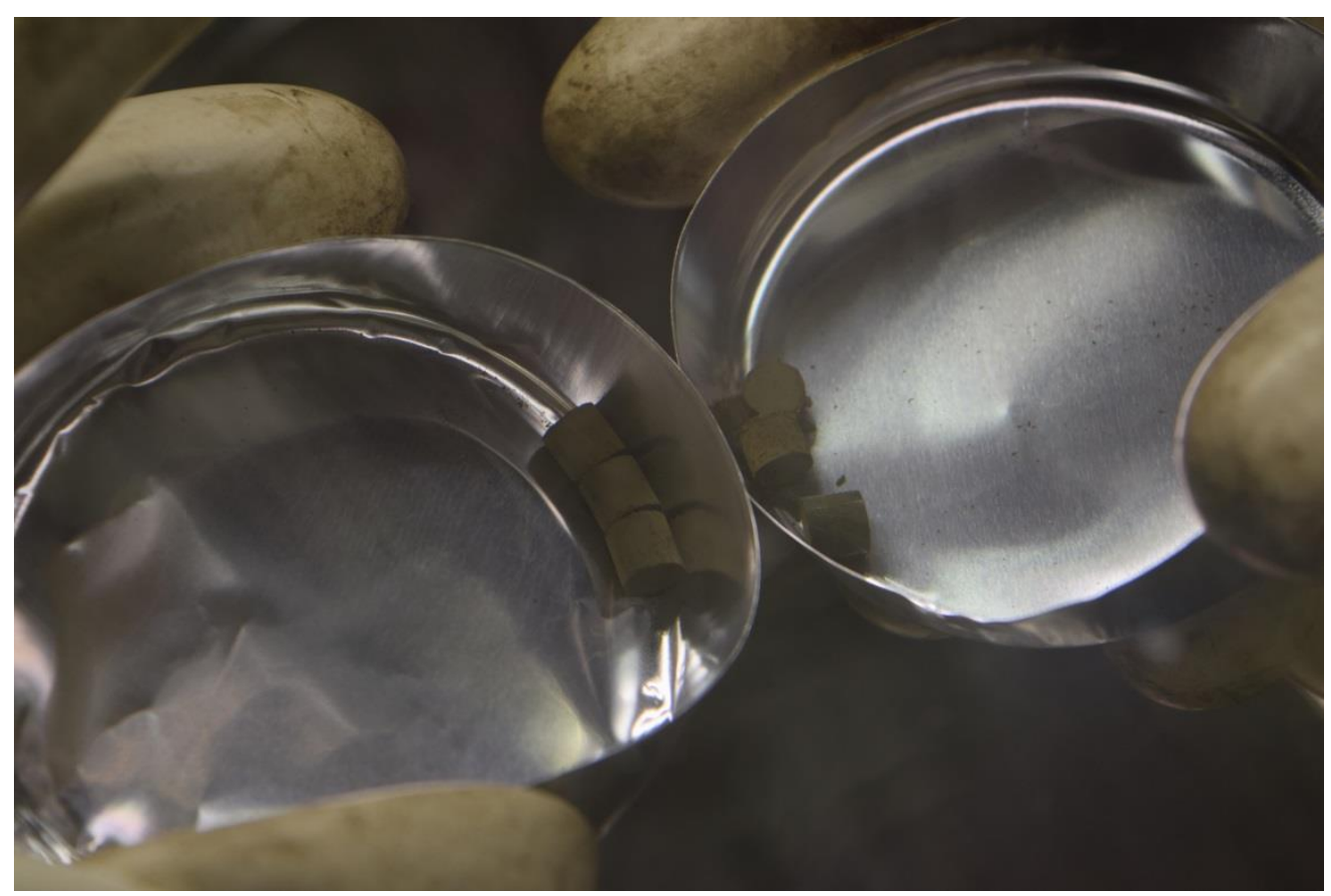

Figure 13. Pressed samples at $800 \mathrm{lb}$ (left) and $1600 \mathrm{lb}$ (right)

Parts have been fabricated to allow the reconstruction of the hot uniaxial press in the casting laboratory glovebox. This will allow for its use by additional fuel development activities (R. Fielding)

- [INL] AFC-4F will include samples including an integral FCCI barrier. Previously it has been shown that U-10Zr fuels can be successfully arc cast into a wrapped foil, with $50 \mu \mathrm{m}$ foil appearing to be the optimized thickness for ease of fuel fabrication. Another concept has been proposed where the wrapped foil is simply loosely inserted into the cladding before the sodium and fuel are loaded. It is proposed that as the fuel is sodium bonded, the zirconium liner will also be bonded making a tight fit less critical. The major question is whether the zirconium will be sodium bonded or will there be large voids in between the zirconium and the cladding. To test this concept, several mockup rodlets were fabricated and will go through radiographic tomography to determine if any voids are left after a standard bonding process. (R. Fielding)

- $\quad$ IINL] In the area of optimized fuel composition, SEM characterization was performed on two diffusion couples that ran for 500 hours, $\mathrm{U}-10 \mathrm{Zr}-4.3 \mathrm{Sn} / \mathrm{Ln}$ and $\mathrm{U} 10 \mathrm{Zr} 3.86 \mathrm{Pd} / \mathrm{Ln}$. Figure 14 is from $\mathrm{U}-10 \mathrm{Zr}-4.3 \mathrm{Sn} / \mathrm{Ln}$, where $\mathrm{Ln}=53 \mathrm{Nd}-25 \mathrm{Ce}-16 \mathrm{Pr}-6 \mathrm{La}$. After analyzing the data, it was determined the diffusion couples need to run longer. The diffusion couple experiments were set up again, and will 
run for 2 months. A journal article has been submitted and accepted for publication in the Journal of Nuclear Materials titled, "SEM characterization of two advanced fuel alloys: U-10Zr-4.3Sn and U10Zr-4.3Sn-4.7Ln," authored by M. T. Benson, J. A. King, R. D. Mariani, and M. Craig Marshall. (R. Fielding)

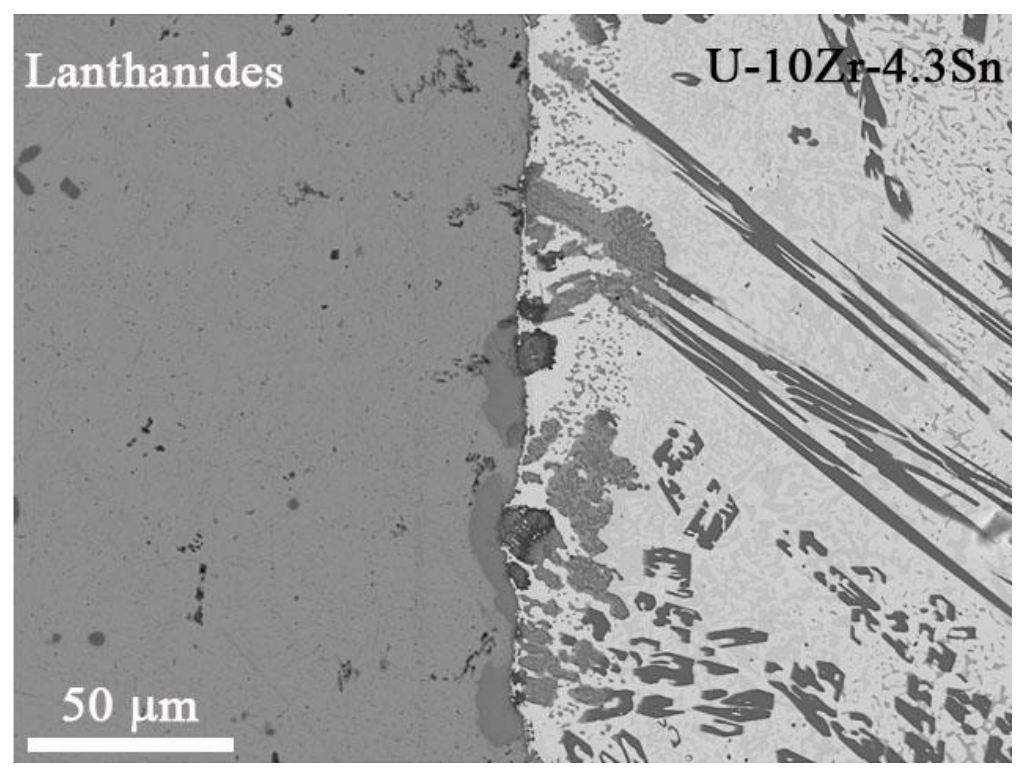

Figure 14. Interaction zone between U-10Zr-4.3Sn and lanthanides.

\section{AR Core Materials}

- $\quad$ [LANL] The Mechanical test machine in the hot cells is being prepared for tensile testing. This requires an entry into the hot cell to change out the fixtures and load cell followed by calibration testing on the load cell. (T. Saleh)

- [PNNL] Edits to the draft version of Milestone report "M3FT-17PN020302043-Issue Report on Microstructural Studies on Neutron Irradiated MA957 (FY15)," had to be delayed due to other program priorities. The projected completion date is now late August. (M. Toloczko)

- [PNNL] Atom probe investigations of 500 dpa ion irradiated 14YWT continued. (M. Toloczko)

- [PNNL] A manuscript was completed on the topic of identification of carbon contamination in ion irradiated materials, and has been submitted for review and eventual publication. (M. Toloczko)

- [LANL] In an effort to gain an in depth understanding of irradiation effects in ODS alloys, in situ ion irradiation studies are being performed on 14YWT at the ANL IVEM. Initial testing went well and results are being analyzed. (S. Maloy)

- [ORNL] Six new tensile tests were conducted at room temperature (RT) on neutron irradiated SS-J2 tensile specimens of 14YWT-SM6 (ID: FD00, FD03, FD04, FD07 and FD10) and 14YWT-PM2 (ID: P13) in the hot cell at ORNL. The specimens were irradiated in rabbit capsules in HFIR at target conditions of $80-100^{\circ} \mathrm{C}$ (FD10) to $\sim 14.3 \mathrm{dpa} ; 300^{\circ} \mathrm{C}$ to $\sim 6 \mathrm{dpa}$ (FD00) and $\sim 8.6 \mathrm{dpa}$ (P13); $500^{\circ} \mathrm{C}$ to $\sim 8.6 \mathrm{dpa}$ (FD03 and FD04); and $650^{\circ} \mathrm{C}$ to $\sim 8.6 \mathrm{dpa}$ (FD07). The $\mathrm{SiC}$ thermometry indicated that the actual irradiation temperatures of each rabbit exceeded the target temperature by over $\sim 100^{\circ} \mathrm{C}$ to $200^{\circ} \mathrm{C}$. Collectively, five RT tensile tests have been conducted on 14YWT-PM2 specimens that were neutron irradiated at target temperatures of 300,500 and $650^{\circ} \mathrm{C}$ to doses ranging from $\sim 0.36$ to 8.6 dpa. The results showed scatter in the ultimate tensile strengths (UTS) between 1200-1350 MPa 
( $<10 \%$ increase) compared to the $\sim 1200$ MPa UTS observed for two unirradiated control specimens and no appreciable differences in ductility for all specimens. The five additional RT tensile tests conducted on 14YWT-SM6 revealed scatter in strength properties compared to two unirradiated control specimens but that the scatter followed no consistent trend with irradiation temperature or neutron irradiation dose. In addition, the plastic deformation behavior and total elongation of the SM6 heat was not altered by any of the irradiation conditions. Other than the previously reported softening that occurred for FD09 (target temperature $-650^{\circ} \mathrm{C}$ and dose $-14.3 \mathrm{dpa}$ ), none of the five tensile tests exhibited softening. Overall, the numerous PIE tensile tests that have been conducted on the SM6 and PM2 heats of 14YWT demonstrate that no significant radiation hardening has occurred, which is a significant contribution to understanding the radiation tolerance of 14YWT during neutron irradiation. The funding for the PIE tensile tests is provided by NSUF Rapid Turnaround Experiment for the proposal "Neutron Irradiation Effects on Tensile Properties and Deformation Behavior of 14YWT" (16-696) that was awarded on August 16, 2016. (D. Hoelzer)

- [ORNL] The broken half of the two neutron irradiated SS-J2 tensile specimens of 14YWT-SM6 that were tested at room temperature in the hot cell at ORNL were transferred to LAMDA for preparation of specimens for microstructural characterization studies. The specimens were FD01 and FD09, which were neutron irradiated to target conditions of $300^{\circ} \mathrm{C}$ to $\sim 8.6 \mathrm{dpa}$ and $650^{\circ} \mathrm{C}$ to $\sim 14.3 \mathrm{dpa}$, respectively. The specimens were prepared from the deformed gage section and the shoulder section located away from the loading surface of the broken half of the SS-J2 tensile specimen using the liftout and focused ion beam (FIB) method. The microstructure of the specimens was examined using the FEI Talos F200X Scanning/Transmission Electron Microscope located in LAMDA. The results will be analyzed and reported in the next monthly report. The PIE results obtained in this study will be valuable in understanding how neutron irradiation conditions affect the microstructure of 14YWT after deformation via tensile testing. The funding for the PIE tensile tests is provided by NSUF Rapid Turnaround Experiment for the proposal "Neutron Irradiation Effects on Tensile Properties and Deformation Behavior of 14YWT" (16-696) that was awarded on August 16, 2016. (D. Hoelzer)

- [PNNL] A milestone report (M3FT-17PN020302071) titled "High-Temperature Mechanical Behavior of HT9 Steels after Modified Processing Routes," was completed. This reported is based on the first step effort for processing development to improve high-temperature mechanical properties of HT9 steels. This task aimed to find a new processing route that can produce a microstructure of HT9 steel with improved mechanical properties including high-temperature fracture toughness. The report presents the results of two main activities: First, a comprehensive thermodynamics calculation was performed for the two HT9 steels, with and without N addition, to obtain key information on equilibrium phase formation and elemental distribution within main phases and precipitates. Second, the first round of new heat-treatment routes, including both the typical normalization plus tempering and the newly designed two-step tempering, were applied and the heat-treated HT9 steels were evaluated by a systematic tensile property testing over room temperature to $600^{\circ} \mathrm{C}$. In all heattreatment conditions, the N-doped HT9 steel exhibited lower strength but higher ductility than the HT9 steel with typical composition. (T.S. Byun)

- $\quad$ [PNNL] As part of the program to fabricate tubing from difficult-to-fabricate materials, MA956, 9YWT, and 14YWT are being extruded and pilgered to final dimensions. Two 14YWT thick-wall tubes, as shown in Figure 15 below, have been extruded and are staged for pilgering. With the current as-extruded dimensions, and to achieve the final target dimensions, a reduction of area of $82 \%$ will be required. To ensure maximum success, the inner diameters are being measured with an air gauge and the outer diameters are being measured with a laser gauge. These measurements, which will provide an accurate assessment of the wall thickness and its variations with respect to length, will be used to determine the first and successive areal reductions during pilgering. (R. Omberg) 


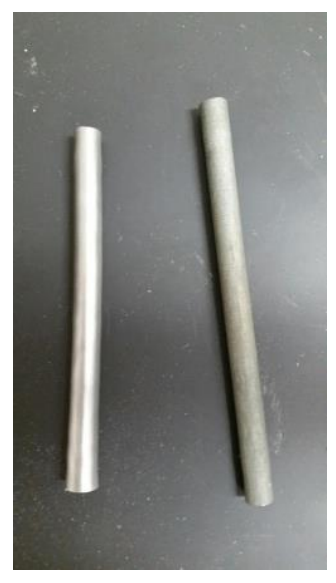

Figure 15. Two 14YWT thick-wall tubes extruded and staged for pilgering.

\section{AR Irradiation Testing \& PIE Techniques}

- [INL] The Level 3 milestone titled, "Complete Fabrication of Aluminum-Cadmium Baskets" was completed on July 14, 2017. In order to irradiate the AFC experiments, five experiment capsules are placed in each basket, the basket are then placed into the Advanced Test Reactor and the experiment is irradiated. Without the baskets, experiment irradiation could not occur. (D. Dempsey)

- [INL] A sample from FUTURIX-FTA DOE1 was loaded into the EPMA exam in IMCL. Initial activities to begin the quantitative analysis have begun. Results will be forthcoming. (J. Harp)

- [INL] Visual exam and Neutron radiography was performed on AFC-3C rodlets and AFC-3D rodlets (Figure 16). No obvious defects were observed. (J. Harp)

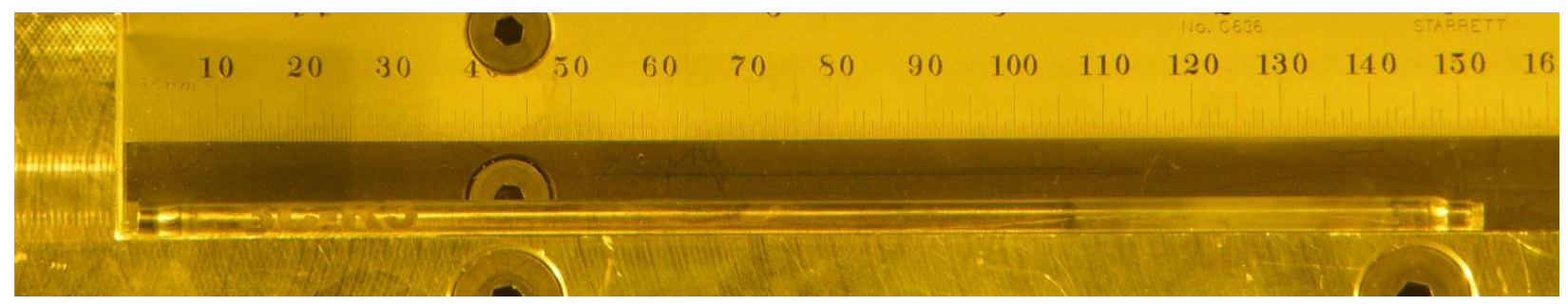

Figure 16. Visual exam of AFC 3C R5 that contained U-1Pd-13Zr sodium bonded fuel.

- [INL] Samples from AFC-4A were dissolved in the Analytical Laboratory for burnup analysis. Chemical analysis will commence in the next reporting period (J. Harp)

\section{CAPABILITY DEVELOPMENT}

\section{Fuels}

- [INL] The Thermal Conductivity Microscope (TCM) is being prepared for testing at the FCF Mockup shop. The TCM stand which integrates the instrument head and sample scan stages has been completed. Feedthroughs for signal testing have been received and fabrication of the instrumentation cable from the workstation to the glove box has been completed. The longer travel sample stage has been incorporated. Bails have been incorporated into the film thickness monitor and the sample stage to allow re-positioning/removal using manipulators. Assembly of the system in the configuration for FCF testing is now being completed with a goal of testing in August. (D. Hurley) 


\section{Irradiation, Testing, and PIE}

- $\quad$ INL] Specimens were shipped and received at the Advanced Photon Source for EXAFS experiments. One graduate student attended an EXAFS workshop put on by Illinois Institute of Technology. Data interpretation of unirradiated and irradiated Mo was carried out. A graduate student is learning a new EXAFS data analysis code, FEFF. (M. Okuniewski)

For more information on Fuels contact Jon Carmack (208) 533-7255. 


\section{MATERIAL RECOVERY AND WASTE FORMS DEVELOPMENT}

\section{REFERENCE TECHNOLOGIES AND ALTERNATIVES}

- [INL] The level two milestone (M2FT-17IN030102011), "ALSEP Scrub Section Test Loop Irradiation," has been completed. Completion of this milestone required performing a series of irradiation experiments in the INL radiolysis test loop. For the experiments, the ALSEP solvent (0.050 M T2EHDGA + 0.75 M HEH[EHP] in dodecane) was irradiated in contact with either $3.0 \mathrm{M}$ nitric acid or a simulated ASLEP feed solution adjusted to 3.0 M nitric acid. Samples of the irradiated aqueous and organic phases were used to perform simplified extraction, scrub, and strip batch contact flowsheet tests. The scrub solution contained $0.2 \mathrm{M}$ citric acid adjusted to $\mathrm{pH}=3$ and the strip solution contained $0.125 \mathrm{M}$ HEDTA $+0.2 \mathrm{M}$ citric acid adjusted to $\mathrm{pH}=3$. The americium and europium distribution ratios, determined via the simplified flowsheet tests, were used to evaluate the impact of gamma radiolysis on the efficacy of the scrub section of the ALSEP flowsheet.

The americium and europium scrub distribution ratios both exhibit a near linear increase with increasing absorbed dose. The observed increase is consistent with the degradation of the AHA present in the ALSEP scrub solution. Whether the degradation of AHA is dominated by hydrolytic or radiolytic degradation processes cannot be ascertained at this point in time. In order to differentiate the impacts of hydrolytic and radiolytic degradation processes, a follow-on experiment in which the ALSEP scrub section will not be irradiated is planned for the near-future.

The INL radiolysis/hydrolysis test loop was used to investigate the possible impacts of gamma radiolysis upon the efficacy of the ALSEP scrub section. Distribution ratio analysis of the irradiated ALSEP solvent and aqueous scrub solutions suggest that gamma irradiation should have only a minimal impact of the separation of the minor actinides from the lanthanides. Further analyses are necessary (ICP-MS, ICP-OES, GC, etc.) in order to determine the possible impacts, if any, of gamma radiolysis on distribution of fission products and other matrix components in the ALSEP scrub section. (D. Peterman)

- [ORNL] The ORNL "Nuclear review panel" reviewed our plans for a hot demonstration for FY2018 and identified some high level issues. Our Division director Cecil Parks is going to contact senior DOE-NE officials to discuss and hopefully resolve these issues. (B. Jubin)

- [ORNL] Interaction with the off-gas sigma team to coordinate testing of the off-gas system to capture tritium and iodine continued. The actual design and testing of this system is part of the off-gas-sigma team FY2017 activities. The actual work will be started in early August. (B. Jubin)

- [ORNL] In the June report, difficulties were reported in LTA membrane synthesis to obtain high permeability membranes. The $\mathrm{H} 2 \mathrm{O}$ permeance of these membranes were about an order of magnitude lower than the reported vapor permeances of LTA membranes in the literature. The technical issues were addressed with improved LTA membrane synthesis. NaA membranes were prepared by secondary growth on tubular-type $\alpha$-alumina supports (10 $\mathrm{mm} \mathrm{O.D,} 7 \mathrm{~mm} \mathrm{I.D.} \mathrm{and} 1 \mathrm{~mm}$ thickness, Inopor $\mathrm{GmbH}$ ). XRD patterns of as-synthesized NaA seeds and membrane were obtained. The characteristic peaks associated with the LTA structure were identified in the XRD pattern, and it was confirmed that no other competing phases are formed during synthesis. The bulk compositions of the as-synthesized $\mathrm{NaA}$ and cation-exchanged KA membranes were determined using EDX analysis of the $\mathrm{Na}, \mathrm{K}, \mathrm{Si}$ and $\mathrm{Al}$ content. After three times of repeated ion exchange ( $1 \mathrm{~h}$ for each stage), almost $95 \%$ of sodium ions were exchanged to potassium ions. SEM images of ion-exchanged LTA membrane (KA) were obtained which showed a dense and integrated zeolite layer on the surface of the substrate. Compared to the membrane synthesized on the macroporous disk support (CoorsTek), seed/gel penetration was not observed inside the support material, which can be attributed to the small pore size $(\sim 100 \mathrm{~nm})$ of top layer of the tubular substrate. The thickness of the membrane was 
estimated to be $\sim 2.5 \mu \mathrm{m}$. The K-LTA membrane was evaluated on tritiated water at neutral $\mathrm{pH}$ and a $\mathrm{pH}$ of 4.5 to simulate the water recycle in nuclear fuel processing. It appears that LTA membrane under neutral $\mathrm{pH}$ conditions may preferentially retain $\mathrm{HTO}$ over $\mathrm{H}_{2} \mathrm{O}$, with $\mathrm{H}_{2} \mathrm{O}$ permeance almost three times higher than HTO. If the observed preferential retention of HTO in the feed is found to be reproducible, it could be indicative of the separation mechanism by molecular sieving. The molecular diameter of water molecules is $0.28 \mathrm{~nm}$. The synthesized K-LTA membranes have a pore size of 0.3 $\mathrm{nm}$. This small difference in pore size could be responsible for molecular sieving where the larger HTO molecule is preferentially blocked or retained on the feed side. For sake of comparison, the SAPO-34 membranes evaluated in the past have an effective pore size of $0.38 \mathrm{~nm}$. (R. Bhave, B. Jubin)

\section{Sigma TeAm for AdVANCEd ACTINIDE RECYCLE}

- [ANL] To simplify advanced fuel cycle by minimizing the number of the process flowsheets, the Actinide Lanthanide SEParation (ALSEP) process was successfully demonstrated on a lab scale at the Nuclear Engineering Division of Argonne National Laboratory. A simulant of PUREX raffinate containing the major fission products was spiked with ${ }^{241} \mathrm{Am},{ }^{244} \mathrm{Cm}$ and ${ }^{147} \mathrm{Pm}$ and used as a feed for the ALSEP demo. The process was run using a bank of $1.25-\mathrm{cm}$ centrifugal contactors produced by additive manufacturing. Preliminary results show that the minor actinides were quantitatively recovered from the feed. As a following step, the minor actinides (MA) were completely separated from the lanthanides: less than 0.5 milligram/Liter of total Ln reported in the MA product while no actinides were detected in the Ln product. The only minor drawback of the performed flowsheet was incomplete Mo scrubbing - around $0.8 \%$ of the total Mo was carried out in the organic phase, thus contaminating the MA product at the concentration level of 2 milligram/Liter. This can easily be prevented by adding 2-3 stages to the Mo scrub section. Detailed sample analysis is ongoing. The solvent stage profile for the MA strip section is presented in Figure 17. (A. Gelis)

\section{MA Strip organic phase concentration profile}

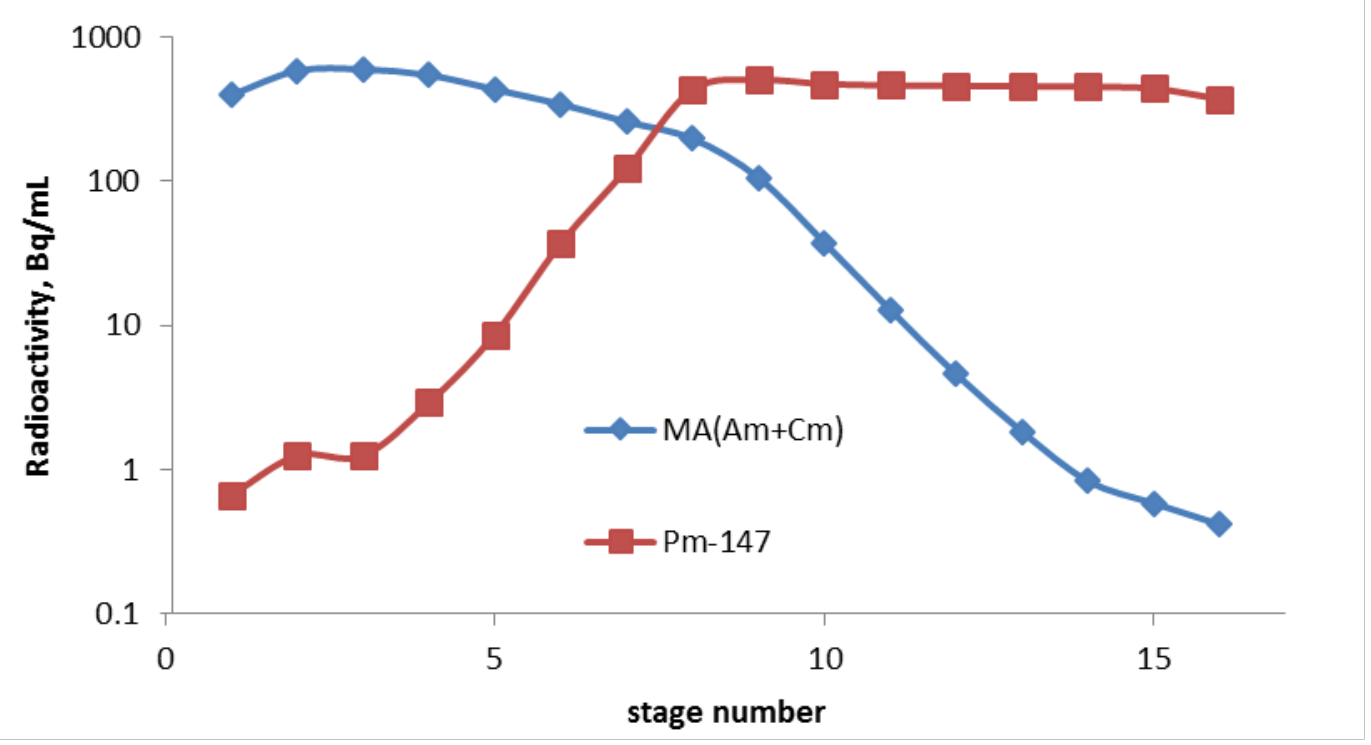

Figure 17. Concentrations of ${ }^{241} \mathrm{Am},{ }^{244} \mathrm{Cm}$ and ${ }^{147} \mathrm{Pm}$ in the organic phase of the ALSEP minor actinide strip section.

- $\quad$ INL] The cause of recent inability to oxidize Am in the last several hot tests was identified as being due to the materials of construction of new filters being used for bismuthate filtration. A successful 
hot test was then performed achieving a DAm of 2.5 and DCe of 4.7. It was attempted to selectively strip Am by allowing the loaded organic phase to stand for 5 minutes; however, both metals were reduced and stripped in this time frame. This informs the design of a further hot test using a shorter reduction time. (B. Mincher)

- [ORNL] In fulfillment of the technical milestone M3FT-17OR03010310, "Evaluate the behavior of key fission products in actinide co-crystallization," the following paper has been submitted to the peer-reviewed journal Inorganic Chemistry: Jonathan D. Burns and Bruce A. Moyer, "Uranyl nitrate hexahydrate solubility in nitric acid and its crystallization selectivity in the presence of nitrate salt." Results showed an increase in uranyl nitrate hexahydrate crystal yields as initial nitric acid concentrations decrease in the range 4.0-8.5 $\mathrm{M}$ upon cooling a saturated solution of U(VI) from $50^{\circ} \mathrm{C}$ to $2^{\circ} \mathrm{C}$, with over $70 \%$ recovery of $\mathrm{U}(\mathrm{VI})$ at all nitric acid concentrations and nearly quantitative recovery starting at $4 \mathrm{M}$ nitric acid. By reducing the cooling rate, the separation factor was increased to greater than 81 for the separation of U(VI) from Sr, Cs, and Nd. Separation factors decreased with a decrease in the acidity. There was also no indication that tetravalent metal double-salt precipitation occurred with either $\mathrm{Zr}^{4+}$ or $\mathrm{Ce}^{4+}$. These results indicate that a high-yield, high-purity hexavalent actinide crystallization scheme may offer attractive benefits for nuclear-fuel recycle in that only a single very simple and well-understood technology is employed, and the use of organic compounds and solvents is avoided. (B. Moyer)

- [ORNL] The following manuscript in which STAAR researchers Alexandr Ivanov and Vyacheslav Bryantsev made a theoretical contribution has been accepted in Talanta: V. Radchenko, et al., "Radiometric evaluation of diglycolamide resins for the chromatographic separation of actinium from fission product lanthanides." Talanta, 2017, 175, 318-324.Toward potential targeted alpha therapy, actinium and lanthanide equilibrium distribution coefficients and extraction-chromatography column elution behavior for two diglycolamide extractants were determined. Density functional theory calculations were performed and were in agreement with experimental observations, providing the foundation for understanding the apparent selectivity for trivalent lanthanides over actinides. (B. Moyer)

- $\quad$ PNNL] A batch ALSEP test was performed using solution generated from irradiated used nuclear fuel. After first removing uranium, neptunium, and plutonium from the dissolved fuel solution by extraction with tri-butyl phosphate, a series of ALSEP extraction, scrub, minor actinide strip, and lanthanide strip steps were performed in a batch mode. Preliminary results determined by gamma spectroscopy indicate the ALSEP system performed as expected, with good extraction of Eu and Am from HNO3 solution, retention of these elements in the organic phase during scrubbing, and selective stripping of Am from the ALSEP solvent with either N-(2-hydroxyethyl) ethylenediamine-N,N',N'triacetic acid or diethylenetriaminepentaacetic acid. Europium was quantitatively stripped from the solvent with N,N,N',N'-tetraethyldiglycolamide. Additional analyses of the samples generated during this test are in progress to determine the behavior of other fuel components in the ALSEP system. (G. Lumetta)

\section{Sigma Team for Off-Gas CAPTURE AND IMMOBILIZATION}

- [INL] Successful completion of the Level 2 Milestone M2FT-17IN030107011, "Evaluate Xe/Kr adsorption at representative process velocity using multi-column testbed and DGOSPREY model," was documented in a report titled "Multi-Column $\mathrm{Kr} / \mathrm{Xe}$ Separation Testing at Representative Superficial Velocities with DGOSPREY Model Validation," NTRD-MRWFD-2017-000033. This report provides test results for selective $\mathrm{Xe} / \mathrm{Kr}$ separation at superficial velocities $10-40$ times higher than previously performed, which required a full modification to the previously existing experimental setup. Test results indicated that increasing superficial velocity does not impact sorbent capacity or initial breakthrough for Xe across the AgZ-PAN column, for HZ-PAN, however, there is some 
indication that $2000 \mathrm{sccm}$ may cause earlier initial breakthrough of $\mathrm{Kr}$. Given the impractical column lengths that would be required to operate at those flow conditions for reasonable adsorption times at lab-scale, this likely wouldn't matter from an operability standpoint, as columns would be appropriately sized for process conditions. (T. Garn, M. Greenhalgh, A. Welty)

- [INL] In collaboration with Georgia Institute of Technology, the DGOSPREY model was fully coupled with an Extended Langmuir isotherm model for adsorption. Both Xe and $\mathrm{Kr}$ breakthrough results were used to evaluate and validate the fully coupled DGOSPREY model. DGOSPREY failed to accurately predict the initial Xe/KR breakthrough times for both HZ-PAN and AgZ-PAN. DGOSPREY also overestimated adsorption strength for both columns under all of the test conditions. The errors are likely attributed to the simplified adsorption equilibrium model. In addition, rigorous adsorption kinetics and isotherm models must be developed that can be fully coupled in DGOSRPEY and account for non-ideal surface behavior. (T. Garn, M. Greenhalgh, A. Welty)

- [ORNL] Experimental testing on the effect of iodine concentration on the removal of iodine from VOG streams by AgZ is complete. The results from this milestone will continue to support M2 efforts and will be included in the M2 report, M2FT-17OR030107021 due 8/21/2017. (S. Bruffey, B. Jubin)

- [ORNL] Work is ongoing to determine the impact of variations in $\mathrm{NO}, \mathrm{NO}_{2}$ and water concentrations on iodine adsorption rates. The $\mathrm{I}_{2}$ test matrix for $\mathrm{AgZ}$ sorbent is $87 \%$ complete. TGA loading tests have been completed on iodine adsorption by $\mathrm{AgZ}$ in the presence of dissolver off-gas stream components $\left(\mathrm{H}_{2} \mathrm{O}, \mathrm{NO}\right.$, and $\left.\mathrm{NO}_{2}\right)$. The iodine content of the loaded material will be assessed by neutron activation analysis, as weight analysis alone cannot resolve the loading of iodine from the loading of other components onto the sorbent. This milestone was originally delayed due to facility shutdowns and required instrument modifications. These obstacles have been resolved. The associated milestone, M3FT-17OR0301070217, due 3/31/17 will be completed by 9/30/17. There will be no impact to the M2 milestone. (S. Bruffey, B. Jubin)

- [ORNL] The milestone to complete phase $1 \mathrm{~B} \mathrm{CH}_{3} \mathrm{I}$ tests was originally delayed due to facility shutdowns and required system modifications. These obstacles have been resolved, however, completion of this milestone requires some of the same test equipment that is being used to complete milestone M3FT-17OR0301070217. With the upcoming forced relocation of the equipment in Lab 17 to alternate lab space to permit the renovation of Wing 1 of $4500 \mathrm{~N}$, an evaluation of temporally relocating an additional TGA to the High Hazard Lab area to accelerate the testing is underway. There is no impact to any M2 milestone. Without the temporary relocation of the TGA and gas supply system the estimated completion of this milestone is now 11/30/2017. (S. Bruffey, B. Jubin)

- [ORNL] The hot isostatic pressing of engineered forms of I-AgZ milestone was delayed in order to meet with other campaign personnel. These meetings were intended to ensure that the data collected during this effort would have maximum impact for both the Sigma Team and other ongoing work packages. The 16 samples were sent to American Isostatic Presses, Inc., for HIPing. These represent the final set of samples required to complete this milestone. We are currently awaiting the return of the HIPed samples. Initial analysis will be limited to sample density, XRD and optical microscopy. Due to the time required to prepare the samples, section each one and complete the XRD, the expected completion of the initial analysis phase of these samples is now 9/30/2017. (S. Bruffey, B. Jubin)

- $\quad$ OORNL] All experimental testing for the milestone, "Comparison of AgZ and AgAerogel performance under VOG conditions with penetrating forms of iodine," has been completed and samples are being analyzed for iodine content at ORNL's High Flux Isotope Reactor. Preparation of the milestone report is in progress and will be completed by 8/21/2107. (S. Bruffey, B. Jubin)

- [ORNL] The custom glass pieces have been fabricated and all other parts have been procured for the task to evaluate performance of Ru removal systems in prototypical TOG streams. The tube furnaces 
intended for use in this experiment were reconfigured and rewired. The safety basis has been approved and testing is expected to commence in early August. This milestone is expected on schedule for 9/29/2017. (S. Bruffey, B. Jubin)

- [ORNL] The milestone, "Preparation of hot isostatically pressed AgZ waste form samples" is expected to be on schedule for completion on 9/29/2017. (S. Bruffey, B. Jubin)

- $\quad$ OORNL] The safety basis for testing of an iodine and tritium removal system for advanced tritium pretreatment awaits final approval. All test system parts have been procured. A general schematic of the test system is provided in Figure 18. Testing will begin immediately upon approval of safety documentation. This milestone is expected on schedule for 8/31/2017. (S. Bruffey, B. Jubin)

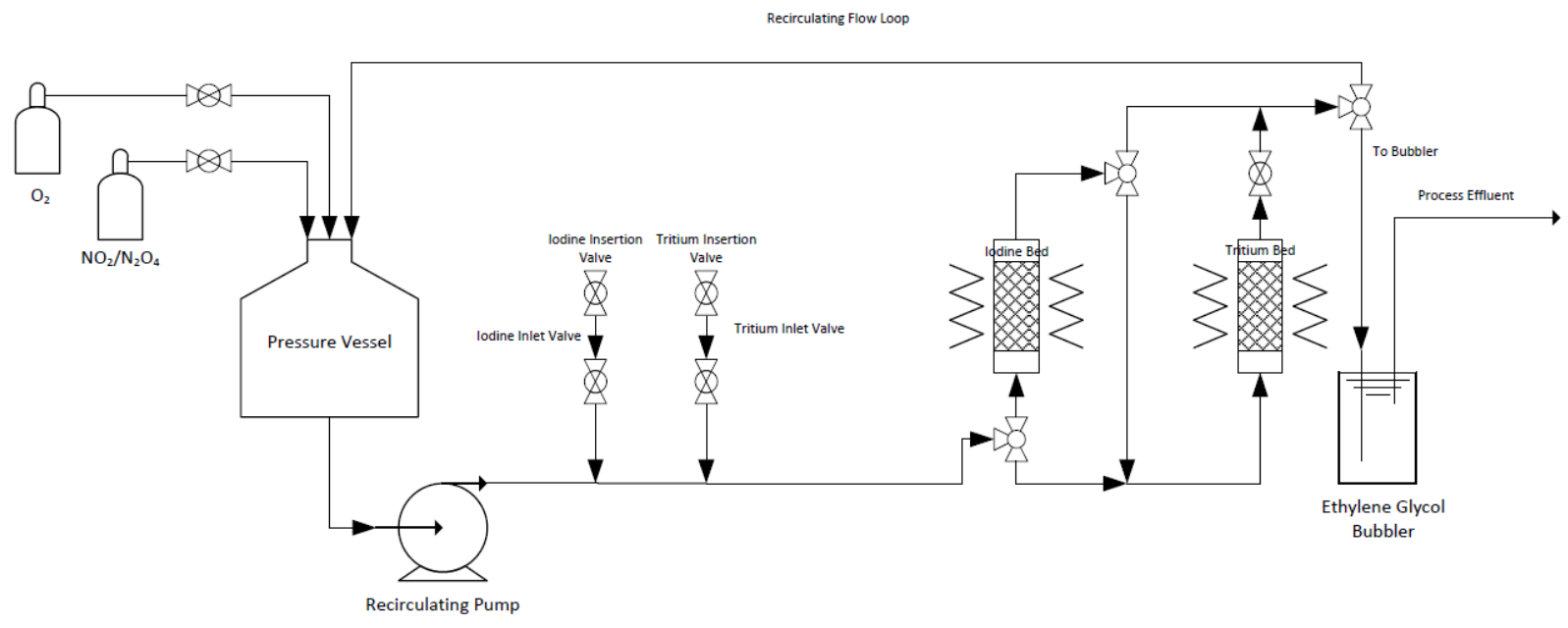

Figure 18. Schematic of test system for cold testing of iodine and tritium traps.

- $\quad$ PNNL] A follow up article on the best Xe sorbent at room temperature (CaSDB) was published in the Journal of the Material Chemistry A. 2017, 10.1039/C7TA02746J (P. Thallapally)

\section{Fundamental SEPARATION DATA/METHOdS}

- [INL] Stability constants for the complexation of $\mathrm{Nd}^{3+}, \mathrm{Am}^{3+}$ and $\mathrm{Cm}^{3+}$ with $N$-methylpyridyl- $N, N^{\prime}$, $N^{\prime \prime}, N^{\prime \prime}$-diethylenetriaminetetraacetic acid have been determined, adding to the library of structurally modified aminopolycarboxylate aqueous holdback complexants characterized for enhanced $\mathrm{An}^{3+} / \mathrm{Ln}^{3+}$ differentiation. (P. Zalupski, J. Law)

- [INL] An irradiation campaign to measure degradation rates of DEHBA was completed in July. This work is conducted in collaboration with CEA Marcoule, and contributes toward completion of milestone M3FT-17IN030104031. Uranium/plutonium solvent extraction experiments were run using the irradiated solvents, and are currently being analyzed by ICP-MS. Irradiated samples for DEHBA concentration determination were delivered to the INL mass spec group for analysis. Splits of these samples are en route to CEA. This work is analogous to the FY16 work with DEHiBA, also in collaboration with CEA. The status of that work is that a joint CEA/INL manuscript (Drader, J.; Saint-Louis, G.; Muller, J.M.; Charbonnel, M-C.; Guilbaud, P.; Berthon, L.; Roscioli-Johnson, K. M.; Zarzana, C.A.; Rae, C.; Groenewold, G.S.; Mincher, B.J.; Mezyk, S.P.; McCann, K.; Braley, J. Radiation Chemistry, of the branched-chain monoamide di-ethyl-hexyl-isobutyramide. SEIX) has 
received positive review comments. That manuscript is being revised for re-submission and is expected to be accepted for publication this summer. (B. Mincher)

- [INL] A joint manuscript between Chalmers University, Cal State Long Beach and INL was accepted for publication. (Ekberg, C.; Jensen, H.; Mezyk, S.P.; Mincher, B.J.; Skarnemark, G. Extraction of 211At from nitric acid into various organic solutions. In press $J$ Radioanal Nucl Chem). (B. Mincher)

\section{WAste Form DeVelopment and Performance}

\section{Electrochemical Waste Forms}

- [ANL] The report, NTRD-MRWFD-2017-000190, which summarizes the development and assessment of advanced ceramic waste form (ACWF) materials made with $\mathrm{LiCl} / \mathrm{KCl}$ - and LiCl-based surrogate waste salts was completed. The basis of waste form formulations, detailed analyses of 13 ACWF materials made for testing, and the results of corrosion tests conducted to assess the degradation mechanism and relative durabilities are discussed. For example, Figure 19 shows the results of ASTM C1285 tests conducted for 7 days using different ACWF materials and separate "rapid water soluble" tests used to estimate the amount of unconsolidated residual salt in a CWF product. Figure 19a shows elements from the salt for comparison with the RWS results. As expected, materials having high $\mathrm{Cl}^{-}$concentrations in the RWS also had high $\mathrm{Cl}^{-}$concentrations during the PCT. The differences in the NL $(\mathrm{Cl})$ values from the RWS and PCT are attributed to analytical uncertainty in measuring the $\mathrm{Cl}^{-}$concentrations. The relative releases of $\mathrm{B}, \mathrm{Li}, \mathrm{Na}, \mathrm{Si}$, and $\mathrm{Cs}$ provide insight into the presences of unconsolidated salt and the glass durability: B is only present in the glass, $\mathrm{Li}$ and $\mathrm{Cs}$ can be dissolved in the glass or present in salt inclusions, Si can be released from sodalite and the glass, and $\mathrm{Na}$ can be in the glass, sodalite, and salt inclusions. The high $\mathrm{Si}$ concentrations attained in PCTs due to dissolution of glass and sodalite greatly attenuate dissolution of solalite. The high NL(B) in the PCT with ACWF N6-11 indicates glass dissolution is most significant in that test, and the high $\mathrm{NL}(\mathrm{Li})$ and $\mathrm{NL}(\mathrm{Cs})$ values result from glass dissolution; NL(Na) and $\mathrm{NL}(\mathrm{Si})$ are low in that test because only a small amount of sodalite dissolves. In contrast, the values of NL(Na) and NL(Cs) are high in the PCTs with ACWF N4-12 and ACWF N4-14 while $\mathrm{NL}(\mathrm{B})$ and $\mathrm{NL}(\mathrm{Si})$ are low. This indicates the $\mathrm{Na}$ and $\mathrm{Cs}$ are from the dissolution of unincorporated salt, consistent with the high $\mathrm{NL}(\mathrm{Cl})$ values in both the RWS and PCT. The results of PCT with the other materials indicate the salt was efficiently incorporated in the waste form and the glass phase is durable. The salt was incorporated into ACWF N6-11, but the glass phase was less durable than the glass phases in the other materials. (W. Ebert) 

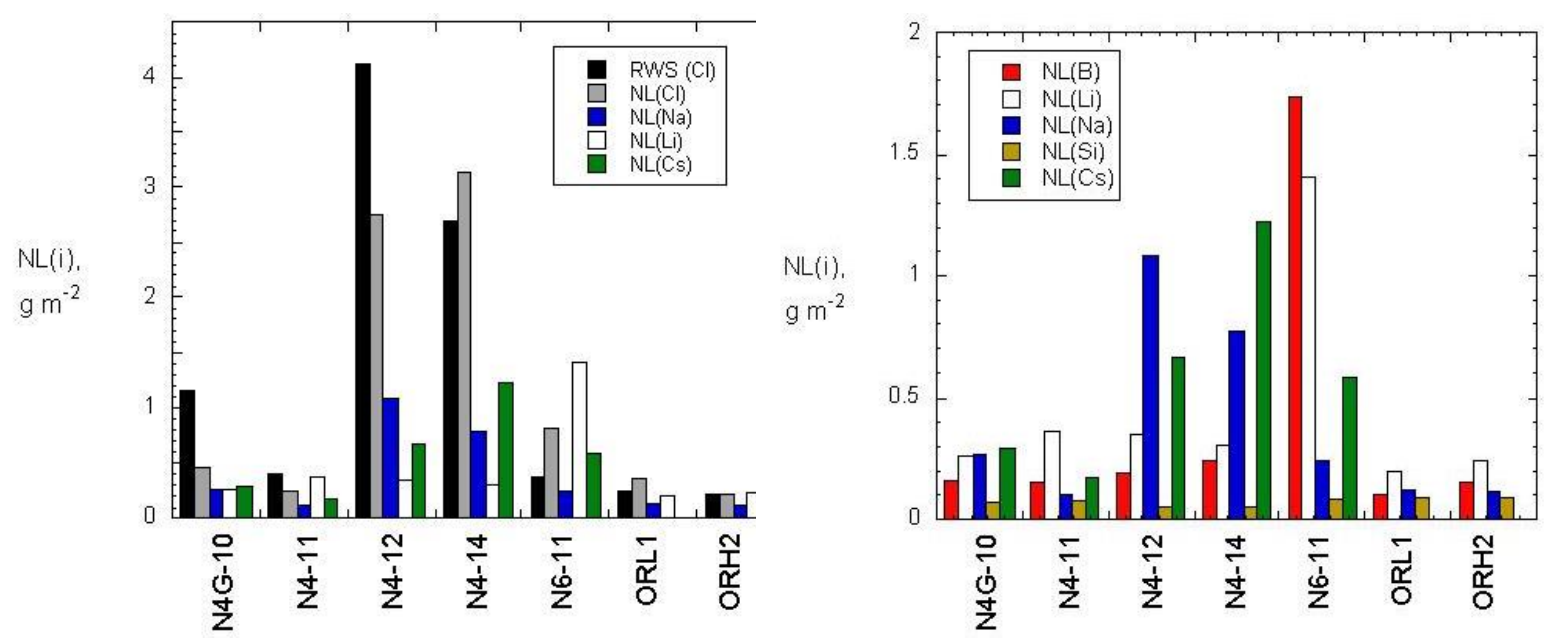

(a)

(b)

Figure 19. Results of 7-d PCT and RWS with various ACWF materials.

- $\quad$ [ANL] The electrochemical method developed to evaluate metallic waste forms is being applied to Type 4320 carbon steel to demonstrate the applicability of the method and model to non-passivation steel phases. Figure 20a shows the current measured at an applied potential of $-0.4 \mathrm{~V}_{\text {SCE }}$ and Figure $20 \mathrm{~b}$ shows the evolution of the surface properties in terms of a Nyquist plot. The steady-state current achieved within six days is used to model long-term behavior, in this case for active corrosion. It appears that the current depends on the applied voltage exponentially, as was found for passivating materials. Immersion tests are being conducted for comparison. (W. Ebert)

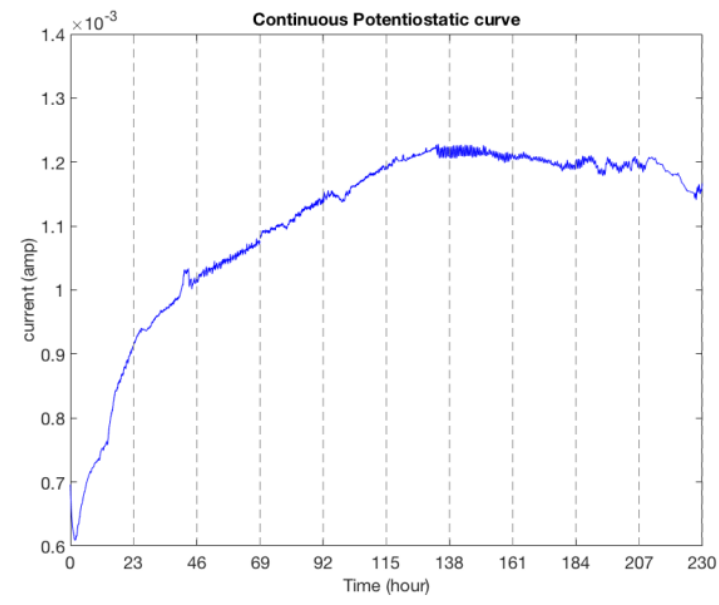

(a)

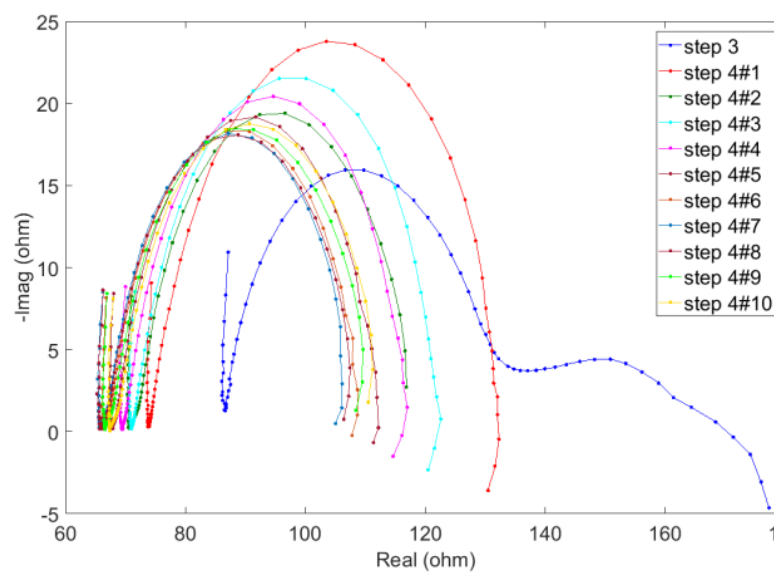

(b)

Figure 20. Results of potentiostatic test with Type 4320 carbon steel in $\mathrm{pH} 4$ brine solution at -0.4 $\mathrm{V}_{\text {SCE. }}$. 


\section{Ceramic Waste Forms}

- [LANL] High dose ion irradiation was completed on four multiphase ceramic waste form samples (two from ANSTO, two from SRNL). The experiment is to mimic previous neutron radiation or actinide doping in glass and SYNROC samples, and the objectives are to study radiation-induced (1) volume swelling (we covered half surface of the sample during irradiation, so characterization of the interface between unirradiated and irradiated areas could provide us the irradiation induced volume swelling result), (2) microcrack (the radiation dose we chose is equivalent to the neutron radiation dose, in which dose people observed microcrack in waste form samples), (3) microstructural evolution. These radiation effects not only affect radiation stability of nuclear waste form's long term storage, but also affect its chemical durability. Further characterizations are in progress. (M. Tang)

- [SRNL] Milestone M2FT-17SR030105025, "Perform ceramics waste form melter test in cylindrical induction melter," was completed. Researchers at the Savannah River National Laboratory (SRNL) performed a melt-pour operation on a SYNROC crystalline composition using a cylindrical induction melter. In this initial test, $1 \mathrm{~kg}$ of calcined feed was heated to a nominal melting temperature of $\sim 1550 \mathrm{C}$ followed by a complete drain of the contents of the melt at temperature (Figure 21). This test is believed to be the first test of its kind in the world and demonstrates the feasibility of meltprocessing ceramic nuclear waste forms. Subsequent testing will be used to evaluate control of the process and to collect information to perform a cost-benefit analysis and complete a technology maturation plan. (J. Amoroso, P. Smith)

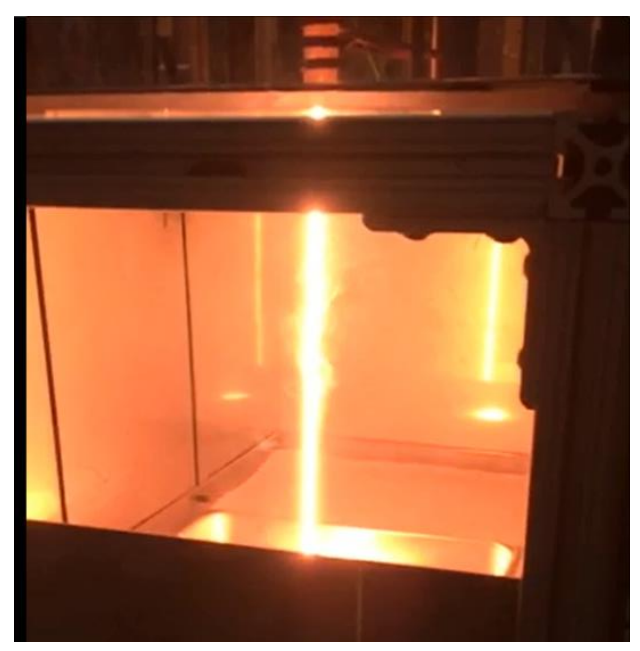

Figure 21. Image of pour stream at ${ }^{~} 1550^{\circ} \mathrm{C}$ of SYNROC material being drained from a cylindrical induction melter at SRNL.

\section{Glass Ceramics Waste Forms}

- [LANL] High dose ion irradiation was completed on three multiphase glass ceramic waste form samples (labeled as GC-4, GC-Mo-5.85, and 2-2013). The experiment is to mimic previous neutron radiation or actinide doping in glass and SYNROC samples, and the objectives are to study radiationinduced volume swelling, microcrack, and microstructural evolution. Further characterizations are in progress. In previous monthly reports, we presented static leaching data and SEM observations of non-irradiated and irradiated glass ceramic samples to investigate radiation damage effects on chemical durability of glass ceramic waste form samples. Figure 22 shows cross-sectional TEM observations of irradiated I2-2013 glass ceramic sample after a duration time of 28 days. In the low magnification image (left), a surface area ( 1300 nm in thickness) with different contrast and a buried 
layer are observed. The thickness around $100 \mathrm{~nm}$ of the buried layer is observed in the high magnification image (right). We interpreted this surface area as a result of irradiation damage because the thickness of layer is close to the ion penetration depth, while the explanation for this buried layer is open to discuss. Chemical analysis is in progress to help us to understand these observations. (M. Tang)

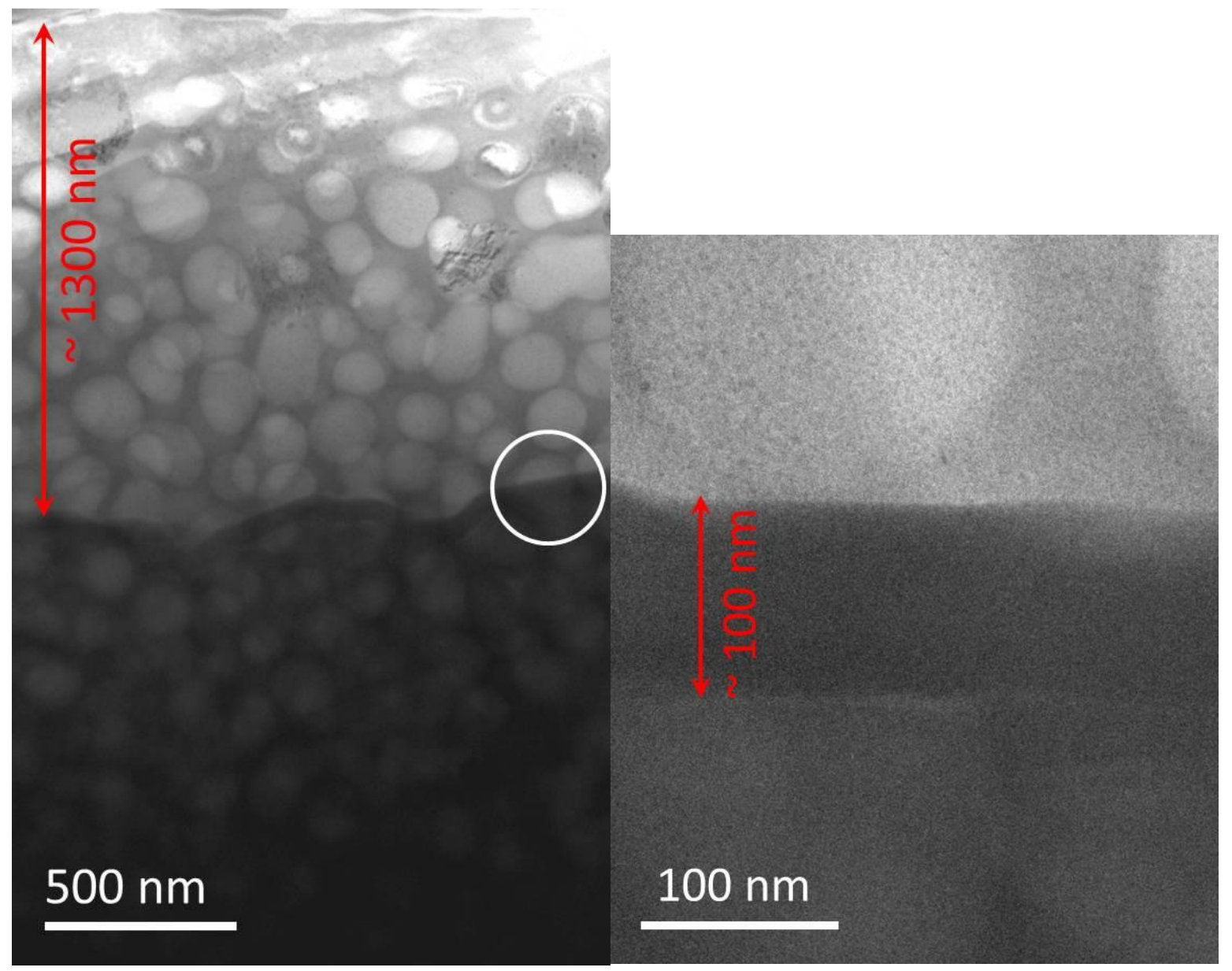

Figure 22. X-sectional TEM observations of irradiated I2-2013 samples after 28 days test.

- [PNNL] Milestone M2FT-17PN030105041was completed to initiate static and flow-through corrosion testing of powellite, oxyapatite and the remainder glass composition, the individual phases that are found in the glass ceramic waste form. Initial results from flow-through testing of the remainder glass phase was compared to the glass ceramic waste form and documented in a memo. The reminder phase has $\sim 4 \mathrm{x}$ lower release rate than the glass ceramic waste form in flow-through testing and is on par with the French high-level waste glass named SON68. (J. Crum)

\section{Zirconium Recycle}

- [ORNL] The broken filter-absorber unit repair and slight modification was completed in midJuly. Both inlet and outlet filter porosities were 40 um previously: the new unit will have an outlet filter with $10 \mathrm{um}$ porosity. Plans for the third chlorination were also slightly modified to increase the cladding feed to $250 \mathrm{~g}$ to provide a larger amount of $\mathrm{ZrCl}_{4}$ product salt for future purification tests. Also, in anticipation of purification tests next year in the hot cell, the Radioactive Safety Summary is being modified to include some of the reagents shown to be successful in the non- 
radioactive NEUP and ORNL tests $\left(\mathrm{SOCl}_{2}, \mathrm{ZrH}_{2}\right.$, etc.). The goal in the initial hot cell purification tests will be to remove the Nb-94 and Sb-125 impurities that have been found (see monthly report for June 2017) to be the remaining source of radioactivity in the $\mathrm{ZrCl}_{4}$ chlorination product. (E. Collins, B. Jubin)

- [ORNL] Preparation of the hot cell for the third chlorination is in progress and the test is expected to begin in early August. The goals of this test are to test the tritium trap in the chlorination condenser off-gas and to modify the chlorination heating process to include a pre-cut of product containing a small amount of the zirconium with most of the impurities, and the bulk of the zirconium with fewer impurities. (E. Collins, B. Jubin)

\section{Advanced Waste Form Characterization}

- $\quad[$ ANL] Tests to measure the solution conditions triggering the increased Stage 3 glass dissolution rate and that rate remain in progress with solutions sampled every 14 days. Available results indicate the importance of the $\mathrm{Al}$ concentration and confirm previous findings. A technical report describing the method and results will be issued in September. (W. Ebert)

- $\quad$ ANNL] Specimens of materials prepared at PNNL and ORNL to encapsulate AgI particulates in silicate and zeolite matrices were received for testing at ANL. Tests with these materials will be coordinated with electrochemical tests conducted with an AgI electrode and free AgI powder to develop a test method and degradation model. (W. Ebert)

- [PNNL] Dilute dissolution tests on iodine waste forms were started on masked portions of three HIPed Ag-zeolites from ORNL (1-3, 1-7, 1-8) and two spark plasma sintered Ag-aerogel samples from PNNL. In each case, the samples were mounted in epoxy and cut into $2 \mathrm{~mm}$ slices and polished to a sub-micron finish. The exposed face of the sample was masked by both a sputtered $\mathrm{Cr}$ dot and a silicone masked region. The planned experiments call for immersion in dilute conditions for 10-14 days at $90^{\circ} \mathrm{C}$. At the completion of the studies, the masked and unmasked areas will be compared for height and phase map. (J. Ryan)

- [PNNL] A manuscript titled "Non-destructive characterization of corroded glass surfaces by spectroscopic ellipsometry," was submitted to the Journal of Non-Crystalline Solids that details the application of spectroscopic ellipsometry (SE) characterization for a set of corroded glass surfaces. Although SE is an established surface and thin film characterization technique, it has not seen development in the field of glass corrosion. Our results reproduce the alteration layer thickness observed by SEM, and provide the valuable insight that the alteration layer has compacted during corrosion or the drying process. Future SE characterization of corroded glass surfaces can be achieved, with even in situ characterization possible. (J. Ryan)

- [PNNL] Modeling/Simulation Fits with a modified version of the GRAAL model that accounts for nonlinear transport of water in the gel layer were extended to the complete series of CJn glasses (Gin et al. JNCS 358 (2012) 2559) and SON68. The modification of the GRAAL model involves raising the unitless diffusion term to a power factor $\mathrm{p}$. The optimal value for the parameter $\mathrm{p}$ was found to vary significantly and could be correlated with the glass composition. For those glasses with $\mathrm{Ca}$ and $\mathrm{Al}$, a $\mathrm{p}$ value of 3.0 was found most suitable. However if Ce was added to the glass, the optimal value was reduced to 2.6. For glasses without $\mathrm{Ca}$ or without $\mathrm{Al}$, the optimal $\mathrm{p}$ value was 1.0. This illustrated the strong dependence of water diffusion and thus glass alteration on the synergistic interaction of $\mathrm{Ca}$ and $\mathrm{Al}$. The addition of $\mathrm{Zr}$ did not in most cases impact the $\mathrm{p}$ value unless $\mathrm{Al}$ was not present in the glass. The addition of $\mathrm{Li}$ also did not influence the value of $\mathrm{p}$ but did alter the retention of $\mathrm{Na}$ in the hydrated or gel layer. A manuscript summarizing these results is in preparation. (S. Kerisit)

- $\quad$ [SRNL] Electrochemical testing of surrogate metal alloy waste forms was performed on alloy composition RAW-6(Ni1) alloys. Multiple electrodes from this surrogate alloy waste form were 
fabricated, then polished and the polished surfaces characterized via SEM and light microscopy. Two of these electrodes were held at $300 \mathrm{mV}$ at $\mathrm{pH} 3$ and $\mathrm{pH} 8$. Post corrosion electrode surface conditions will be analyzed via SEM. Solution aliquots from electrochemical testing were analyzed by ICP-MS. EChem potentiostatic tests are designed to characterize corrosion behavior and oxide film formation on waste forms after exposure to characteristic ground water conditions. When testing data is fully compiled, the data from testing will be sent to collaborators at ANL for incorporation of into their model. (L. Olson, P. Smith)

\section{DOMESTIC Electrochemical PROCESSING}

- [ANL] The objective of this work is to characterize the co-deposition of uranium and rare-earth metals at a non-alloying solid cathode at the engineering scale. At the end of the most recent codeposition test, the co-deposition cathode assembly was raised to an elevation where the top of the catch crucible about 1 inch above the salt for a period of time and then fully raised up out of the electrorefiner salt. Figure 23 below clearly shows a region of white salt extending up from the top of the crucible. The lack of any violet color to the salt indicates that the salt region around the cathode, above the crucible top was depleted in $\mathrm{U}^{3+}$ as predicted. When the upper crust was removed, a layer of co-deposit was visible on the cathode surface (Figure 24). The white salt and the co-deposited material have been sampled and will be submitted for chemical analysis. There appears to be no reaction of the crucible material with the electrorefiner salt. (J. Willit)

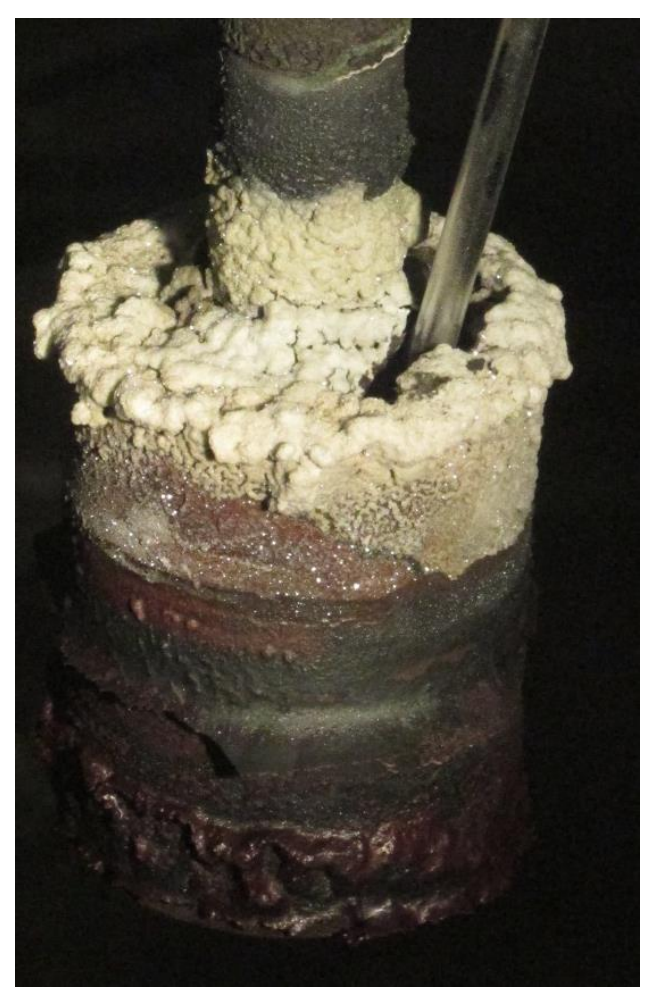

Figure 23. Co-deposition cathode test in which the cathode assembly was raised above the salt level while passing current. White crust layer is clear confirmation of local $\mathrm{UCL}_{3}$ depletion near the cathode as predicted. 


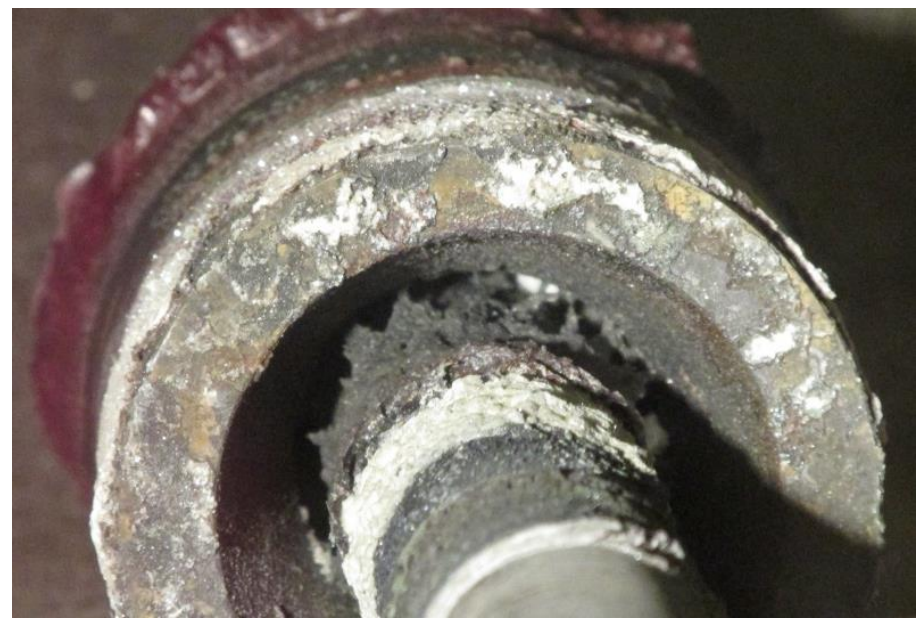

Figure 24. Same co-deposition cathode as previous photograph after removal of the crust of white salt. Co-deposited metal on cathode is clearly visible.

- [INL] Work in support of milestone "M3FT-17IN030106021 - MASTERS: ASC Module," is nearly complete and a draft copy of the final report is being reviewed and edited. The purpose is to incorporate experience with the Advanced Solid Cathode (ASC) studies into the MASTERS code and compare the modeled performance of the Liquid Cadmium Cathode (LCC) to the ASC with respect to separations between actinides and lanthanides. (G. Fredrickson)

- [INL] Work in support of milestone "M3FT-17IN030106022 - Technology-Gap Study," is nearly complete and a draft copy of the final report is being reviewed and edited. This is a follow-on study to milestone "M3FT-17IN03010602 - FY16 Technology-Gap Study" which was completed earlier. The earlier study examined the relationship between uranium recovery and zirconium retention in the anode basket during electrorefining of Experimental Breeder Reactor II (EBR-II) and Fast Flux Test Facility (FFTF) driver fuels in the Mk-IV electrorefiner in the Fuel Conditioning Facility (FCF). The later study will examine similar relationships between uranium recovery and the retention of select transuranics and lanthanides. These data, based on the historical performance of the Mk-IV electrorefiner, will be used to improve the reliability of the MASTERS pyroprocessing flowsheet modeling code. (G. Fredrickson)

- [INL] Work in support of milestone "M3FT-17IN030106026 - MATERS: Chlorine Flowsheet Study," is nearly complete and a draft copy of the final report is being reviewed and edited. The purpose is to incorporate processes that generate or consume chlorine gas $\left(\mathrm{Cl}_{2}\right)$ into the MASTERS code to study the effect of these processes on flowsheet performance and waste generation. In other words, dealing with chlorine gas in an engineering challenge, so if such processes are to be employed the benefits must outweigh the costs. (G. Fredrickson)

- [INL] Work in support of milestone "M3FT-17IN030106023 - Electrochemical Measurements," is being performed at the Center for Advanced Engineering Studies (CAES) Radiochemistry Laboratory (RCL). This effort will use non-radiological surrogates to mimic the behavior of uranium and plutonium chlorides (in electrorefiner slats) to study the performance of the advanced solid cathode (ASC) in the lower concentration regions of uranium chloride where it is proposed that cathodic potential control will be more manageable. The electrochemical behaviors of yttrium chloride, gadolinium chloride, scandium chloride, and magnesium chloride are being studied. (G. Fredrickson)

- [INL] The cyclic voltammetry (CV) plot shown in Figure 25 was obtained using tungsten for working and counter electrodes and nickel for the reference electrode. The bulk electrolyte was CILiK eutectic at $500^{\circ} \mathrm{C}$ with additions of $\mathrm{ScCl}_{3}$ and $\mathrm{YCl}_{3}$. It is noted that two redox couples appear in the 
$\mathrm{CV}$, which result from $\mathrm{ScCl}_{3}$ and $\mathrm{YCl}_{3}$ in the salt. The (onset) reduction potentials of Sc and $\mathrm{Y}$ are estimated to be $-1.63 \mathrm{~V}$ and $-1.85 \mathrm{~V}$ versus Ni metal, respectively. (G. Fredrickson)

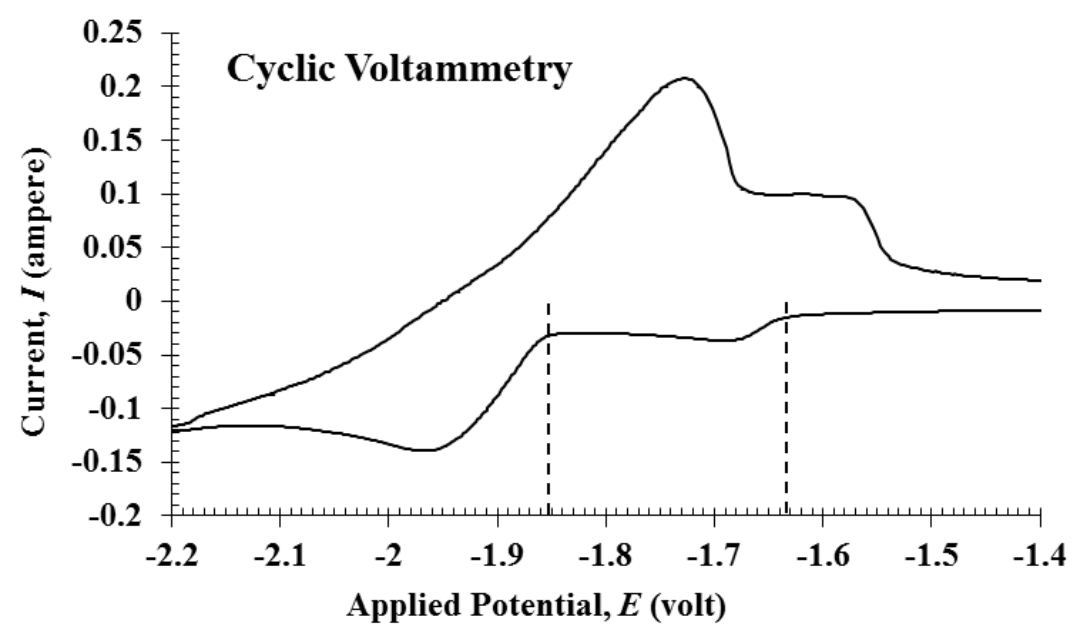

Figure 25. Cyclic voltammetry (CV) plot obtained using tungsten for working and counter electrodes and nickel for the reference electrode.

- [INL] The chronopotentiometry (CP) plot (Figure 26) below indicates that the (onset) reduction potentials of Sc and Y are estimated to be $-1.60 \mathrm{~V}$ and $-1.815 \mathrm{~V}$ versus Ni metal, respectively. It can be seen as the magnitude of current is increased, the curve tends toward more negative potentials and two plateaus become apparent. The plateaus correspond to Sc and Y reduction. If current were increased sufficiently, the potential would drop to that of Li reduction. It is expected that by adding $\mathrm{ScCl}_{3}$ to the salt, the plateau near $-1.6 \mathrm{~V}$ will become longer and larger currents will be required to force the transition to the Y reduction plateau. (G. Fredrickson)

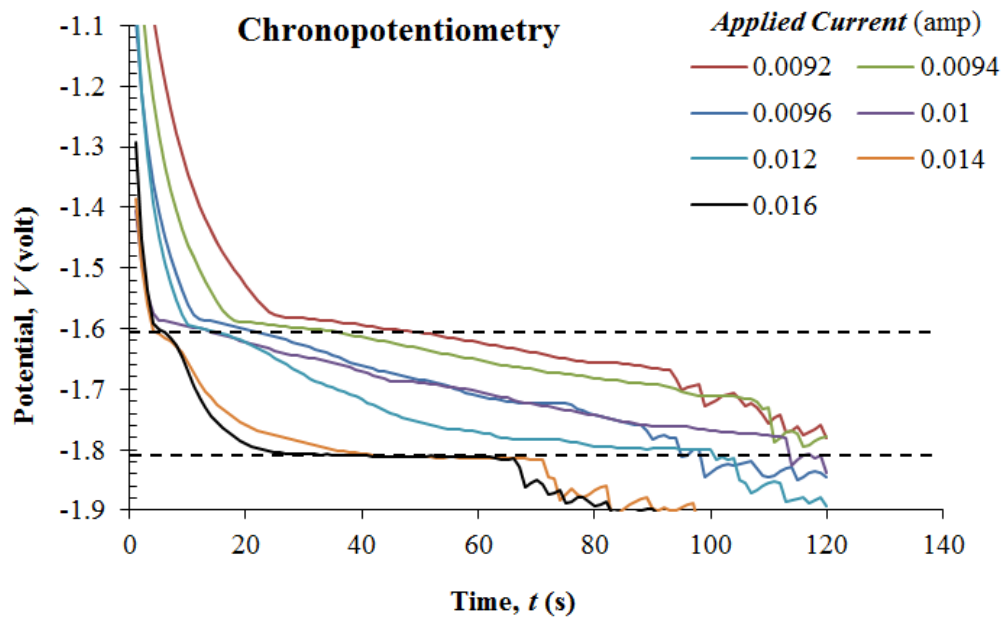

Figure 26. Chronopotentiometry (CP) plot.

- [INL] There is discrepancy in estimation among the two measurement techniques shown above; CV versus $\mathrm{CP}$. It seems using $\mathrm{CP}$ technique to estimate reduction potentials would be more reliable, by looking for plateaus where the slope is close to zero. The values found by $\mathrm{CP}$ may also provide 
insight into a more accurate method to estimate reduction potential via $\mathrm{CV}$. For example, by finding the inflection point on the right-side of a reduction peak. (G. Fredrickson)

- [INL] The CV plots shown in Figure 27 were obtained from three salt systems: $\mathrm{ScCl}_{3}, \mathrm{YCl}_{3}$, and a mixture of $\mathrm{ScCl}_{3}$ and $\mathrm{YCl}_{3}$. The far left side was limited by the reduction of lithium metal, and the far right side was limited by the generation of chlorine gas. The (onset) reduction potentials for Sc and $\mathrm{Y}$ are consistent between the different salt systems. (G. Fredrickson)

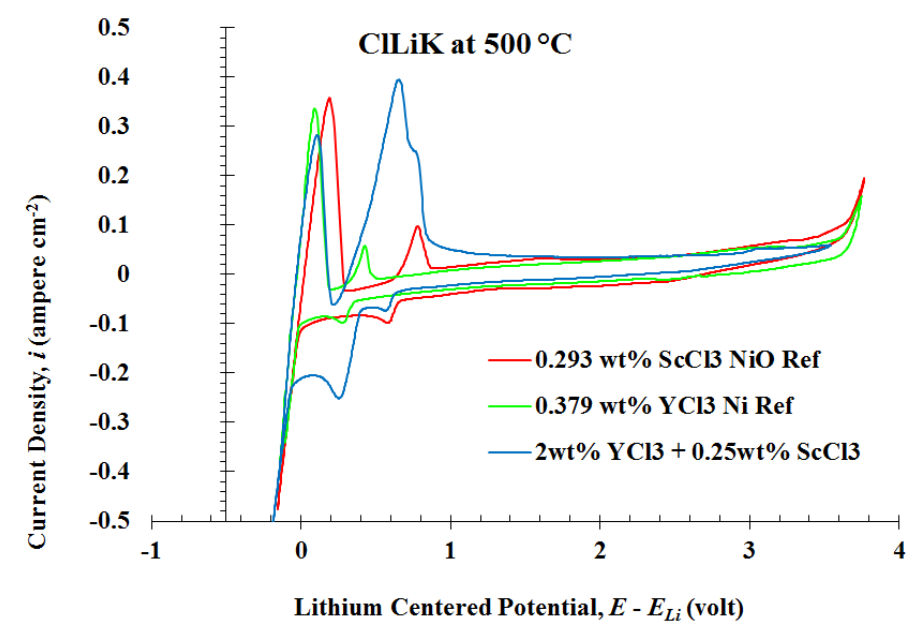

Figure 27. CV plots obtained from three salt systems: $\mathrm{ScCl}_{3}, \mathrm{YcL}_{3}$, and a mixture of $\mathrm{ScCl}_{3}$ and $\mathrm{YCl}_{3}$.

\section{FUEL RESOURCES}

- [ORNL] New adsorbents have been synthesized based on radiation-induced graft polymerization at a degree of grafting ranging between 250 and $700 \%$. These adsorbents will be prepared and sent to the Marine Sciences Laboratory of PNNL for uranium adsorption from seawater testing. (C. Janke)

- [ORNL] Conditions for nitrile conversion with N-methylhydroxylamine (MHA) were optimized, and samples were sent to MSL/PNNL for uranium adsorption testing with seawater. (S. Brown)

- [ORNL] A study conducted by ORNL has revealed a new strategy for the design of novel adsorbents. It was found that lowering the pKa of the adsorbent's functional groups, and at the same time preserving high stability constant values, is practically feasible and provides a new direction toward the development of efficient, economic, and applicable adsorbents for uranium capture. (S.

Bryantsev) 
a)<smiles>CC(N)NO</smiles>

HAO

b)

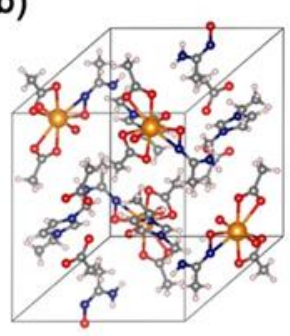

c)

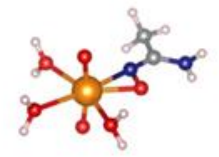<smiles></smiles>

$\mathrm{NH}_{2} \mathrm{paOH}$
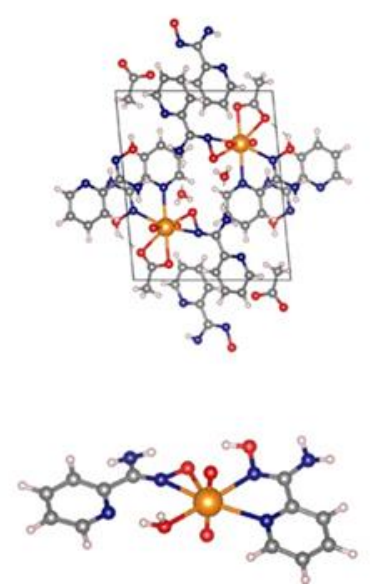<smiles>N=C(N)c1cccc(C(N)=NO)n1</smiles>

$\mathrm{LH}_{2}$
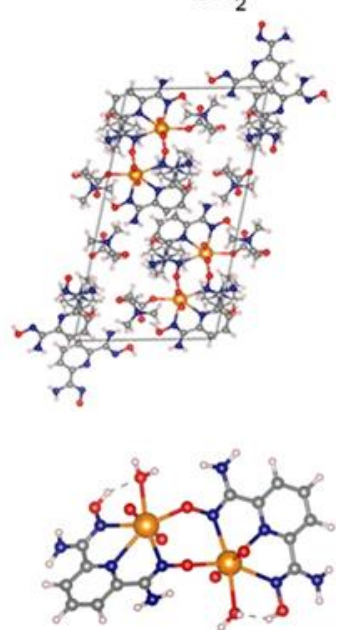

Figure 28. a) Ligands considered in our study; b) experimental crystal structures; c) the most stable complexes in aqueous solution obtained at the M06/SSC/6-311++G** level of theory.

- [ORNL] The salicylaldoxime-MOF ligand synthesis is underway. This will provide the appropriate salicylaldoxime within a crystalline matrix for coordination studies. This effort is attempting to bridge the gap between theory and experimentation where theory predicted a strong chelator, which was not verified by experiments. This effort supports Carter Abney's spectroscopic task, which will determine the coordination modes once the MOF is synthesized. (R. Mayes)

- [ORNL] A refined fit of Ni XAFS data reveal cyclic imidedioxime to be the predominant binding species, with approximately $25 \%$ of all $\mathrm{Ni}$ content attributable to Ni0 nanoparticles; elimination of the cyclic imidedioxime should dramatically suppress co-extraction of Ni. (C. Abney)

- [ORNL] A level 3 milestone report titled, "Influence of Temperature and pH on Uranium and Vanadium Adsorption by Amidoxime Functionalized Adsorbent," has been submitted to the PICS/NE electronic system. This report is the result of collaboration between Oak Ridge National Laboratory and Georgia Institute of Technology and describes how the coupling of molecular studies and adsorption process modeling has produced a methodology wherein one can accurately predict the uptake of uranium by polyamidoxime-functionalized polyethylene fibers. This result represents an important step forward in better understanding the influence of various thermodynamic and environmental variables on uranium adsorption, which can lead to the design of better adsorbent materials and selection of suitable deployment sites for uranium recovery from seawater. By following such a multi-scale design approach, one can potentially utilize quantum chemical methods to selectively screen ligands that have optimal uranium adsorption properties without needing to resort to extensive experimental work. (C. Tsouris)

- $\quad$ PNNL] A manuscript titled "Reusability of amidoxime-based polymeric adsorbents for seawater uranium extraction," was submitted to Industrial and Engineering Chemistry Research by Li-Jung Kung in June 2017. The full authors on the paper are: Li-Jung Kuo, Horng-Bin Pan, Chien M. Wai, Margaret F. Byers, Erich Schneider, Jonathan E. Strivens, Christopher J. Janke, Sadananda Das, Richard T. Mayes, Jordana R. Wood, Nicholas Schlafer, and Gary A. Gill. 


\begin{abstract}
The ability to re-use amidoxime-based polymeric adsorbents is a critical component in reducing the overall cost of the technology to extract uranium from seawater. This report describes an evaluation of adsorbent reusability in multiple re-use (adsorption/stripping) cycles in real seawater exposures with potassium bicarbonate $(\mathrm{KHCO})$ elution using amidoxime-based polymeric adsorbents developed by Oak Ridge National Laboratory (ORNL). The KHCO3 elution technique achieved $\sim 100 \%$ recovery of uranium adsorption capacity in the first re-use. Subsequent re-uses showed significant drops in adsorption capacity. After the 4th re-use with the ORNL AI8 adsorbent, the 56-day adsorption capacity dropped to $28 \%$ of its original capacity. FTIR spectra revealed that there was a conversion of the amidoxime ligands to carboxylate groups during extended seawater exposure, becoming more significant the longer the exposure time. Calcium and $\mathrm{Mg}$ adsorption capacities also increased with each re-use cycle supporting the hypothesis that long term exposure resulted in converting amidoxime to carboxylate, enhancing the adsorption of $\mathrm{Ca}$ and $\mathrm{Mg}$. Shorter seawater exposure (adsorption/stripping) cycles (28 vs. 42 days) had higher adsorption capacities after re-use, but the shorter exposure cycle time did not produce an overall better performance in terms of cumulative exposure time. Recovery of uranium capacity in re-uses may also vary across different adsorbent formulations. Through multiple re-use, the ORNL adsorbent AI8 can harvest $10 \mathrm{~g}$ uranium $/ \mathrm{kg}$ adsorbent in $\sim 140$ days, using a 28-day adsorption/stripping cycle in $20^{\circ} \mathrm{C}$ seawater with a salinity of 35 . This is a much better performance much better than would be achieved with a single use of the adsorbent through very long-term exposure (saturation capacity $=7.4 \mathrm{~g} \mathrm{U} / \mathrm{kg}$ adsorbent). A time dependent seawater exposure model to evaluate the cost associated with reusing amidoxime-based adsorbents in real seawater exposures was developed. The cost to extract uranium from seawater ranges d from $\$ 560-750 / \mathrm{kg}$ U. was predicted. Cost model simulations suggests that a short seawater exposure cycle ( $<15$ days) is the optimal deployment period for lower uranium production cost in seawater uranium mining extraction. (G. Gill)
\end{abstract}

- [PNNL] A biofouling study was conducted with the ORNL adsorbent AI8 as part of the marine testing activities at Broad Key Island marine research station at the University of Miami which concluded on June 1, 2017. The AI8 adsorbent was simultaneously deployed in a darkened flume that received filtered seawater (control) and in two locations in the adjacent seawater of Broad Key Island. One of the sites was in full sun and the other in the shade of a boat house. A full 56-day deployment was conducted with time series samples collected during the exposure period. Surprisingly, very little impact on adsorption capacity was observed. The adsorbent in the full sun showed no loss, while the shaded adsorbent showed a $23 \%$ loss of capacity. The adsorbent deployed in the flume reached a 56day adsorption capacity of $5.57 \pm 0.67 \mathrm{~g} \mathrm{U} / \mathrm{kg}$ adsorbent, while the capacity in full sun deployment was $5.56 \pm 1.70 \mathrm{~g} \mathrm{U} / \mathrm{kg}$ adsorbent, and the adsorbent in the shade was $4.51 \pm 0.87 \mathrm{~g} \mathrm{U} / \mathrm{kg}$ adsorbent. One unusual observation was that the half-saturation time was long for all three deployments. The flume deployed sample had a half-saturation time of $72 \pm 14$ days, while the shaded and full sun deployments were $87 \pm 25$ and $101 \pm 45$ days, respectively. More typical half-saturation times are around 3 weeks. (G. Gill)

- [Stanford] Sea water selectivity tests are still ongoing based on a new type of sorbent material using electrochemical method. Performance optimization is being investigated by exploring the parameter space. (C. Liu)

\title{
CODCON DEMONSTRATION
}

- [PNNL] Gregg Lumetta attended the 58th Annual Institute of Nuclear Materials Management meeting in Indian Wells, California, where he presented a paper titled The Alliance of Advanced 
Process Control and Accountability - A Future Safeguards-By-Design Tool. Co-authors on this paper were James Bresee, Patricia Paviet, Daniel Vega, Michael Miller, and Terry Todd. (G. Lumetta)

- [SRNL] The modified direct denitrations (MDD) of nitric acid solutions containing uranium and a mixture of uranium and plutonium were demonstrated using batch equipment which employed mechanical mixing. The MDD of the uranyl nitrate solution produced a uranium trioxide $\left(\mathrm{UO}_{3}\right)$ product (Figure 29) with some water of hydration $\left(\mathrm{UO}_{3} \cdot 0.8 \mathrm{H}_{2} \mathrm{O}\right.$ and $\left.\mathrm{UO}_{3} \cdot 0.3 \mathrm{H}_{2} \mathrm{O}\right)$. In the mixed nitrate solution, the masses of uranium and plutonium were at the ratio expected in the product solution from the CoDCon Demonstration. The MDD of the solution produced a caked powder (Figure 30) which was easily broken-up in the reaction vessel. Characterization of the mixed oxide by $\mathrm{x}$-ray diffraction and scanning electron microscopy is in progress. Demonstration of the MDD of the uranium and plutonium solution completes milestone M4FT-17SR030108052. (T. S. Rudisill, P. Smith)

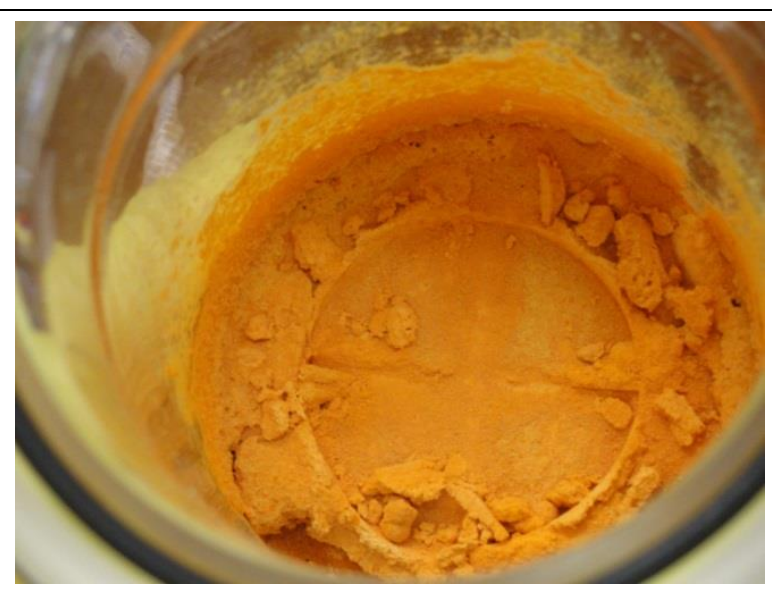

Figure 29. UO3 produced by MDD.

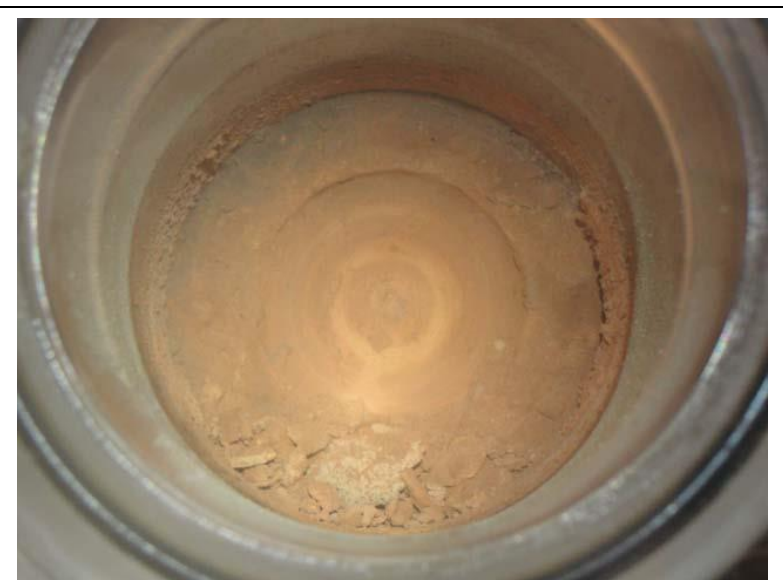

Figure 30. Mixed uranium/plutonium oxides produced by MDD.

For more information on Material Recovery and Waste Forms Development contact Terry Todd (208) 526-3365 


\section{MPACT Campaign}

\section{MANAGEMENT AND INTEGRATION}

\section{Management and Integration}

- [INL] MPACT NTD attended the ANS Annual meeting and participated as a panelist in the Advancing Global Nuclear Energy and Strengthening National Security session. Preparations continue for the FY 2018 Planning Package Meeting in July and the fall MPACT Working Group Meeting.

\section{CAM \& Technical Support}

- [LANL] Prepared for the fall MPACT Working Group Meeting scheduled to be held in Washington, DC, August 3-4. Compiled input to the Advanced Integration Roadmap Update.

\section{SAFEguARDS AND SECURITY by DESIGN - ECHEM}

\section{Microfluidic Sampler}

- $\quad$ [ANL] The components for the flow cell version of the molten salt droplet generator were assembled. Custom automated molten salt valves were tested and modified to ensure smooth operation. Water testing of the vacuum filling system and flow cell were conducted and several modifications were made. The modified vacuum filling system was determined to be sufficient, while further modifications to the flow system are required. Specifically, larger diameter custom micro-machined orifices are being fabricated to allow droplet generation at higher flow rates. A paper entitled "Development of a Micro-Sampling System to Support Pyroprocess MC\&A" was presented at 58th Annual INMM meeting, Indian Wells, CA.

\section{Modeling and Simulation for Analysis of Safeguards Performance}

- $\quad$ [ANL] A dynamic unit operation model has been created in MATLAB for the actinide recovery and lanthanide drawdown steps of a pyroprocessing flowsheet. The code has been validated against experimental data from electrolysis of a uranium- and cerium-containing $\mathrm{LiCl}-\mathrm{KCl}$ eutectic salt. Validation of the DyER (dynamic electrorefiner model) has also been performed for with experimental data for electrotransport of plutonium from a liquid cadmium anode to a liquid cadmium cathode under constant current control.

\section{Electrochemical Sensor}

- $\quad$ IINL] Experimenter continued mentoring process to become qualified to work in actinide glovebox. Ion exchange experiments were performed with $\mathrm{UCl} 3$, and $\mathrm{K}+-\mathrm{B}$ "alumina and $\mathrm{Sr} 2+-\mathrm{B}$ "alumina. The exchanged ceramic discs were transferred to an air atmosphere fume hood to prepare for analysis.

\section{Sensor for Measuring Density and Depth of Molten Salt}

- $\quad$ INL] Experiments with the triple bubbler systems in aqueous solutions were completed in the Engineering Development Laboratory (EDL) at the Materials and Fuels Complex (MFC). The tests were performed in de-ionized (DI) water, $20.9 \mathrm{wt} \% \mathrm{CaCl} 2$ solution, $37.1 \mathrm{wt} \% \mathrm{CaCl} 2$ solution, and $22.5 \mathrm{wt} \% \mathrm{NaCl}$ solution. Each of the fluids was tested twice, on different days, to provide an estimate on the daily variations in the data. Data analysis/calibration of these experiments is ongoing. Preliminary calibration coefficients have been calculated as an average of 550 data points used in the calibration. In addition, the triple bubbler and all of the instrumentation has been moved to the Center 
for Advanced Energy Studies (CAES)in preparation for experiments with molten salts. The work control document (test plan) has been approved by CAES' safety committee and work has been done to set up both a transparent furnace and a two zone crystallization furnace. These furnaces will be used to perform two different type of tests with molten salts.

\section{Voltammetry}

- [INL] Data from experiments is being compared to preliminary oxide reduction experiments in the Integrated Recycle Test (IRT-OR) to validate results. Platinum was acquired to be used as working electrode in upcoming tests.

- $\quad$ [ANL] Use of the prototype sensor for concentration measurements in multicomponent molten salts has continued and the test results have been very good. Preparations have been made for transient experimental tests involving the drawdown of $\mathrm{UCl} 3$ using metallic Gd that is placed in the anode of the small scale electrorefiner.

\section{Electrochemical Signatures Development}

- [LANL] The FY17 Level 3 milestone (M3FT-17LA040104071: Echem Radiation Signatures), "Calculation of Time-Dependent Radiation Signatures for Electrochemical Reprocessing Using MCNP6 Moving Objects FY17 Summary Report,” was completed. Prepared for the Working Group Meeting scheduled for August 3-4 in Washington, D.C.

\section{ADVANCED INTEGRATION}

\section{Advanced Integration (Methods)}

- [LANL] Continued work on the Advanced Integration Roadmap Update. Prepared a presentation for the upcoming MPACT Working Group Meeting, scheduled to take place in Washington, DC, Aug. 34.

\section{Advanced Integration (Facility Models)}

- [SNL] The draft report for the integration of SSPM and STAGE in the Virtual Test Bed has been completed and is going through review. Spent fuel ratio (SFR) research was presented at the 58th Annual INMM Meeting. The results were also documented and uploaded to meet the deliverable for M4FT-17SN040105033: Spent Fuel Ratio Grid Refinement. These modeling efforts continue to indicate that the SFR is much closer to unity than previously assumed (SFR $=3$ in Yucca Mountain FEIS).

\section{MIP Monitor and CoDCon}

- $\quad$ [PNNL] Work at UTK continued to focus on two areas: evaluating the effects of background subtraction and data alignment methods. Dr. Jamie Coble brought on a new student at UTK. Hannah Willoughby supports this effort by developing the PCA models and also executes the data alignment methodologies. Of the five groups evaluated last month, useful data was identified in only in the initial dissolution/head end, high activity waste, and low activity waste streams. Work is still ongoing with identifying appropriate radiological features associated with the first uranium cycle, second uranium cycle which both involve a purified uranium product. 


\section{EXPLORATORY RESEARCH / FIELD TESTS}

\section{Microcalorimetry}

- [LANL] Major progress was made towards the high-bandwidth array readout demonstration. Roomtemperature testing of microwave components was completed, and the expected $4 \mathrm{GHz}$ of bandwidth per readout channel was achieved. Testing of the FPGA system is ongoing. Installation of major cryostat components has begun, and all remaining components are expected to be received in August. We are on schedule to operate the first detectors at LANL with the new readout system in August. Mark Croce, Katrina Koehler, and Michael Rabin participated in the 17th International Workshop on Low Temperature Detectors in Kurume, Fukuoka, Japan from July 17-21. Our recent work on instrumentation development, new measurements, and microcalorimeter theory was very well received. There is significant interest in the high-bandwidth microwave frequency division multiplexed readout, as many applications are moving to large-scale microcalorimeter arrays. Our work is advancing large-scale array technology, but we can also leverage developments from other groups. For example, microfabricated bismuth absorbers have recently been demonstrated for hard xray microcalorimeters. This technology may enable gamma detectors with improved speed and more uniform response.

\section{In situ Measurement of Pu Content in U/TRU Ingot}

- [INL] The electrical and temperature control wiring for the furnace continue to be modified so that the furnace can be remotely operated in the Hot Fuel Examination Facility with the second JFCS liquid cadmium cathode product, currently scheduled for November 2017.

For more information on MPACT contact Mike Miller at (208) 526-2813. 


\section{Fuel Cycle Options Campaign}

\section{Campaign Management}

- [ANL, INL] Working with the Federal Manager for the campaign, completed all elements of the planning package for the FCO Campaign activities in FY 2018. Presented the information during the FY 2018 Planning Package Meeting held in DOE-HQ, Germantown, July 25-26, 2017.

- [ANL, INL] Planning for the Campaign Meeting in mid-October 2017 has started and initial instructions on the meeting have been provided to potential meeting participants from the national laboratories and NEUP project teams.

\section{EQUILIBRIUM SYSTEM PERFoRMANCE (ESP)}

\section{Equilibrium System Analyses}

\section{Specific Accomplishments:}

- $\quad$ [ANL] Developed a list of the advanced reactor concepts that are under development/ consideration in the U.S., and provided the list to DOE-NE. The document contained information on reactor types, power ratings, fuel types, coolants types, and proponents of the advanced light-water reactors, advanced small modular reactors, and advanced non-water cooled reactors.

- [ORNL] All 4 of the fuel cycle evaluations assigned to ORNL for the ANL deliverable report were completed in the last month, and the 4 write-ups issued to ANL personnel that will integrate information for a milestone report. A number of the reference documents used have been collated and included in the documentation sent to ANL.

- $\quad[$ ANL] Reviewed the following summaries on the innovative and advanced fuel cycles that were developed by BNL and ORNL:

- Natural Uranium Equivalent (NUE) fuel in CANDU

- ThorEnergy - Thorium-plutonium fuel for existing and new LWRs

- Advanced Fuel CANDU Reactor (AFCR)

- CONVERT for management of UK legacy separated Pu stock

- TOP MOX fuel

- UK policy debate on open vs. close fuel cycle for low carbon future.

- [INL] Continued assessment on two fuel cycle evaluations assigned to INL for the ANL deliverable report. Analysis of the French concept for reuse of recovered slightly enriched uranium in Pressurized Heavy Water Reactors was completed and the write-up is in review. Analysis is underway for the Japanese concept using an Accelerator Driven System to burn minor actinides recovered during reprocessing of thermal or fast reactor used fuels.

- [INL, ANL] Working with several other campaigns, continued gathering demonstrated performance information on specific technologies that could be used to implement the most promising fuel cycles in the E\&S report and noting technology gaps. Evaluated the benefit fuel cycle metrics for the most promising fuel cycles using this information. This analysis showed that the use of demonstrated technology-specific performance would not lead to any changes in environmental and resource utilization metrics, but noticeable change was observed in the nuclear waste management metrics. These results were used to identify where additional research advancements are needed to achieve 
E\&S performance in deployed systems. Drafted a report with these findings in preparation for an August milestone.

- [INL] Continued additional analysis activities in support of the nuclear load following assessment using Omnibus funding increases. These analyses are using year-long synthetic demand and wind supply curves to assess impacts of increasing renewable market share on net demand and impact on load factors for nuclear plants that load follow. A second analysis is examining how small amounts of rapid response storage can augment nuclear load factors under different nuclear ramp rate assumptions.

\section{Economics and Financial Risk Assessment}

- [INL] Began implementing changes to be made in each module of the Cost Basis Report (CBR), including indicating the primary method of cost estimating used, adding a change history and a list of pending revisions, and updating to current year dollars. Applied these changes for all A, B, and C modules and some D modules of the CBR.

- $\quad$ [ANL] Continued the evaluation of the material currently existing in the CBR on the integrated remote fabrication/reprocessing costs, in order to identify the best approach for the improvement of the module. Began development of comparison across evaluation groups for inclusion in the cost basis report that will show how the relative importance of different elements to the Levelized electricity cost at equilibrium.

- [INL] Completed development of alternate methods for estimating future unit "costs" for those modules of the CBR that are based on market prices (yellow cake, conversion, enrichment). This methods will provide additional rigor and enable users to tailor unit costs based on different analysis timeframes.

\section{Maintenance of Fuel Cycle Catalog}

- $\quad$ [SNL] Three fuel cycle options were put through the verification process; two were verified and uploaded to the public Nuclear Fuel Cycle Options Catalog. The third was found to have an error; this error is currently being corrected. The information for four additional nuclear fuel cycle options is being input into the catalog.

\section{DEVELOPMENT, DEPLOYMENT AND IMPLEMENTATION ISSUES (DDII)}

\section{Technology and System Readiness}

- [BNL, INL] It has been decided to apply the Technology and System Readiness Assessment (TSRA) process to evaluate the status of metallic fuel for the sodium-cooled Versatile Test Reactor as an example of the implementation of the approach to a specific technology. The Advanced Fuels Campaign (AFC) Focus Area Lead for Advanced Reactor Fuels is continuing to apply the process for metallic U-10Zr fuel and HT9 and SS316 cladding by evaluating the questionnaires for TRL-1 through TRL-6.

- [INL] Continuing work on the technology and system readiness analysis of the aqueous recycle portion of the fuel cycle for the Materials Recovery and Waste Form Development Campaign. Continued developing the Technology Readiness Level (TRL) evaluations for the U/Pu/Np Separations subsystem. Completed an initial draft of the Critical Technology Elements evaluation for the Am/Cm Separations subsystem. Developed an initial draft of a structure (a form of work breakdown structure) to facilitate summarizing of progress and tracking of key details for the technology readiness analysis. Also researching approaches for development technology maturation roadmaps from TSRA results. 


\section{Transition to Alternative Fuel Cycle}

- [INL, ANL, ORNL] Five FCO personnel attended the second annual Technical Workshop on Fuel Cycle Simulation hosted by the University of South Carolina and gave seven talks: fuel composition transition modeling (INL), next generation fuel cycle simulation missions and use cases (INL), fuel cycle transition analysis (ANL), visualization of simulation results (INL), code-to-code verification of fuel cycle analysis codes (ANL), simulation tool benchmarking and verification (INL), and the use of cross sections versus recipes in transition analyses (ORNL). Based on FCO Campaign Management suggestions, the workshop format was substantially modified from the prior year to allow more time for discussions. The new workshop format was focused on discussing issues and advancements in the fuel cycle modeling community (mostly from U.S. and France). The French (CNRS) are focusing much of their work on uncertainty analysis and quantification. There was also a lot of enthusiasm to couple an open benchmark with the next meeting in Paris to further help establish the fuel cycle modeling community.

- [INL] Began development of the summary report for fuel cycle transition, including identification of some of the key findings from the previous four transition reports.

\section{Transition Economics}

- [INL] Initiated work using Omnibus plus-up funds to update the analysis of SFR reprocessing facilities from 2016, but with zero growth and LEU startup, then expand the effort to also include enrichment, and different types of fuel fabrication (contact, glovebox, remote). Pre-enrichment, prefabrication of LEU fuels, and delayed reprocessing will all be examined as part of a sensitivity study on facility size and economies of scale.

\section{Regional and Global Impacts}

- $\quad$ [BNL] Provided initial input to INL for their L2 Deliverable "Market Penetration of Nuclear Power for Various Climate Change Policy Scenarios" including work with MARKAL, and a preliminary discussion comparing the capabilities of MARKAL and GCAM for assessing the potential role of nuclear technologies in the mix of energy options in the U.S. under various scenarios.

- $\quad[B N L]$ Received comments from INL and are addressing them in next iteration of write-up described above, as well as expanding material on MARKAL.

- $\quad[$ PNNL] Preparing milestone report on the market penetration of nuclear power for various climate change policy scenarios. The report synthesizes recent analyses on a range of issues affecting nuclear energy deployment and its potential response to climate change mitigation.

For more information on Fuel Cycle Options contact Roald Wigeland (516) 732-4234. 


\section{Joint Fuel Cycle Study Activities}

\section{JFCS OVERSIGHT}

- Research of critical technology aspects to support the Integrated Recycling Test (IRT) continues. Campaign personnel continue to operate and test equipment with irradiated fuel to acquire data to support assessments of technical and economic feasibility and nonproliferation acceptability of electrochemical recycling.

- Electrorefining of the first batch of irradiated mixed-oxide (MOX) fuel from the Fast Flux Test Facility (FFTF) previously processed in the oxide reduction system began in July.

- A level 2 milestone "Successful casting of surrogate U-Zr fuel in the remote casting/sampling system" was completed in July.

- The scalability testing glovebox was installed in FCF room 26. Running of utilities and equipment control cabinets is complete and installation of process equipment within the glovebox is also complete.

\section{ELECTROCHEMICAL RECYCLING ACTIVITIES}

\section{Head-End}

- In July, head-end equipment remained in storage within HFEF main cell to allow for continued testing of the casting and sampling equipment at window $10 \mathrm{M}$.

\section{Oxide Reduction System}

- The oxide reduction system was held in hot standby during July pending additional process experiments. The second of two electro-reduction experiments was completed in June.

\section{Electrorefiner System}

- In July, process experiments began on the first FFTF MOX batch previously reduced in the oxide reduction system, and two uranium products were produced. Preparation for the second batch of FFTF MOX is underway and expected to begin electrorefining in August. Phase II qualification of the liquid cadmium cathode equipment was initiated in July and is expected to be completed in August.

\section{Remote Distillation Systems}

- The remote distillation system was used to separate salt from the second MOX batch from the oxide reduction system in July. Distillations were also performed on two ER MOX uranium products.

\section{JFCS CRITICAL GAP RESEARCH AND DEVELOPMENT}

- [INL] Experiments with alternative crucible materials are ongoing. Efforts in this area are focused on alternatives to $\mathrm{BeO}$ crucibles destined for use in electrorefining, distillation, and casting systems. Experiments continued for the development of a real-time Li2O sensor for the oxide reduction system. Method development for cadmium and salt distillation process continued in the prototype distillation apparatus at the Engineering Development Laboratory.

- $\quad$ [PNNL] In July, a journal article summarizing the aerogel sorbent work was submitted to ACS Applied Materials \& Interfaces. 


\section{JFCS FUELS}

\section{Fuels - IRT}

- In July, a successful suction cast of U-10Zr was performed. This completed the Level 2 milestone "Successful casting of surrogate U-Zr fuel in the remote casting/sampling system." Additionally, engineering paperwork was completed for the initiation of management self-assessment in August.

\section{Fuels - Critical Gap}

- Several casting runs were performed using the Glovebox Advanced Casting System furnace in the casting laboratory. These runs have focused on suction casting of U-10Zr-3RE using a solid Yttria crucible liners. Results were positive and showed minimal dross formation. FCCI diffusion couple testing continued in July. Samples were prepared and awaiting analysis via electron microscopy.

For more information on Joint Fuel Cycle Studies Activities contact Mike Goff (208) 526-1999 or Ken Marsden (208) 533-7864. 


\section{Program Assessment \& Coordination}

\section{Program Management}

- Participated in the Planning Package Review

- Prepared for the FY18 planning cycle

\section{QUALITY SUPPORT}

- $\quad$ [ANL] Participated in site review by QA Manager. Participated in teleconferences as required.

- $\quad$ [BNL] Completed and submitted M4 deliverable on 6/15/17.

- [LANL] Participated in biweekly conference calls, continuation of editing on rev. 3 of QAPP interface document to ensure no conflicts with rev. 4 of the QAPD effective 7/5/17.

- [ORNL] Continued to perform my duties as ORNL QA Point of Contact including reviewing plans for installing FC-funded research equipment in hot cell facilities at ORNL.

- [SRNL] SRNL continue to participate in biweekly conference call, answer emails, and working on completing the Interface Document revision. The Interface document is routing for approval, but was pulled back to be in compliance with the QAPD latest revision.

\section{COMMUNICATIONS}

- Received replacement TREAT model to complement the set of models used to communicate INL's nuclear fuel R\&D capabilities to various audiences.

\section{INFORMATION MANAGEMENT}

- Documentum D2 Upgrade completed in Development and Test environments. The upgrade is on track to be completed by the scheduled due date.

- All approved FY18 deliverable documents to-date have been uploaded to the DMS from PICS-NE.

- Continue to update and finalize DMS system documentation.

\section{REACTOR DIGITIZATION}

- Reviewing the draft report. The model is going through the process of being accepted for storage on EDMS.

\section{MOLTEN SALT}

- The technical writing team has been assembled, a draft outline for the standards of practice paper developed, and team members assigned review / writing responsibilities.

For more information on Program Assessment and Coordination contact Bonnie Hong (208) 526-0629. 


\section{AFCI-HQ Program Support}

\section{UNIVERSITY PROGRAMS}

Site: University Research Alliance at West Texas A\&M University in Canyon TX, and the following universities: University of Arkansas, University of Idaho, Vanderbilt University, University of Texas at Austin, Georgia Institute of Technology, Pennsylvania State University, Rensselaer Polytechnic Institute, University of Nevada at Las Vegas, University of Michigan, University of Notre Dame, Northwestern University, Boise State University, University of Florida, Idaho State University, Virginia Commonwealth University, Clemson University, and other universities.

\section{Universities engaged in Nuclear Technology research via URA programs since 2001:}

Boise State University

Boston College

Clemson University

Colorado School of Mines

Georgia Institute of Technology

Idaho State University

Florida State University

Kansas State University

Massachusetts Institute of Technology

Missouri University of Science and

Technology

North Carolina State University

Northern Illinois University

Northwestern University

Ohio State University

Pennsylvania State University

Purdue University

Rensselaer Polytechnic Institute

Rutgers University

Texas A\&M University

University of Arkansas

University of California at Berkeley
University of California at Santa Barbara

University of Chicago

University of Cincinnati

University of Florida

University of Idaho

University of Illinois at Urbana-Champaign

University of Michigan

University of Missouri

University of Nevada at Las Vegas

University of New Mexico

University of North Texas

University of Notre Dame

University of Ohio

University of South Carolina

University of Tennessee at Knoxville

University of Texas at Austin

University of Virginia

University of Wisconsin

Vanderbilt University

Virginia Commonwealth University

Washington State University

INNOVATIONS IN NUCLEAR TECHNOLOGY R\&D AWARDS (FORMERLY INNOVATIONS IN FUEL CYCLE RESEARCH AWARDS)

\section{Summary Report}

- University Research Alliance completed processing award checks for the 2017 Innovations in Fuel Cycle Research Award winners.

- University Research Alliance received letters of congratulations for the 2017 winners from the DOE and sent them with the award checks.

- University Research Alliance completed preparing press releases on behalf of the 2017 winners. Winners' department heads, advisors, and school newspapers are among those who are formally notified of the winners' achievement. 
- University Research Alliance completed collecting photos of the 2017 winners and prepared the announcement on the nucleartechinnovations.org website.

- University Research Alliance continued to improve the email distribution list in preparation for the 2018 Innovations Awards.

For more information on the University Research Alliance contact Cathy Dixon (806) 651-3401. 